\title{
Studies on general practice out-of-hours care
}

Citation for published version (APA):

van Uden, C. J. T. (2005). Studies on general practice out-of-hours care. [Doctoral Thesis, Maastricht University]. Maastricht University Press. https://doi.org/10.26481/dis.20050512cu

Document status and date:

Published: 01/01/2005

DOI:

10.26481/dis.20050512cu

Document Version:

Publisher's PDF, also known as Version of record

\section{Please check the document version of this publication:}

- A submitted manuscript is the version of the article upon submission and before peer-review. There can be important differences between the submitted version and the official published version of record.

People interested in the research are advised to contact the author for the final version of the publication, or visit the DOI to the publisher's website.

- The final author version and the galley proof are versions of the publication after peer review.

- The final published version features the final layout of the paper including the volume, issue and page numbers.

Link to publication

\footnotetext{
General rights rights.

- You may freely distribute the URL identifying the publication in the public portal. please follow below link for the End User Agreement:

www.umlib.nl/taverne-license

Take down policy

If you believe that this document breaches copyright please contact us at:

repository@maastrichtuniversity.nl

providing details and we will investigate your claim.
}

Copyright and moral rights for the publications made accessible in the public portal are retained by the authors and/or other copyright owners and it is a condition of accessing publications that users recognise and abide by the legal requirements associated with these

- Users may download and print one copy of any publication from the public portal for the purpose of private study or research.

- You may not further distribute the material or use it for any profit-making activity or commercial gain

If the publication is distributed under the terms of Article $25 \mathrm{fa}$ of the Dutch Copyright Act, indicated by the "Taverne" license above, 
Studies on general practice out-of-hours care

Caro van Uden 
The studies presented in this thesis were performed at the Care and Public Health Research Institute (CAPHRI), which participates in the Netherlands School of Primary Care research (CaRe), acknowlectged in 1995 by the Royal Dutch Academy of Science (KNAW).

These studies are in part supported by the Dutch Health Insurance Board (CVZ), Districs General Practitioners Association Limburg, and AstraZeneca.

Printing of this thesis was financially supported by Zorgverzekeraar VGZ.

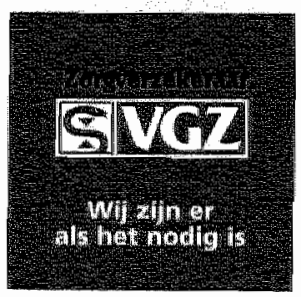

Studies on general practice out-of-hours care. C.J.Th. van Uden. Thesis, Maastricht University - with references - with summary in Dutch.

MeSH subject headings: Family Practice, Out-of-hours Medical Care, Delivery of Health Cate, Utilisation, Satisfaction.

(1) 2005, C.J.Th. wan Uden, Mastricht

University Hospital Maastricht, Department of Integrated Care (BZe7)

Universiteit Maastricht, Department of General Practice

e-mail: caro.vanuden@hag.unimaas.nl

Coverdesign: The Night Watch by Rembrandt Harmensz. van Rijn (with permission from the Rijksmuseum Amsterdam) 


\title{
Studies on general practice out-of-hours care
}

\author{
PROEFSCHRIFT
}

ter verkrijging van de graad van doctor aan de Universiteit Maastricht, op gezag van de Rector Magnificus.

Prof. mr. G.P.M.F. Mols,

volgens het besluit van het College van Decanen,

in het openbaar te verdedigen

op donderdag 12 mei 2005 on 16 uur

door

Cornelis Johannes Theodorus van Uden

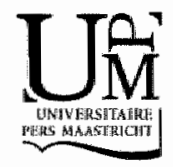


Promotores:

Prof. dr. H.F.I.M. Crebolder

Prof. dr. C.P. van Schayck

Co-promotores:

Dr. R.A.G. Winkens

Dr. G. Wesseling

Beoordelingscommissie:

Prof. dr. J.A.M. Maarse (voorzitter)

Prof. dr. P.R.G. Brink

Prof. dr. mr. R.P.T.M. Grol

Prof. dr. J. de Haan (Rijksuniversiteit Groningen)

Dr. Y.D. van Leeuwen 
Voot mijn ouders, ter nagedachtents aan mijn vader Aan Brigittc 



\section{CONTENTS}

Chapter

1. General introduction.

2. The impact of a primary care physician cooperative on the caseload of an emergency department. The Maastricht integrated out-of-hours service.

3. Use of out-of-hours services: a comparison between two organisations.

4. Out-of-hours primary care. Implications of organisation on costs.

5. General practitioners's satisfaction with and attitudes to out-of-hours services.

6. Does setting up out-of-houts primary care cooperatives outside a hospital reduce demand for emergency care?

7. Patient satisfaction with out-of-hours care in the Netherlands.

8. Telephone triage during out-of-hours primary care: patients' and doctors' opinions

9. Follow-up care by patient's own general practitioner after contact with out-of-hours care. A descriptive study.

10. General Discussion

Summary

Samenvatting

Dankwoord

Curriculum Vitae 

Chapter 1

General introduction 


\section{INTRODUCTION}

Within the last ten years, the organisation of out-of-hours general practice in the Netherlands has experienced a radical shift from general practitioners (GPs) providing care to patients in small practice groups (rotas) to a situation where out-of-hours care is otganised in large-scale GP cooperatives. This thesis focuses on the effect of this reorganisation on utilisation of out-of-hours care, and reports on patient and doctor satisfaction, costs, and triage aspects with respect to current out-of-hours GP cooperatives.

In the Netherlands, out-of-hours care was and still is an important part of general practice. Recently, the Dutch College of General Practitioners (NHG) and the Dutch Association of General Practitioners (LHV) have formulated a tenewed mission statement on the content and tasks of general practice'. In this statement, personal continuity of care is emphasised as an important feature of general practice. Moreover, the 24-hour responsibility of GPs for their patients was acknowledged as one of the cornerstones of general practice.

Personal continuity of care has been proven to be strongly related to patient satisfaction with primary care $^{2}$, and the medical profession also emphasises the importance of continuity of care $e^{3-5}$. However, the changes in out-of-hours primary care organisation over the past decades have been an impediment for this personal continuity of care. Not only in the Netherlands, but also internationally.

Until the 1960s many GPs took care of their own patients during out-ofhours, which indicated that GPs were on call most of the time. There was one exception; during World. War II a GP cooperative was already set up in The Hague. After the 1960s, more and more GPs formed small practice rotas (generally 6 to $8 \mathrm{GPS}$ ) in which they performed out-of-hours care to each other's patients. At first this covered only the weekends, but subsequently the evenings and nights on weekdays followed. This change in out-of-hours care provision was the first step to a less personal out-ofhours care provision, because GPs and patients were not so familiar with each other anymore. However, this reduced personal continuity of care may be only a minor problem, since research has indicated that there is not a strong preference for patients to be familiar with the doctor during out-ofhours ${ }^{7}$. Moreover, patients' reason for attending an out-of-hours care facility is most often the urgency of their complaint ${ }^{8}$. Nevertheless, there are some indications that older people prefer contact with their own doctor?

While in the 1990s almost all GPs were joined in practice rotas for their out-of-hours care, another reform announced itself. It was from the late 
At the moment, Dutch out-of-hours primary care organisation most resembles the organisation in the UK and Denmark. Nevertheless, still many differences can be identified. For example, in Denmark telephone triage is performed by GPs, whereas in the Netherlands this is done by doctor's assistants. In the UK many different models of out-of-hours primary care exist next to each other, while in the Netherlands only the GP cooperatives are performing out-of-hours primary care (excluding the hospital emergency departments). The UK model of out-of-hours care that represents the Dutch situation the best is the GP cooperative.

\section{THE DUTCH SITUATION}

Nowadays, over 120 GP cooperatives in the Netherlands have been set up that cover over $90 \%$ of the population. There is some variety in the way these cooperatives are organised. Generally, there is a distinction in accessibility - GP cooperatives requiring telephone contact before a patient can attend the cooperative versus those that accept patients attending the cooperative on their own initiative - and a distinction in cooperation with the hospital emergency department. An important part of this thesis addresses issues related to the effects resulting from differences in organisation between GP cooperatives working in close collaboration with a hospital emergency department and those GP cooperatives that are organised independently of hospital emergency services.

Currently only three GP cooperatives in the Netherlands perform outof-hours care in close collaboration with the hospital emergency departments ${ }^{47}$. In this thesis this form of collaboration is referred to as integrated out-of-hours care. This term is chosen, because out-of-hours primary and hospital emergency care in these systems is joined into one facility. In case of GP cooperatives that work independently from the hospital emergency department, but may have some agreements on referring patients to one another, we speak of a separated system. An important motive to join primary and emergency care is to improve GPs gtip on patients skipping primary cate and attending emergency departments without a GP's refertal. A large percentage of these so-called self-referred patients can as well be attended by GPs. An additional advantage of joining primary and hospital emergency in one out-of-hours care facility is that patients do not have to choose anymore which out-ofhours care facility they have to attend.

In the Netherlands the GP acts as a gatekeeper to secondary care. In the Dutch health care system all patients are required to have a referral from their family physician to utilize hospital services ${ }^{48}$. However, to be seen at a 
hospital emergency department in the Netherlands, a referral is tecommended but not strictly needed. As mentioned before, it has been found that large numbers of patients skip the GP and attend the hospital emergency department without referra ${ }^{48}$. Reasons for skipping the GP cited most frequently by patients are convenience, lack of timely access to primary care providers, the belief that the medical complaint was very urgent, and the belief that radiography is necessary ${ }^{28,49,50}$. A substantial number of patients attending the emergency department present with nonurgent or minor problems that can be resolved by a $\mathrm{GP}^{31,51}$. Depending on setting and healthcare system, studies have shown that this number ranges from $17 \%$ to $57 \% 3 \pi, 41,46,5 \pi$. Reinstalling the GP gatekeeper function may have significant effects on hospital emergency care utilisation. Studies have shown that patients with minor injuties or primary care problems attending the hospital emergency department without referral can be treated safely and at lower costs in primary care ${ }^{32,41,52}$.

The GP cooperatives in the Netherlands use telephone triage to prioritise patient treatment. During telephone triage the urgency of the patient's problem is assessed and a decision is made about the appropriate action to be taken. This decision includes giving self-care advice without seeing the patient, advising patients to attend their own GP the next day, referring patients to a GP at the cooperative, or ordering home visits. At most Dutch GP cooperatives the telephone is staffed by doctor's assistants. In addition, the doctor's assistant is supervised by a GP, who can be consulted in case of doubt and who authorises all calls handled by the doctor's assistant.

The telephone triage process is an important and critical link in the chain of out-of-hours primary care. It is essential that patients receive adequate and timely care, and therefore, telephone triage must be safe and effective. At all GP cooperatives in the Netherlands, triage protocols and guidelines are available to support the doctor's assistant. Some GP coopetatives have even started using computer based decision software ${ }^{53}$. Telephone triage is also an important aspect of out-of-hours primary care that is addressed in this thesis.

In the Netherlands, out-of-hours primary care as organised in GP cooperatives is more and more reaching a stable phase. Nevertheless, as also indicated by a recent report of the Dutch Health Care Inspectorate ${ }^{5.3}$, many aspects still have to be improved or developed.

Before the start of the study presented in this thesis, it was largely unknown which specific effects different models of out-of-hours primary care have on care utilisation, patient and GP satisfaction, and costs. The studies in this thesis focus on these aspects in order to provide insight in 
advantages and disadvantages of different organisations of out-of-hours care.

\section{SETTING OF THE RESEARCH}

The research in this thesis has concentrated mainly on the province of Limburg. In total, seven GP cooperatives (organised in five GP out-ofhours care organisations) are operational in this province providing out-ofhours primary care to a population of about 1.1 million inhabitants.

The first cooperative that was set-up in this region was the GP cooperative in the Heerlen region. This GP cooperative started in March 1999 performing out-of-hours care for a population of 100,000 inhabitants. In 2000 the number of participating GPs increased to 120 and the coverage area to apptoximately 285,000 inhabitants. In January 2000 , the GP cooperative in Maastricht was set-up and was the first in the Netherlands that integrated primary and hospital emergency care. Because this was the first integrated cooperative and at the time of the study the only one, this GP cooperative is used in this thesis as a representative of integrated primary and hospital emergency care. Halfway through 2001 the other five GP cooperatives in the province of Limburg were set up. A more detailed description of some of these GP cooperatives, if relevant, is given in related chapters in this thesis.

\section{AIMS OF THE STUDY}

The purpose of this study is to gain insight into different aspects of outof-hours primary care. These aspects are related to changes in care utilisation, costs, GP and patient satisfaction, and telephone triage. The results of the study can support health care professionals and health policy makers in optimising out-of-hours primary care in the Netherlands.

\section{OUTLINE OF THE THESIS}

This thesis describes the outcomes of different studies we conducted to gain insight in the current organisation of general practice out-of-hours care.

Chapter 2 focuses on the reorganisation of out-of-hours care in the Maastricht region and its effect on patient flow. More specifically, the 
number of patients utilising out-of-hours primary care and hospital emergency care before and after the reorganisation have been investigated.

Chapter 3 reports differences in out-of-hours care utilisation between a GP cooperative located separate from a hospital emergency department and a GP cooperative which is functionally integrated with a hospital emergency department. In chapter 4 the costs of these two organisations are presented, and also the effect of integrating primary and hospital emergency care on costs of the hospital emergency department is described.

Chapter 5 reports of results of a study on GP satisfaction with and opinions on out-of-hours primary care organised in the separated model and the integrated model.

Chapter 6 describes the influence of the reorganisation of out-of-hours primary care to GP cooperatives functioning independent of the hospital emergency department on utilisation of hospital emergency services outside office hours.

Chapter 7 reports the findings of a large patient satisfaction study in the province of Limburg.

Chapter 8 focuses on telephone triage and compares patient and GP opinions between a cooperative that uses computer assisted decision software to guide the telephone triage process and a cooperative that uses only written protocols and guidelines.

Chapter 9 describes the results of a study that investigated the care process after patients have contacted a GP cooperative for out-of-hours care.

A general discussion is presented in chapter 10.

Because chapters 2 to 9 are based on research manuscripts published in scientific journals or submitted to a journal for publication, most of the chapters are written to stand alone and some reperition will be inevitable.

\section{REFERENCES}

1. Furure view on general practice. [Project Toekomstvisie Huisattsenzorg. Huisartsenzorg in 2012: "Medische zorg in de buurt".] Utrecht: LHV/NHG, March 2002. Available at: http://nhgartsennet.nl/upload/104/12081/Visie_A4_Do.pdt.

2. Saultz $J W$, Albedaiwi W. Interpersonal contimuity of care and patient satisfaction: a critical review. Ann Fan Med. 2004;2:445-51.

3. Guthrie $\mathrm{B}$, Wyke $\mathrm{S}$. Does continuity in general practice really matrer $B M$. $2000 ; 321: 734-736$.

4. Freeman GK, Olesen F, Hjortahl P. Continuity of care: an essential element of modern general practice? Faw Pract. 2003;20:623-7. 
5. Schere HJ, Maat $C$, van de Ven $C$, wan de Hoogen HJM, Grol RPTM, van den Bosch WJHM. GPS" opinions on continuity of care. [Hoe denken huisartsen over continuïteit in de zorge] Husants W $2002,45,4504$.

6. van Ejijk JTM, Gubbels J, de Koningh AGJ, van det Meer K, van Noort J. General practice out-of hours cate in the Netherlands. De weekenddienst van huisartsen in Nederland (1). Med Contact. 1978;33:17-22.

7. Morgan $A_{y}$ Shackley $P$, Pickin M, Brazier I. Quantifying patient preferences for out-ofhours primaty care. J Healit Seri Res Policy. 2000;5:214-8.

8. Drummond N, McConnachie A, O'Donnell CA, Moffat KJ, Wilson P, Ross S. Social variation in reasons for contacting genetal practice out-of- hours: implications for daytime service provision? BrJ Gen Prat. 2000;50:460-4.

9. Foster J, Dale J, Jessopp L. A qualitative study of older people's views of out-of-hours services. Br J Gent Pract. 2001:51:719-23.

10. Leibowitz R, Day $S$, Dunt D. A systematic review of the effect of different models of after-hours primary medical cate scrvices on clinical outcome, medical workload, and patient and GP satisfaction. Fakn Prat. 2003;20:311-7.

11. Hallam L. Primary medical care outside normal working hours: review of published work. BM. 1994,308:249-53.

12. Hetcher J, Pickard D, Rose J, et al. Do out-of-hours co-operatives improve general practitionets" health? BrJ Gen Prat. 2000;50:815-6.

13. Heaney $D$, Goman D, Porter M. Self-reconded stress levels for general practitioners before and after forming an out-of-hours primary care centre. BrJ Gen Pract. $1998 ; 48: 1077-8$.

14. Giesen PHI, Haandrikman LGR, Broens S, Schreuder JIM, Mokkink HGA. GP cooperatives: Does it benefit the GP? [Centrale huisartsenposten: wordt de huisarts er beter van?]. Fenisarts Wet 2000;43:508-10.

15. Salisbury C, Trivella M, Bruster S. Demand for and supply of out of hours care from general practitioners in England and Scotland: observational study based on routinely collected data. BMI. 2000;320:618-21.

16. Salisbury $C$. Evaluation of a genetal practice out of hours cooperative: a questionnaire survey of general practitioners. BM/. 1997;314:1598-9.

17. Pickin DM, O'Cathain A, Fall M, Morgan AB, Howe A, Nicholl JP. The impact of a general practice co-operative on accident and emergency services, patient satisfaction and GP satisfaction. Fam Prat. 2004:21:180-2.

18. Hallam L. Out of hours primary care. BMJ. 1997,314:157.8.

19. Hallam I, Cragg D. Organisation of primary care services outside normal working hours. BMJ. 1994;309:1621-3.

20. Hallam L., Henthorne K. Cooperatives and their primary care emergency centres: organisation and impact. Combined report on seven case studies. Heally Tebnol Arsers. $1999: 3: 11 i-85$.

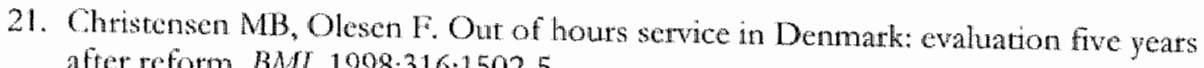
after reform. BMI. 1998;316:1502-5.

22. Hansen BL, Munck A. Out-of-hours service in Denmark: the effect of a structural change. BrJ Gen Pract. 1998;48:1497-9. 23. Olesen I. Jolkys JV. Out of hours service the Danish solution examined. BMJ.
$1994 ; 309: 1624-6$.

24. Vedsted $P$, Christensen MB. The effect of an out-of hours reform on attendance at casualy wards. "The Danish example. SrandJ Prim Heatt Cart. 2001;19:95-8.

25. Jessopp L, Beck 1, Hollins I., Shipman C, Reynolds M, Dale J. Changing the patten out of hours: a survey of general practice cooperatives. BMJ. 1997;314:199-200. 
26. Brogan C, Pickand D, Gray A, Faiman S, Hill A. The use of out of hours health services: a cross sectional survey. BMJ. $1998,316: 5247$.

27. Cooke M. Employing general practitioners in accident and emetgency departments. Better to increase number of consultants in accident and emergency medicine. $B M$. $1996 ; 313: 628$

28. Coleman $P$, Irons $R$, Nicholl J. Will alternative immediate cate services reduce demands for non-urgent treatment at accident and emetgency? Emeng Mod J. 2001;18:482-7.

29. Cragg DK, McKinley RK, Roland MO, et al. Compatison of out of hours care provided by patients' own general practitioners and commercial deputising services: a randomised controlled trial. I: The process of care. BMJ. 1997,314:187-9.

30. Dale I, Crouch R, Lloyd D. Primary care: nursewed telephone triage and advice out of hours. Narr Stand 1998;12:41-5.

31. Dale J, Green J, Reid F, Glucksman E. Primaty care in the accident and emergency department: I. Prospective identification of patients. BMJ. 1995;311:423-6.

32. Dale J, Green J, Reid F, Glucksman E, Higgs R. Primary care in the accident and emergency department: II. Comparison of general practicioners and hospital doctors. BMI. 1995;311:427-30.

33. Fortune T. Telephone triage: an Irish view, Accid Exkerg Nwr. 2001;9:152-6.

34. Freeman GK, Meakin RP, Lawnenson RA, Leydon GM, Craig G. Primary care units in A\&E departments in North Thames in the 1990s: inirial experience and future implications. Br/ Gen Pract. 1999;49:107-10.

35. George S. NHS Direct audited. BMJ. 2002,324:558-9.

36. Green J, Dale J. Primary care in accident and emergency and general practice: a comparison. Sac Sa Med 1992;35:987-95.

37. Heyworth J, Egleston C. Providing primary care in accident and emergency departments. Telephone triage could help. BMJ. 1998;317:207-8.

38. Lattimer $V$, Smith $H$, Hungin $P$, Glasper A, George S. Future provision of out of hours primary medical care: a survey with two general practitioner reseatch networks. BMJ. 1996;312:352-6.

39. McKinley RK, Cragg DK, Hastings AM, et al Comparison of out of hours care provided by parients' own general practitioners and commercial deputising services: a randomised controlled trial. II: The outcome of care. BMJ. 1997;314:190-3.

40. Murphy AW, OHanlon CM, McKeown D, Cosgrove A, Culliane J, Taheny C. Do rutal GPs have more out-of hours patient consultations? Few / Gen Pract. 2001;7:75-6.

41. Murphy AW, Bury G, Plunkett PK, et al. Randomised controlled trial of general practitioner versus usual medical care in an urban accident and emergency deparment: process, outcome, and comparative cost. BM. 1996;312:1135-42.

42. Rajpar SF, Smith MA, Cooke MW. Study of choice between accident and cmergency departments and general practice centres for out of hours primary care problems. I Arcil Emeng Med 2000; 17:18-21.

43. Robertson-Steel TR. Providing primary care in the accident and emergency deparment. BMJ. 1998;316:409-10.

44. Roberts $\mathrm{E}$, Mays $\mathrm{N}$. Can primary care and communicy based models of cmergency care substitute for the hospital accident and emergency ( $\&$ E) department? Healls Policy. 1998;44:191-214.

45. Roland M. Nurse-led telephone advice. Med J Awst. 2002;176:96.

46. Ward P, Huddy J, Hargreaves S, Touquet R. Hutley J, Fothergill J. Primary care in London: an evaluation of general practitioners working in an inner ciry accidene and emergency department. I Acid Emerg Med. 1996;13:11-5. 
47. Balestra W, Whechers I. Rozeboom A. van Dalen J. Coopetarion, coherence, and integration with the emergency department. Report (part 3). [Samenwerking, samenhang en integratic met de spoedeisende hulp. Raport (deel 3).J Ansterdam: Plexus Medical Group; 2004.

48. Kulu-Glasgow $I$, Delnoij D, de Bakker D. Self-referral in a gatekeeping system: patients' teasons for skipping the genetal-practitioner. Health Polioy. 1998;45:221-38.

49. Singh $\mathrm{S}$, Self teferral to accident and emergency department: patients' perceptions. BMJ. 1988;297:1179-80.

50. Kini NM, Strait RT. Nonurgent use of the pediatric emetgency department during the day. Pediatr Emerg Care 1998;14:19-21.

51. Lee $A$, Lau $\mathrm{HL}, \mathrm{Hazlett} C \mathrm{CB}_{3}$ er al. Factors associated with non-urgent utilization of Accident and Emergency services: a case-control study in Hong Kong. Sar Sai Med. $2000 ; 51: 1075-85$.

52. Dale J, Lang $\mathrm{H}$, Roberts JA, Gteen J, Glucksman E. Cost effectureness of treating primary care patients in accident and emergency: a comparison between general practitioners, senior house officers, and registrars. BMJ. 1996;312:1340-4.

53. Geteral Practitioner Cooperatiwes in the Netherlands (Huisartsenposten in Nederland: Inspectie voor de Gezondheidszorg|. The Hague: Health Care Inspectorate; 2004. 


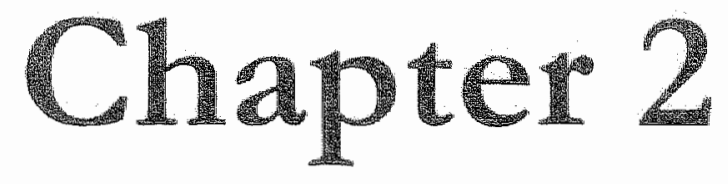

\section{The impact of a primary care physician cooperative on the caseload of an emergency department. The Maastricht integrated out-of-hours service.}
C.J.T. van Uden ${ }^{1,2}$
Journal of General Internal Medicine 2005,
R.A.G. Winkens ${ }^{1,2}$ accepted for publication
G. Wesseling ${ }^{1,3}$
H.F.B.M. Fiolet ${ }^{1}$
C.P. van Schayck ${ }^{1}$
H.F.J.M. Crebolder ${ }^{2}$ 


\section{ABSTRACT}

Objective: To determine the effect of an out-of-hours primary care physician (PCP) cooperative on the caseload at the emergency department and to study characteristics of patients utilizing out-of-hours care.

Design: A pre-post intervention design was used. During a three-week period before and a three-week period after establishing the PCP cooperative, all patient records with out-of-hours primary and emergency care were analyzed.

Setting: Primary care in Mastricht (the Netherlands) is delivered by 59 PCPs. Primary cate physicians formerly organized out-of-hours care in small locum groups. In January 2000 out-of-hours primary care was reorganized, and a PCP cooperative was established. This cooperative is locared at the emergency department of the University Hospital Maastricht, the city's only hospital, which has no emergency medicine specialists.

Main Outcome Measures: The number of patients utilizing out-of-hours care, their age and gender, diagnoses, post-ED care, and serious adverse events.

Results: After establishing the PCP cooperative, the proportion of patients utilizing emergency care decreased by $53 \%$, and the proportion of patients utilizing primary care increased by $25 \%$. The shift was the largest for patients with musculoskeletal disorders or skin problems. There were fewer hospital admissions, and fewer subsequent refertals to the patient's own PCP and medical specialists. No substantial change in new outpatient visits at the hospital or in mortality occurred.

Conclusions: In the city of Maastricht, the Netherlands, the PCP cooperative reduced the use of hospital emergency care during out-of-hours care. 
1990s onwards that out-of-hours care in the Netherlands was reorganised into large-scale GP cooperatives. In these cooperatives, generally between 40 and $120 \mathrm{GPs}$ are joined, providing care for populations ranging from 80,000 to 300,000 inhabitants.

The main reason for reorganising out-of-hours primary care was the growing dissatisfaction among GPs with former out-of-hours care, GPs' decreased personal commitment with these services, and an impending shortage of $\mathrm{GPs}^{10,11}$. Important factors leading to this dissatisfaction were: the workload accompanying these services, especially because after the out of hours service a regular day of work followed; the lack of separation between work and private; increased demand of out-of-hours care; and the perception of generally increased workload. Out-of-hours cate used to be an extra load on the already demanding week of usual care in general practice. Studies have reported beneficial effects to GPs with the introduction of GP cooperatives for out-of-hours care, like improved GPs' health ${ }^{12}$ and decreased levels of stress ${ }^{13}$. Moreover, in a Dutch study by Giesen et al. ${ }^{14}$ it was found that GP satisfaction incteased after reorganising out-of-hours care from practice based to cooperative based.

\section{INTERNATIONAL PERSPECTIVE}

The reorganisation of out-of-hours care in the Netherlands was preceded by reorganisations in out-of-hours primary care in the early $1990 \mathrm{~s}$ in the United Kingdom (UK) ${ }^{11,15.20}$ and Denmark ${ }^{21.24}$. The changes in out-of-hours care in these countries are very similar to those that occurred a couple of years later in the Netherlands. In a way, one can say that the changes in outof-hours care in the UK and Denmark have set an example for Dutch general practice. In countries like the UK and Australia, the trend away from GPs looking after their own patients at home during out-of-hours started already in the late 1960 s with the use of deputising services ${ }^{10,11}$

Internationally, there is diversity in health care systems offering primary care to patients outside normal office hours ${ }^{10,11,15-46}$. Mainly seven models can be identified that provide primary cate to patients during out-of-hours. These are: (1) GPs taking care of their own patients; (2) practice-based services (GPs within a practice or rota looking after their own patients during out-of-hours); (3) deputizing services (commercial companies employing doctors to provide out-of-hours care); (4) GP cooperatives (GPs from different practices providing care for their own patients in a nonprofit making organisation); (5) emergency departments; (6) primary care centres (a centre patients can attend); (7) telephone triage and advice centres (where primary patients receive telephone advice during out-of-hours). 


\section{INTRODUCTION}

Primary care gatekeeping in the Netherlands, as in the UK, is less controversial than in the USA. Whereas in the USA only about $40 \%$ of the population has a primary care physician (PCP) who acts as a gatekeeper to specialist care ${ }^{2}$, in the Dutch health care system all patients are required to have a referral from their PCP to utilize hospital services ${ }^{3}$. However, for an emergency department (ED) visit in the Netherlands a referral is not strictly needed. Many patients skip the PCP and attend the ED without referral ". In Maastricht (Netherlands) over $50 \%$ of all ED visitors were self-referred. Increasing numbers of self-referrals and lack of inpatient beds can cause overcrowding at EDs ${ }^{48}$.

Many patients present non-urgent or minor primary care problems at the $\mathrm{ED}^{7,9}$. Initiatives to deal with this problem were employing PCPS in EDs, establishing a separate stream for minor injuries, or directing patients with non-acute conditions to next-day care ${ }^{10-16}$. Such initiatives did not focus exclusively on out-of-hours care.

PCPs in the Netherlands have a 24-hour care responsibility for their patients. To deliver out-of-hours care, Dutch PCPs organized themselves in locum groups, establishing an out-of-hours coverage system ${ }^{17}$. Recently, out-of-hours care in the Netherlands was reorganized into larger PCP cooperatives, similar to British and Danish initiatives ${ }^{17,18}$. An important motive for this change was the PCP's dissatisfaction with the high and increasing workload (out-of-hours care combined with regular work), and poor separation between work and private life.

Usually 40 to 120 full-time PCPS participate in these cooperatives, providing care for 80,000 to 300,000 patients. Currently, there are over 120 PCP cooperatives in the Netherlands providing out-of-hours primary care for approximately $90 \%$ of the Dutch population. By and large, the cooperatives are either situated at a central and easily accessible place at some distance from a hospital, or are located within or adjacent to a hospital.

In Maastricht, the PCP cooperative aims to decrease the number of selfreferrals to the ED and to reduce PCP's dissatisfaction with the former outof-hours care system. To that end, the Maastricht PCP cooperative was set up within the ED of the University Hospital Maastricht. Most other out-ofhours services, in the UK, Denmark, and in the Netherlands, work independently of the local hospital and do not provide an explicit gatekeeper function to specialist care. The current organization of out of hours care in Maastricht forces patients, attending the ED without teferral, to be seen first by a PCP. When necessary, the PCP refers the patient to the ED. Because of this emphasis on PCP's gatekeeper function, we expected a 
shift from ED services to primary care services for minor or non-urgent problems.

We assessed the effect of out-of-hours care in the city of Maastricht before and after the reorganization of the PCP's out-of-hours cate.

\section{METHODS}

\section{Setting}

Maastricht is a city in the south of the Netherlands with a population of approximately 120,000 inhabitants. Out-of-hours service is delivered by 59 PCPs. Before the reorganization the 59 PCPs were organized into eight locum groups, delivering out-of-hours care separate from the ED. Per locum group, one PCP was on call. Consequently, each fulltime PCP had approximately 944 on call hours per year. In the new situation with PCP cooperatives for out-of-hours care this is reduced to 298 hours $70 \%$ reduction), because fewer PCPs are on call for the same population. Apart from telephone contacts and consultations at the practice or at the cooperative, the Dutch PCP also makes home visits.

January 2000 the Mastricht PCP cooperative was established. Every evening, night and during the weekends two to three PCPs, depending on the time of day, are present at the cooperative. Specially equipped chauffeured cars are available for home visits. Until $11 \mathrm{pm}$ a practice nurse is present at the cooperative, after $11 \mathrm{pm}$ one nurse from the ED supports the PCPs. Patients have free access to the PCP cooperative and can come without an appointment or phone call.

The public was informed about the out-of-hours care reorganisation by posters at their own PCP's practice and by the PCP's answering machine service. Patients were encouraged to use out-of-hours services only if they could not wait until the next day to consult their own PCP. There were no economic incentives for any particular behavior.

The University Hospital Maastricht is the only hospital in Maastricht, and its ED is the only ED. The ED is staffed by four to six emergency nurses and one surgical or orthopedic resident. There are no separate emergency medicine specialists. During out-of-hours there is always at least one medical specialist per specialty present at the hospital or on call. From 1993 to 1998 the total number of patients attending the ED increased from 22,248 to 27,358 . The out-of-hours census increased from 12,976 patients in 1993 to 16,125 in 1998 .

The most distinct feature of the new organization of out-of-hours care in Maastricht is that all patients attending the ED during out-of-hours without a referral are fitst screened by a PCP or the practice nurse. Screening of 
these patients is performed based on the triage system developed by the Dutch College of General Practitioners. The triage system is not yet validated, but is considered a 'best practice' guideline. With this system the urgency of the patient's complaint is divided into four categories, from not urgent to highly urgent. PCPs are responsible for adequate triaging of these patients. Severe traumas and other severe conditions such as myocardial infarction or acute stroke will be classified as highly urgent and immediately directed to a medical specialist. Patients with cardiac problems are referred to an existing fast track cardiac care system. In 1998 the number of attendances at this emergency cardiac care unit was 4,925, in 20015,464 contacts were registered. Conditions with a lower urgency category will be examined and, if necessary, treated by the PCP. Ambulances also bypass the PCP cooperative.

About $60 \%$ of the Dutch population is compulsorily insured with public health insurance funds. The government determines the cover provided and the income-linked contribution. People with higher income need a private insurance. PCPs are paid by capitation for treatment of patients who participate in public health insurance funds and by fee-for-service for treatment of those with private insurance.

\section{Data collection}

To detect changes in number and characteristics of patients utilizing outof-hours care before and after establishing the PCP cooperative we used a pre-post design, All patient contact registration forms, with respect to the PCP and the ED, during three weeks (January 15 to February 9) in 1998, and three week (March 5 to March 26) in 2001 were analyzed. Data included patient's age and gender, type of consultation (telephone advice, consultation at the PCP's practice or cooperative, and home visit), and reason for encounter. With respect to the $\mathbb{E D}$ records, data included patient's age and gender, type of referral, post emergency department (ED) care, and reason for encounter. Diagnostic information on the patient registration forms was coded by the researcher ( $\mathrm{CvU}$ ) according to the chapters of the International Classification of Primary Care (ICPC) ${ }^{10}$. In case of doubt an experienced PCP (HC) was consulted. Coding medical. complaints by ICPC is considered reliable and valid ${ }^{20}$. Only patients from Maastricht city, based on postal codes, wete included.

To detect serious adverse events we analyzed all new hospital outpatient visits and the number of deaths in Maastricht from the hospital's annual reports and the Central Database of Statistics Netherlands from 1998 to 2001 (two years before and two years after setting up the PCP cooperative). 
The study was ruled exempt from teview by the Institutional Medical Ethics Board.

\section{Statistics}

We used Pearson chi-square tests to test for proportional differences, and the level of significance was set at 0.05 .

Table 1. Contact rate with out of hours care duning the three-yreek data collection periods:

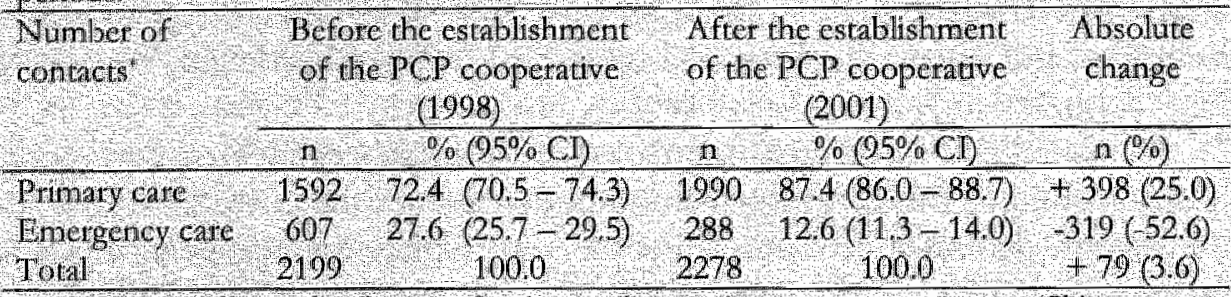

Significanty different distribution of patient utilizing primaty or emengeney cate (Chisquare test $\chi$ ut $=223.06, p<0.001$

\section{RESULTS}

Table 1 lists the out-of-hours patient visits to the PCP and the ED during the two study periods. After setting up the PCP cooperative, the proportion of patients utilizing out-of-hours emergency care decreased by $52.6 \%$, whereas the proportion of patients utilizing out-of-hours primary care increased $(+25.0 \%)(\mathrm{p}<0.001)$.

Particularly, patients utilizing out-of-hours care with musculoskeletal or skin problems were responsible for this shift. The proportion of this patient group seen by the PCP increased by $125 \%\left(\chi^{2}=81.84 ; P<0.001\right)$, whereas the proportion of these patients utilizing emergency care decreased by $60 \%$ $\left(x^{2}=12.72 ; P<0.001\right.$ ) (Table 2). ED data from 1998 showed that, of all patients during out-of-hours with musculoskeletal or skin problems, $84 \%$ was self-referred.

The overall referral tates to the ED during out-of-hours changed substantially after the establishment of the PCP's cooperative (Table 3). The number of self-refertals was reduced significantly, and the number of referrals by PCPS to the ED increased by approximately $45 \%$.

With respect to patients utilizing out-of-hours emergency care after the reorganization, there was an absolute reduction of 39 hospital admissions, 


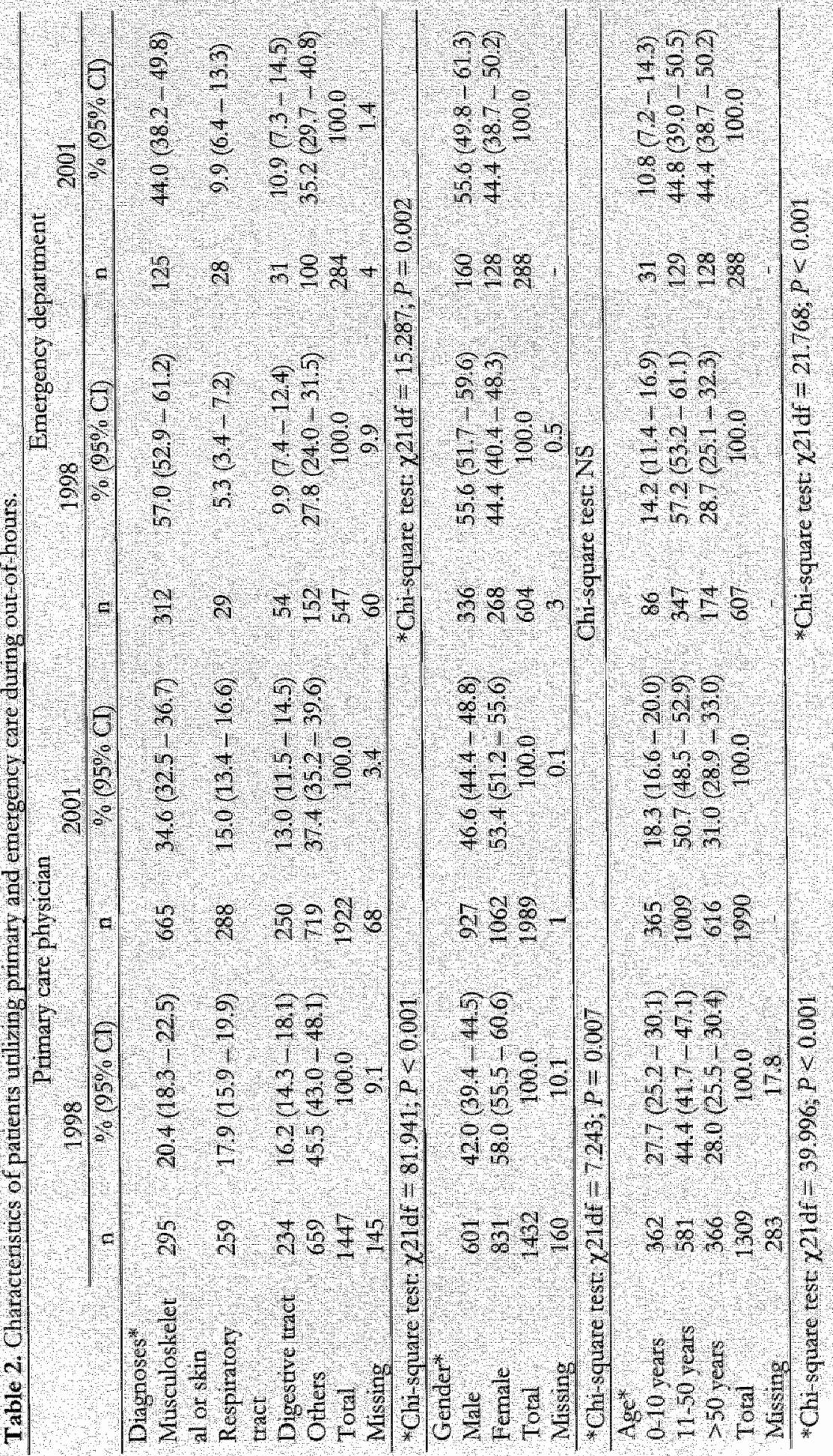




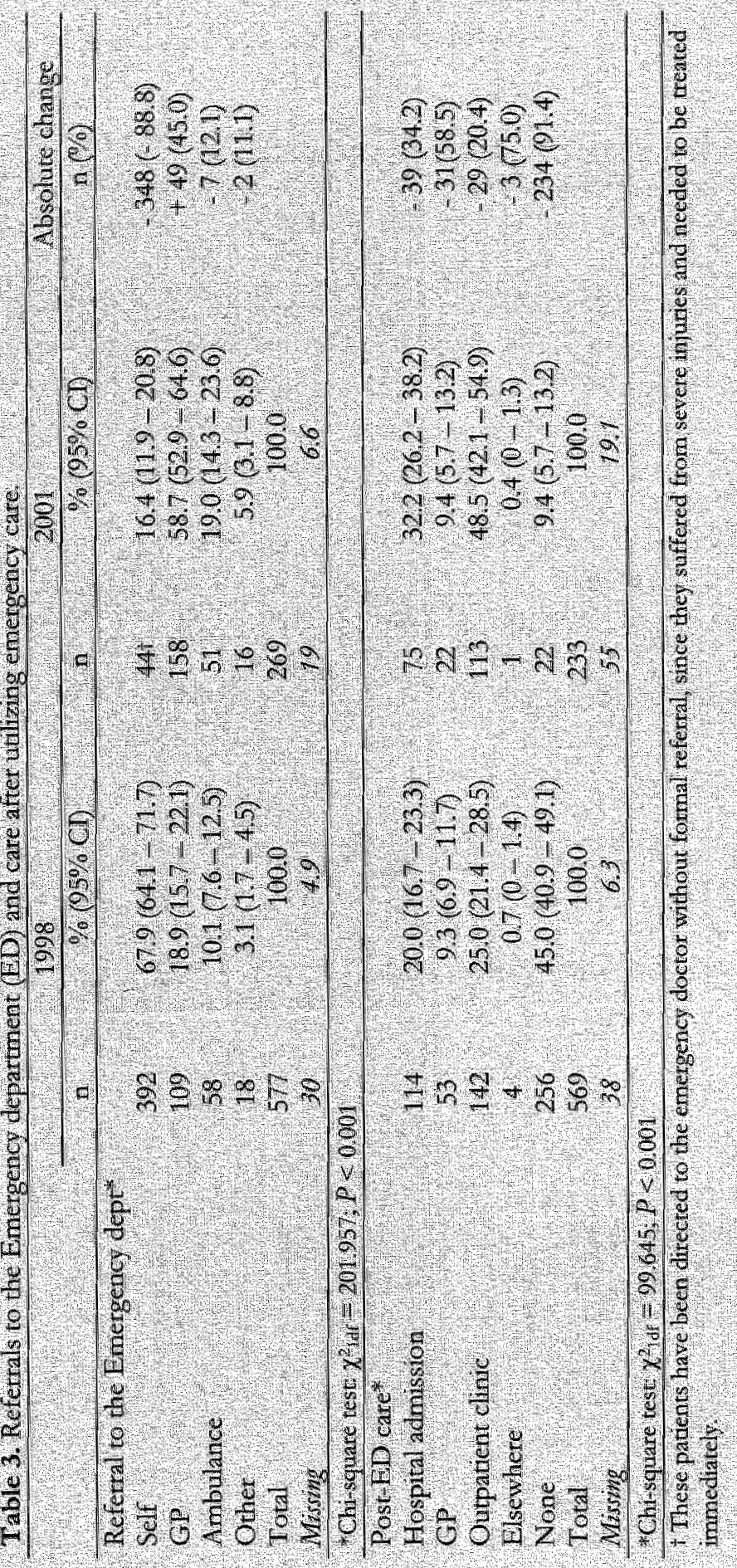


indicating a decrease of $34 \%$. Furthermore, the number of patients not receiving any post-ED care dropped $91 \%$ : from 256 patients in 1998 to 22 in the year 2001.

In 1998 , PCPs handled a substantial number of health problems during out-of-hours by telephone. However, in 2001 the number of telephone consults halved, and the number of consultations at the PCP's office almost tripled (Table 4). Also, fewer home visits were made by the PCP.

In out-of-hours care, the PCP is confronted with four main categories of diagnoses: digestive problems, musculoskeletal problems, respiratory problems, and problems related to the skin and subcutaneous tissue (Table 2). Another large category is general and unspecified diagnoses (about $10 \%$ of all cases). At the ED in 1998 the two biggest medical categories were musculoskeletal and skin problems. These numbers reduced substantially after the establishment of the PCP's cooperative.

In 1998 a total of 76,088 new outpatient visits were registered (during office hours). In 1999 there were 78,726 new outpatient visits. In the first year of the PCP cooperative the total number of new outpatient visits decreased to 74,633 . In 2001 this number hardly changed compared to the year 2000: 74,668 new outpatient visits. Annual numbers of death rates in Maastricht showed no significant changes after setting up the PCP cooperative. In 19981239 people died in Maastricht, in 1999 1217, in 2000 1268 , and in 2001 1278. The population of Maastricht increased during this period from 120,179 in 1998 to 122,163 in 2001 .

Table 4. Type of consultation performed by primary care physicians during our of hlours,

\begin{tabular}{|c|c|c|c|c|}
\hline & & 1998 & & 2001 \\
\hline Type of consullation. & n & $\%, 05 \%(1)$ & n & $00 \%(95 \% \mathrm{al})$ \\
\hline Telephone advice & 730 & $482(45)-50.7)$ & 360 & $184(16.7-2011)$ \\
\hline Consult at practice or & 496 & $32.8(30.4-35,1)$ & 1431 & $73.1(721=751$ \\
\hline $\begin{array}{l}\text { cooperative } \\
\text { Home visit }\end{array}$ & 288 & $190(170-21,0)$ & 166 & $8.5(72-97)$ \\
\hline Total & 1514 & 1000 & 1957 & 1000 \\
\hline Mroms & 78 & 4.9 & 33 & 1,7 \\
\hline
\end{tabular}

Chy-cquare test $\alpha$ zdf $=564,71, p<0.001$. 


\section{DISCUSSION}

This study showed a major shift in patient flow, from emergency care to primary care, after the establishment of the PCP cooperative integrated with the ED.

Although, for practical reasons, we could not involve a control situation, it is unlikely that the observed shift in patient flow has been caused by any other factor than the PCP's out-of-hours reorganization. No other substantial change in the health care system in Maastricht between 1998 and 2001 has occurred. The data collection periods were only three weeks long and were performed in different months. Annual reports of the PCP cooperative and ED however, showed little fluctuation in numbers of patients between January/February as compared to March. In addition, possible confounding because of seasonal changes particularly with influenza is unlikely, since we found no changes in the number of respiratory diseases. The observed changes are large enough to assume that they have not been altered by short or different data collection periods. The total number of patient contacts analyzed in this study is comparable to those in similar studies ${ }^{13,14}$. Missing values in this study are considered random, because they were mainly caused poor handwriting on patient records.

In our study we used two indirect measures of health outcome: deaths and new outpatient visits at the city's only hospital. Although these measures are rather crude and do not supply us with direct information about the patient's health status, they give some insight in the occurrence of serious adverse events. Besides, the Dutch PCP is trained to be a gatekeeper to secondary care and is well equipped to decide whether a patient can be treated in primary cate or should be referred to specialty care.

The absence of specialists for emergency medicine in the Netherlands does not affect the potential role of a PCP cooperative in relation to the $\mathrm{ED}$, as the PCP can still act as gatekeeper to the ED. At the time that PCPS were considering reorganizing their out-of-hours service, the ED suffered from overcrowding, mainly caused by self-referted patients. Therefore, the integration of primary and hospital care during out-of-hours, while keeping professional autonomy, was no more than a logic step.

Several authors have reported inappropriate ED use. Depending on setting and healthcare system, studies have identified a substantial number of ED attendees as primary care patients ranging from $17 \%$ to $57 \% \%^{7,2,12,14}$ The results of our study showed a $53 \%$ reduction of parients utilizing emergency care during out-of-hours. This suggests that about half of all artendees at the ED have minor problems that a PCP can solve. In the literature various other initiatives have been described to deal with this 
substantial number of primary care patients at the $\mathrm{ED}{ }^{10-16}$. These initiatives reduced waiting times ${ }^{10}$, number of investigations ${ }^{13}$, i4 , number of referrals ${ }^{13}$. ${ }^{14}$, and hospital follow up care or admissions ${ }^{12}$. In addition, health outcome was comparable to primary care patients at the ED treated by emergency $\operatorname{staff}^{13}, 14$. Our study showed comparable results with respect to reduced post-ED care, expressed by reduced admission rates and fewer subsequent referrals to the patient's own PCP and medical specialists. A reason for this reduction might be the result of the way PCPs function as gatekeeper in the out-of-hours setting ${ }^{21}$.

On some points the current study differs from other studies on primary care patients at the $\mathrm{ED}^{10-14}$. First, in contrast to other studies that employed PCPS in the ED, this study focused exclusively on out-of-hours care. Second, the PCPS were not employed in the hospital's ED, but operated completely independently. Third, but most important, there was no primary care facility open to patients during out-of-hours other than the one located at the ED. Therefore this study gives a good insight into all patient contacts with out-of-hours care in the city of Maastricht.

The total number of patient contacts with out-of-hours care slightly increased with $3.6 \%$ from 1998 to 2001 . This indicates an increase of no more than $1.2 \%$ per year. Considering the steady increase of about $4 \%$ per year in the number of patient contacts with the ED before the setting up of the PCP cooperative, and the increase of the Mastricht population (approximately $0.5 \%$ per year), we conclude that there was no significant increased demand or usage of out-of-hours care.

This study did not include a cost analysis. However, based on the reduced production at the ED the regional Health Insurance Fund has cut the hospital's annual budget with about $\$ 1.73$ million US dollars. This amount is roughly balanced by the costs of the PCP cooperative, which are about $\$ 1.58$ million US dollars. More specific cost analysis should be performed to supply detailed information on health care costs in the Maastricht situation. In addition, other studies have shown reduced health care costs with PCPs working at EDs ${ }^{13,14,22}$.

The overcrowding at the emergency department, caused by patients with non-urgent health problems, has attracted worldwide attention. Considering the many patients with non-urgent problems utilizing emergency care, it is cleat that there is a role for PCPS in the spectrum of emergency care. When the goal is to reduce inappropriate use of hospital emergency care, a close collaboration between primary and emergency care seems critical. Coleman et al. $^{23}$ showed that alternative services, separate from the hospital, offering first contact care for non-urgent health problems were likely to have little impact on the demand for emergency services. Therefore it may be essential to create an integrated care facility in which the PCP acts as a gatekeeper to 
secondary care. In addition, one of the biggest advantages of the Maastricht out-of-hours care is that the patient always receives adequate care at a single site. No critical time is lost traveling from the primary care cooperative to the emergency department, since both services are at the same location. Moreover, continuity of care is well guaranteed, also because when patients have visited or contacted the PCP cooperative for out-of-hours care, the patient"s own PCP receives a report the next day concerning this contact.

During the first year after the establishment of the PCP cooperative a small survey was held among employees (emergency nurses, physicians, managers, and PCPs) and patients. The results showed that all interviewed people, including emergency department staff, PCPs and patients, were satisfied with the current out-of-hours organization. The emergency department staff and physicians reported that they preferred the new outof-hours organization compared to the former one (survey published only as internal report).

Ferris et al. ${ }^{24}$ found little evidence of beneficial effects of gatekeeping on using secondary care. In contrast, other studies showed positive effects of primary care gatekeeping ${ }^{25,26}$. During the 1990 s, USA managed care organizations tapidly introduced the primary care gatekeeping system, but recently have begun to retreat from this system". Although patients in the USA valued the primary care physician for first-contact care and coordinating care, they seemed to be dissatisfied when they perceive that their PCP kept them from seeing a specialist ${ }^{27}$. Also, PCPs seem not all to be in favor of gatekeeping. However, some believe gatekeeping improves their role as care coordinator ${ }^{28}$. European countries with gatekeeping systems spent less on health care as a percentage of their gross national product than those allowing direct access to specialists ${ }^{29,30}$. High referral rates to specialist care are considered one of the contributing factors of the USA's exceptionally high healthcare expenditure ${ }^{3 !}$.

In conclusion, study showed that a primary care cooperative for out-ofhours care located at the gate of the hospital can reduce the use of hospital emergency care, and provides the PCP with an important coordinative role within the health care system, complementing the ED in the provision of out-of-hours care.

\section{REFERENCES}

1. Bindman $A B$, Majeed A. Primary care in the United States: organisation of primary Care in the United States. BMJ. 2003;326:631 4.

2. St Peter RF. Gatekeeping arrangements are in widespread use. Data Bull (Cent Stud Healch Syst Change). $1997(7): 1-2$. 
3. Kulu-Glasgow 1 , Delnoij D, de Bakket D. Sel-refertal in a gatekeping system: patients" reasons for skipping the general-practitioner. Health Policy. 1998,45:221-38.

4. Schneider SM, Gallery ME, Schafermeyer $\mathbb{R}$, Zwemer FL. Emergency department crowding: a point in time. Ann Emerg Med. $2003 ; 42: 167-72$.

5. Derlet $\mathrm{R}$, Richards I, Kravitz R. Frequent overcrowding in U.S. emergency departments. Acad Emerg Med. 2001;8:151-5.

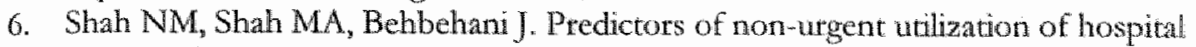
emergency services in Kuwait. Soc Sci Med. 1996;42:1313-23.

7. Lee $A$, Lau FL, Hazlett $C B$, et al. Factors associated with non-urgent untization of Accident and Emergency services: a case-control study in Hong Kong. Soc Sci Med. 2000;51:1075-85.

8. Fatovich DM. Emergency medicine. BMJ. 2002;324:958 62.

9. Dale J, Green J, Reid F, Glucksman E. Primary care in the accident and emergency department: I. Prospective identification of patients. BMJ. 1995;311:423-6.

10. Cooke MW, Wilson $S$, Pearson $S$. The effect of a separate stream for minor injuries on accident and emergency department waiting times. Emerg Med J. 2002;19:28-30.

11. Freeman GK, Meakin RP, Lawtenson RA, Leydon GM, Craig G. Primary care units in A\&E departments in North Thames in the 1990s: inital experience and furure implications. Br J Gen Pract. 1999;49:107-10.

12. Ward $\mathrm{P}$, Huddy J, Fargreaves $S$, Touquet $\mathbb{R}$, Hurley J, Fothergill J. Primary care in London: an evaluation of general practitioners working in an inner city accident and emergency department. I Accid Emerg Med. 1996;13:11-5.

13. Dale J, Green ], Reid F, Glucksman E, Higgs R. Primary care in the accident and emergency department: II. Comparison of general practitioners and hospital doctors. BM]. 1995;311:427-30.

14. Murphy AW, Bury G, Plunkett PK, et al. Randomised controlled teial of general practitioner versus usual medical care in an urban accident and emergency department: process, outcome, and compatative cost. BMJ. 1996;312:1135-42.

15. Washington DI, Stevens CD, Shekelle PG, Baker DW, Fink A, Brook RH. Sarely directing patients to appropriate levels of care: guideline-driven triage in the emergency service. Ann Emerg Med. 2000;36:15-22.

16. Washington DL, Stevens CD, Shekelle PG, Henneman PL, Brook RH. Next-day care for emergency department users with nonacute conditions. A randomized, controlled trial. Ann lntern Med. 2002;137:707-14.

17. Hallam 1. Primary medical care outside normal working hours: revicw of published work. BMJ. 1994;308:249-53.

18. Olesen F, Jolleys JV. Out of hours service: the Danish solution examined. BMJ. 1994,309:1624-6.

19. Lambetts $\mathrm{H}$, Wood $\mathrm{M}$, eds. International Classiffation of Primary Care. Oxford: Oxford University Press; 1987.

20. Britt $H$, Angelis $M$, Harris $E$. The reliability and validity of doctor-reconded norbidity data in active data collection systems. Scand I Ptim Health Care 1998;16:50-5.

21. Starfield B. Is primary care essential? Lancet. 1994;344:1129-33.

22. Dale J, Lang $H$, Roberts JA, Green J, Glucksman E. Cost effectiveness of treating primary care patients in accident and emergency: a comparison between general practitioners, senior house officers, and registrars. BMJ. 1996;312:1340-4.

23. Coleman P, Irons $R$, Nicholl J. Will alternative immediate care serwices reduce demands for non-urgent treatment at accident and emergency? Emerg Med J. $2001 ; 18: 482-7$. 
24. Ferris TG, Chang $Y$, Blumenthal $D$, Pearson SD. Leaving garekeping behind--effects of opening access to specialists for adults in a health maintenance organization. $N$ Engl J Med. 2001;345:1312-7.

25. Schillinger $D$, Bibbins-Domingo $K$, Vranizan $K$, Bachett $P$, Luce JM, Bindman $A B$. Effects of ptimary care coordination on public hospital patients. J Gen Intern Med. $2000 ; 15: 329-36$.

26. Rask K), Deaton (Culler $5 \mathrm{D}$, et al. The effect of primary care gatekeepers on the management of patients with chest pain. Am J Manag Care. 1999;5:1274-82.

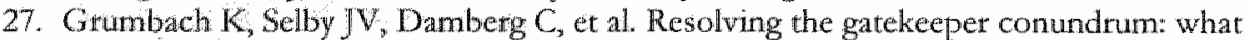
patients value in primaty care and teferrals to specialists. JAMA. 1999;282:261-6.

28. Halm $E A$, Causino $N$, Blumenthal $D$. Is gatekeeping better than traditional care? A survey of physicians' attitudes. JAMA. 1997;278:1677-81.

29. Boerma WG, van der Zee J, Fleming DM. Service profiles of general practitoners in Europe. European GP Task Profile Study. Br J Gen Pract. 1997;47:481-6.

30. Anderson GE, Hurst J, Hussey PS, Jee-Hughes M. Health spending and outcomes: trends in OECD countries, 1960-1998. Health Aff (Millwood). 2000;19:150-7.

31. Forrest CB. Primary care in the United States: primary care gatekeeping and referrals: effective filter or ailed experiment? BMJ. 2003;326:692-5. 

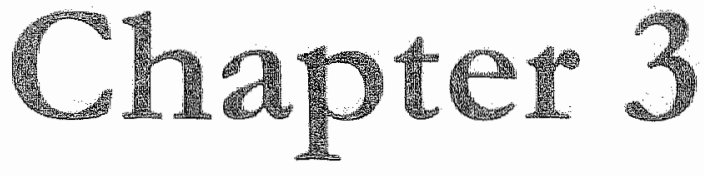

\section{The use of out-of-hours services: A comparison between two organisations.}
C.J.T. van Uden ${ }^{1,2}$
Emergency Medicine Journal 2003; 20: 184-7
R.A.G. Winkens ${ }^{1,2}$
G. Wesseling ${ }^{1.3}$
H.F.J.M. Crebolder ${ }^{2}$
C.P. van Schayck ${ }^{2}$

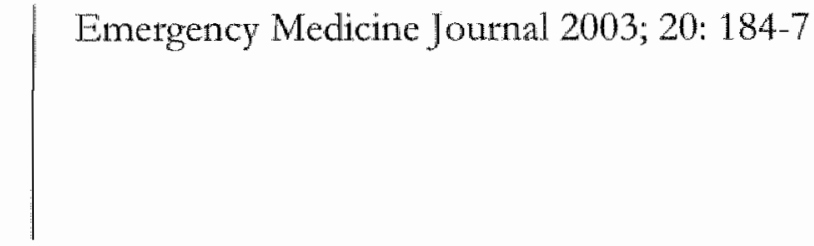




\section{ABSTRACT}

Objectives: To investigate differences in numbers and characteristics of patients utilising primary or emergency care due to differences in organisation of out-of-hours care.

Background: Increasing numbers of self referrals at the accident and emergency (A\&E) department cause overcrowding, while a substantial number of these patients exhibit minor injuries that can be treated by a general practitioner (GP).

Methods: Two different organisations of out of hours care in two Dutch cities (Heerlen and Maastricht) were investigated. Important differences between the two organisations are the accessibility and the location of primary care facility (GP cooperative). The Heerlen GP cooperative is situated in the centre of the city and is respectively $5 \mathrm{~km}$ and $9 \mathrm{~km}$ away from the two A\&E departments situated in the area of Heerlen. This GP cooperative can only be visited by appointment. The Maastricht GP cooperative has free access and is located within the local A\&E department. During a three week period all registration forms of patient contacts with out of hours care (GP cooperative and $A \& E$ department) were collected and wirh respect to the primary care patients a random sample of one third was analysed.

Results: For the Heerlen and Maastricht GP cooperative the annual contact rate, as extrapolated from our data, per 1000 inhabitants per year is 238 and 279 respectively $\left(\chi_{(\text {ldf }}^{2}=4.385, p=0.036\right)$. The contact rate at the A\&E departments of Heetlen $(n=66)$ and Maastricht $(n=52)$ is not different $\left(\chi_{\text {(idf) }}^{2}=1.765, \mathrm{p}=0.184\right)$. Some $51.7 \%$ of the patients attending the $\Lambda \& E$ department in Heerlen during out of hours were self referred, compared with $15.9 \%$ in Maastricht $\left(\chi_{(\text {idf }}^{2}=203.13, p<0.001\right)$.

Conclusions: The organisation of out of hours care in Mastricht has optimised the GP's gatekeeper function and thereby led to fewer self referrals at the $A \& \mathbb{E}$ department, compared with Heerlen. 


\section{INTRODUCTION}

Increased utilisation of emergency care has been reported by several authors ${ }^{1.4}$. It has been argued that this leads to overcrowding of the accident and emergency (A\&E) departments, which can be seen as the biggest impediment of timely and adequate emergency care $2,3,5 . A$ substantial number of patients using emergency care exhibit minor problems that can be treated by a general practitioner (GP) ${ }^{5,6}$. There have been several initiatives reported dealing with this problem, like employing GPs in A\&E departments or by establishing a separate stream for minor injuries $^{7-11}$. All these initiatives mainly focused on reducing the number of primary care patients utilising emergency medicine.

In the Dutch healthcare system the GP acts as a gatekeeper to secondary care. As a rule, patients need a referral from their GP to use hospital services 12. However, to attend an A\&E department a referral is recommended but not strictly needed. Many patients skip the GP and attend the emergency department without referral ${ }^{12}$.

In the past few years GPs out of hours care has been reorganised substantially, motivated by increased dissatisfaction of GPs with former out of hours care. Like in other countries GPS in the Netherlands used to organise their out of hours services in locum groups, in which they joined a rota system $^{13}$. In recent years, large GP cooperatives have been set up following British and Danish examples ${ }^{14,15}$. Generally 40 to 120 full time GPs participate in these services, providing care for populations anging from 80000 to 300000 . There are however, differences in the way these GP cooperatives are organised, such as differences in location (located next to the A\&E department of a hospital or in a separate distant building at the centre of a city or a rural area) or differences in accessibility (free access compared with appointment only).

There are no publications on the effect of different organisation structures of out of hours services by GPS on patient flow. Therefore it is not known to what extent these differences influence attendance of patients at emergency departments and GP cooperatives, or the way care is provided outside normal working hours.

In this study we compared two types of GPS out of hours services. One is located at the A\&E department of a hospital and has free access (Maastricht), and another that is located in the centre of a city where patients can only present themselves by telephone (Heerlen). We envisage that especially the location of these cooperatives influences the number of patients attending the local emergency department (see fig 1). In the first situation the GP's gatekeeper function during out of hours seems fully established, because all patients seeking care during out of hours, including 
those patients attending the A\&E department without referral are first seen by a GP. In other words, skipping the GP and directly attending the A\&E department is not possible. The GP decides which treatment is most appropriate and whether referral is needed.

The objective of this study is to evaluate the effects of differences in the organisation of GP's out of hours services on the number and the charactetistics of patients using out of hours primary and emergency care.

\section{METHODS}

\section{Setting}

This study compares the use of out of hours services (A\&E departments and GP cooperatives) in two Dutch cities and their surrounding areas; Heerlen and Mastricht. The distance between both cities is about $20 \mathrm{~km}$.

In Heerlen the GP cooperative is located in the centre of the city of Heerlen and serves a population of 278000 patients, with 120 participating GPs. During this study the area of Heerlen had two A\&E departments operational during out of hours, together serving a population of 300000 patients. These A\&E departments are about $5 \mathrm{~km}$ and $9 \mathrm{~km}$ away from the GP cooperative, and are located in the suburbs of Heerlen and the centre of a nearby city (Kerkrade), respectively.

The GP cooperative Maastricht is situated at the A\&E department of the university hospital Maastricht and serves a population of 190000 patients, with 83 participating GPs. The university hospital Maastricht is located in the suburbs of Maastricht. Both regions consist of rural and urban areas.

\section{Data collection}

During a three week period in June 2001 in Heerlen and from 22 September to 15 October 2001 in Maastricht, all data of patient contacts with both GP cooperatives and A\&E departments in the corresponding areas were collected. We used standard registration forms completed for every patient contact. Every third consecutive patient contact with the GP cooperative was entered into a database and was analysed. With respect to the A\&E departments all data were analysed.

We had no reason to believe that the differences in registration periods may account for relevant differences between the datasets. Neither of these periods included bank holidays or the summer vacation period, which might influence contact rates. Also Salisbury et al. ${ }^{16}$ showed only little seasonal variation. We assume that the distribution of patient contacts characteristics 
remains comparatively stable over various periods, and therefore differences in characteristics are not likely to be caused by differences in these data collection periods. In August 2001 the patient population of the GP cooperative of Maastricht expanded from 120000 to 190000 patients, with the inclusion of 24 GPs from the Maastricht area. With this expansion the comparability between both regions (distribution of rural and urban areas) increased, which is one of the reasons we choose to perform data collection in September and Octobet in Maastricht.

\section{Outcome measures}

Main outcome measures involved number of patient contacts, diagnostic information, type of consultation with the GP cooperative, and refertals to the A\&E department. Because of lack of detail of telephone consultations, we only analysed patient contact characteristics with respect to consultations at the GP cooperative and home visits. With respect to total number of patient contacts all data were used. The diagnostic information was coded according to the chapters of the International Classification of Primary Care (TCPC) ${ }^{17}$.

\section{Statistics}

Pearson's $\chi^{2}$ tests were carried out to test for differences and the level of significance was set at 0.05 .

Table 1. Chatacteristics of patient contacts with our-of hours care.

\begin{tabular}{|c|c|c|c|c|c|}
\hline & Heenlen & Nlatastricht & Chergutare: & $\mathrm{Pyg}$ \\
\hline & & & & Wallac & 1 \\
\hline \multirow{4}{*}{$\begin{array}{l}\text { Popularion } \\
\text { Contacts / } 1000 / \\
\text { pear }\end{array}$} & (a) co-operative & 270,000 & 190000 & & ; \\
\hline & Aet Iepar & 300,000 & 100,000 & & \\
\hline & GP co operatire & 230 & 270 & 4384,1 & 01036 \\
\hline & A\&L department & 46 & 52 & $1,765 \mathrm{dra}$ & 0.184 \\
\hline \multicolumn{2}{|c|}{ Self referrals at A\&d department } & $\begin{array}{l}51.70 \% \\
(n=592)\end{array}$ & $\begin{array}{r}15.90 / \\
(n=90)\end{array}$ & $203.13 \mathrm{~d}=\mathrm{H}$ & 80,001 \\
\hline \multirow{3}{*}{ GPeo-operative } & Consultation & $47.6 \%$ & $62.8 \%$ & $169,11 \mathrm{dn}=2$ & $\times 0,001$ \\
\hline & $\begin{array}{l}\text { Telephone } \\
\text { consultation }\end{array}$ & $390 \%$ & $29.8 \%$ & & \\
\hline & Home vistt & $13.4 \%$ & $7,4 \%$ & & \\
\hline
\end{tabular}




\section{RESULTS}

Over the three week periods that were monitored, in total 3825 contacts were registered in the Hecrlen GP cooperative, and 3054 contacts in the Maastricht GP cooperative. In the A\&E departments, 1152 contacts and 567 contacts were recorded in Heerlen and Maastricht respectively. We extrapolated the data to an annual contact rate per 1000 inhabitants per year. For the Heerlen and Maastricht GP cooperative the annual contact rate per 1000 inhabitants per year is 238 and 279 respectively $(p=0.036$ ). The contact rate at the $\mathrm{A} \& \mathrm{E}$ departments of Heerlen and Maastricht is not different $(p=0.184$ ) (see table 1$)$.

In Heerlen, comparatively more patients receive telephone advice, fewer patients attend the GP cooperative for a consultation, and more patients are paid a home visit compared with Maastricht. These differences were statistically significant $(p<0.001)$.

Some $51.7 \%$ of the patients attending the A\&E department in Heerlen were coded as self teferred, compared with $15.9 \%$ in Maastricht $(\mathrm{p}<0.001)$.

GPs in Maastricht saw compatatively more patients with musculoskeletal problems, and less circulatory problems compared with GPs in Heerlen ( $p$ $<0.001$ and $p=0.002$ respectively) (see table 2 ).

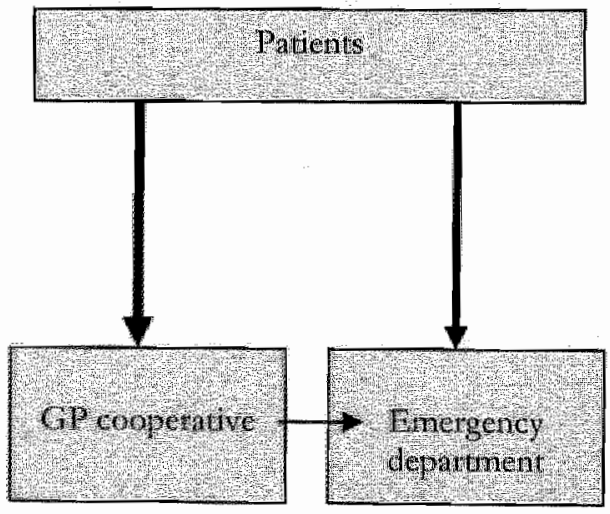

Separated out-of-hours care

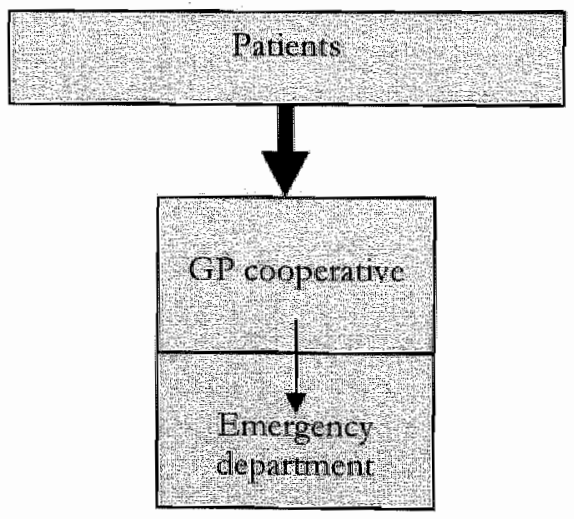

Integratedl out-of-hours care

Figure 1. Ouf-of-hours care organisation. 


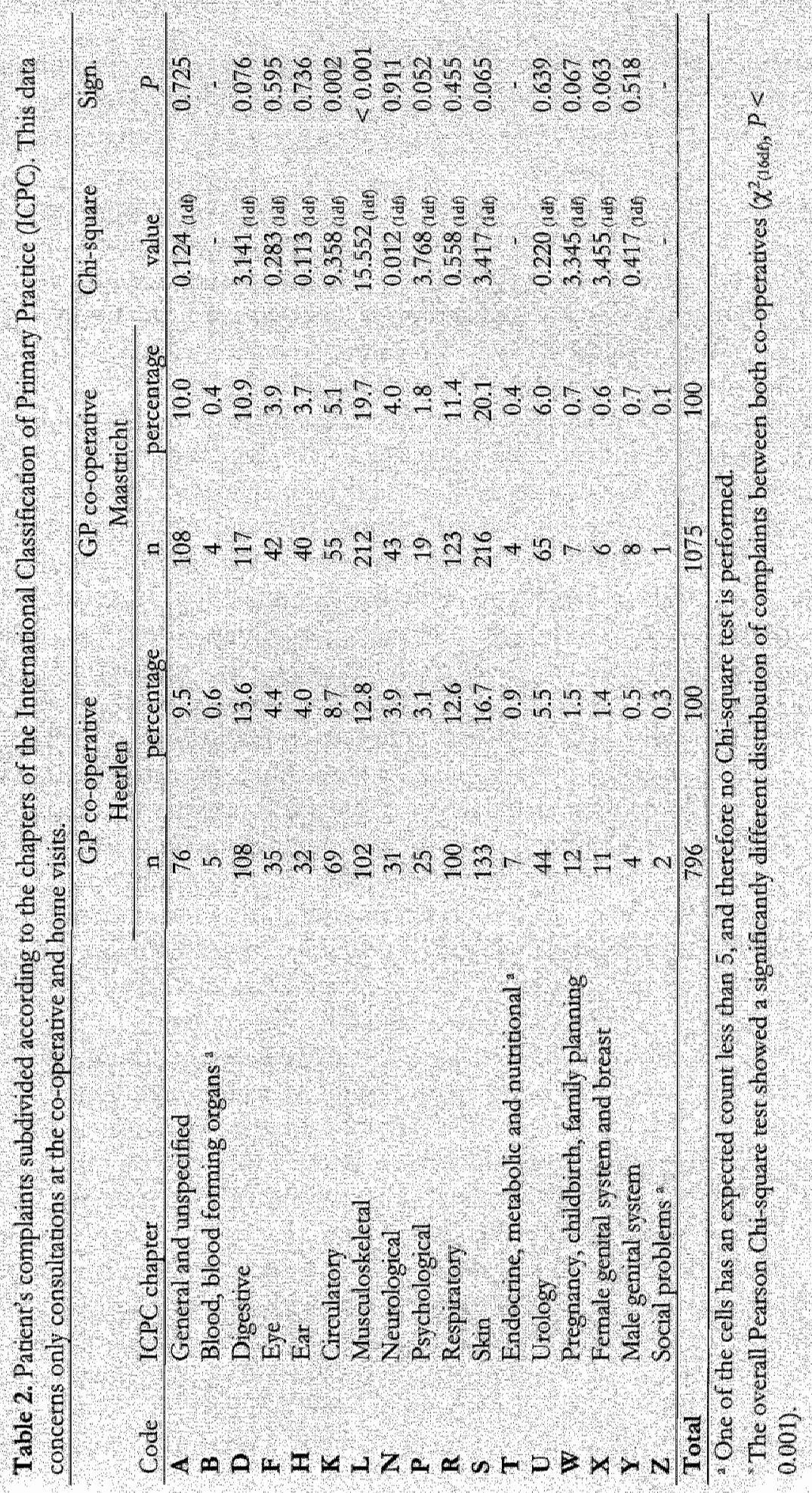




\section{DISCUSSION}

We found no difference in the total number of patient contacts with out of hours emergency care, between Heetlen and Maastricht. However, in Maastricht significantly more patients were seen by a GP, with fewer self referrals to the A\&E department.

The contact rate per 1000 patients per year in Heerlen is comparable to another Dutch study by Van Duijn et al. ${ }^{18}$. However, other studies, mainly in the UK, report lower contact rates ${ }^{13,16,19}$ (130 to 176 per 1000 patients per year). Also higher contact rates have been reported ( 423 to 514 per 1000 patients) 15,20 . Different aspects of the national health care system and definition of out of hours may account for these differences.

The number of self referrals to the A\&E department in Maastricht is much lower than in Heerlen. This is caused by the fact that in Maastricht the GP's gatekeeper function is fully established. The GP decides with respect to all patients attending the GP cooperative and $A \& E$ department whether a patient is suitable for primary care or if the patient should be referred to the A\&E department. Patients entering the hospital with obviously very severe injuries are immediately directed to the $A \& E$ department and ate registered as self referred, while in fact they are not. This completely explains the $15.9 \%$ self referrals in Maastricht.

Assuming that minor injuries mainly relate to musculoskeletal problems and skin or subcutaneous wounds, it is obvious that the Maastricht GP cooperative sees more of these patients at the GP cooperative or during home visits. These two chapters of the ICPC together account for $40 \%$ of all disorders as presented at the GP cooperative in Maastricht, compared with $30 \%$ in Heerlen (see table 2). The finding that GPs in Maastricht seem to handle fewer patients with circulatory problems, lays probably in the fact that in Maastricht patients with clear cardiac complaints are directly referred to the cardiologist, and thereby bypassing the GP cooperative.

Despite the selection function of the GP in Maastricht, there was no statistical difference in the number of patients using emergency care berween Hecrlen and Maastricht. As reported in the literature a lot of patients using emergency care exhibit minor injuries that can be taken care of by a $G P^{5.6}$. Therefore we expected less attendees at the Maastricht A\&E department in comparison with Heerlen. Thete may be two explanations for not finding a difference berween these two A\&E departments. Firstly, the A\&E department in Heerlen advises patients with minor injuries, in case of crowdedness at the A\&E department, to contact the GP cooperative. This causes a reduction of the number of patients using emergency care. However, it is unclear how many patients ate advised to do so, and eventually attend the GP cooperative. Secondly, thete used to be three A\&E 
departments serving the Heetlen region population. A couple of months before this study, one A\&E department was closed during out of hours. This may also have caused a number of patients with minor injuries to decide not to attend one of the other two A\&E departments, as their travel distance to the nearest A\&E department had increased. This assumption is supported by a study of O'Reilly et al. ${ }^{21}$.

This study also showed that GPs in Maastricht performed more consultations at the GP cooperative than their colleagues in Heerlen. There are two predominant explanations for this difference. Firstly, the former self referrals in Maastricht used to enter the A\&E department without an appointment, and now enter the GP cooperative also wirhout an appointment. Secondly, because the GP cooperative in Heerlen uses telephone triage, patients are seen by appointment, which enables the GP cooperative to handle a substantial number of patient contacts by telephone. In Maastricht, annual reports showed that only about $25 \%$ of all consultations at the GP cooperative were preceded by a telephone consultation.

As suggested by others, there is need for primary care at the A\&E department ${ }^{5,6}$. Supplying primary care outside a hospital will only partially fulfil these needs, as numerous patients believe that they should be treated in the A\&E department ". The organisation of out of hours care in Maastricht ensures that all primary care patients are treated by GPS in contrast with Heerlen. Overcrowding at the A\&E department as caused by patients with minor problems is likely to be reduced more in Maastricht than in Heerlen. However, this is not supported by the results of this study. The most important benefit of the way out of hours care as organised in Maastricht, is that health care is oprimally geared to the symptoms of the patient, which implies efficient and appropriate care. The role of the GP as gatekeeper to secondary care is fully established. Patients needing emergency care are directly referred to the A\&E department and primary care patients are seen by a GP. In addition, patients no longer need choose between attending a GP cooperative or the A\&E department. They are always in the right place.

The organisation of out of hours care in Maastricht supports close collaboration between primary and emergency care. This offers possibilitics for exchanging expertise and clinical knowledge. We hope to investigate this aspect in future research.

In summary, the organisation of out of hours care in Maastricht has optimised the GP's gatekeepers function and led to fewer self referrals at the A\&E department, compared with Heerlen. 


\section{REFERENCES}

1. Santos-Eggimann B. Increasing uge of the emergency department in a Swiss hospital: obscrwational study based on measures of the severity of cases. BMJ. 2002;324:1186-7.

2. Fatowich DM. Emergency medicine. BMJ. 2002;324:958-62.

3. Shah NM, Shah MA, Behbehani \}. Predictors of non-urgent utilizarion of hospital emergency services in Kuwalt. Soc Sci Med. 1996;42:1313-23.

4. Robertson-Steel IR. Providing primary care in the accident and emergency depattment. BMJ. 1998,316:409-10.

5. Lee $A_{\text {, }}$ Lau WL, Hazlett CB, et al. Factors associated with non-urgent utilization of Accident and Emergency services: a case-control study in Hong Kong. Soc Sci Med. $2000 ; 51: 1075-85$.

6. Green J, Dale J. Primaty care in accident and emergency and genefal practice: a comparison. Soc Sei Med. 1992;35:987-95.

7. Cooke MW, Wilson $\mathrm{S}$, Pearson $\mathrm{S}$. The effect of a separate stream for minor injuries on accident and emergency department waiting ümes. Emerg Med J. 2002;19:28-30.

8. Cooke M. Employing general ptactitioners in accident and emergency departments. Better to increase number of consultants in accident and emergency medicine. BMJ. $1996 ; 313,628$.

9. Essex B. Providing primary care in accident and emergency departments. Departments. should try educating parients first. BMJ. 1998;317:208.

10. Freeman GK, Meakin RP, Lawrenson RA, Leydon GM, Craig G. Primary care units in A\&E departments in North Thames in the 1990s: initial experience and future implications. Br J Gen Pract. 1999,49:107-10.

11. Ward $\mathbb{P}$, Huddy J, Hargreaves $S$, Touquet $R$, Hurley I, Fothergill I. Primaty care in London: an evaluation of general practitioners working in an inner ciry accident and emergency deparment. J Accid Emerg Med. 1996;13:11-5.

12. Kulu-Glasgow I, Dehoij D, de Bakker D. Self-referral in a gatekeeping system: patients' reasons for skipping the general-practitioner. Health Policy. 1998;45:221-38.

13. Hallam I. Primary medical care outside normal working hours: review of published work. BMJ. 1994;308:249-53.

14. Hallam $L_{\text {, }}$ Cragg D. Organisation of primary care services outside nomal woiking hours. BMJ. 1994;309:1621-3.

15. Olesen F, Jolleys JV. Out of hours service: the Danish solution examined. BMJ. $1994 ; 309: 1624-6$.

16. Salisbury C, Trivella M, Bruster S. Demand for and supply of out of hours care from general practitioners in England and Scotland: observational study based on routinely collected data. BM]. 2000;320:618-21.

17. Lamberts $\mathrm{H}$, Wood $M$, eds. International Classification of Primaty Care. Oxford: Oxford University Press; 1987.

18. van Dujin NP, wan Weert HCPM, Scholte D, Bindels PJE. Out of hours: primary care clinic or hospital cmergency department? Eur J Gen Pract. 1998;4:69-73.

19. Carlisle R, Groom LM, Avery AJ, Boot D, Earwicker S. Relation of on of hours activity by general practice and accident and emergency services with deprivation in Nottingham: longitudinal survey. BMI. 1998;316:520-3.

20. Hansen BL, Munck $A$. Out-of-hours service in Denmark: the effect of a structural change. Br J Gen Pract. 1998;48:1497-9.

21. O'Reilly D, Stevenson M, McCay C, Jamison J. General pracuce out-of-hours service, variations in use and equality in access to a doctor: a cross-sectional study. Br J Gen Pract. 2001:51:625-9. 


\title{
Chapter 4
}

\section{Out-of-hours primary care. Implications of organisation on costs.}

\author{
C.J.T. $\operatorname{van} \mathbb{U d e n}^{1,2}$ \\ A.J.H.A. Ament ${ }^{3}$ \\ G.B.W.E. Voss ${ }^{4}$ \\ G. Wesseling ${ }^{1,5}$ \\ R.A.G. Winkens ${ }^{i, 2}$ \\ C.P. van Schayck ${ }^{2}$ \\ H.F.J.M. Crebolder ${ }^{2}$
}

Submitted for publication

\footnotetext{
Department of Integrated Care, Universty Hospital. Mastricht

Department of General Practice, Masatricht University

- Deparment of Health Organization Policy and Econoracs, Matatrich Universicy

* Department of Clinical Epidemology and Medical Technology Asessment, University Hospilat Matatrat

Deparment of Respiratory Diseases, Universigy Hospinal Matsuch
} 


\section{ABSTRACT}

In the Netherlands, general practice out-of-hours care has experienced a radical change in its organisation during the last ten years. In former days, general practitioners (GPs) used to perform these services in small-scale practice rotas, whereas nowadays they have organised themselves in largescale GP cooperatives. As a result of the rapid development and local preferences, the organisation of out-of-hours primary care varies from region to region. In this study we investigated costs of an out-of-hours model in which the GP cooperative operates separate from the hospital emergency department (ED), and costs of an out-of-hours model in which the GP cooperative is integrated with the hospital ED. In addition, the costs of the hospital ED of the integrated model before and after the set up of the GP coopetative were analysed. Previous studies have shown that integrating the GP cooperative with a hospital ED results in a substantial reduction in patients utilising hospital emergency care and an increase in patients utilising primary care. It was expected that this shift would have an effect on costs of out-of-hours care. This study was performed to provide insight in costs of these two different models of out-of-hours care in order to support health care professionals and policy makers in developing outof-hours primary care. The study results show that the costs of primary care appear to be more dependent on the size of the population the cooperative covers than on the way the GP cooperative is organised, i.e. separated versus integrated. In addition, despite the substantial reduction of patients, locating the GP cooperative at the same site as the ED was found to have little effect on costs of the ED. Sharing more facilities and personnel between the ED and the GP cooperative may improve cost-efficiency. 


\section{INTRODUCTION}

Within the last ten years, out-of-hours primary care in the Netherlands has been substantially reorganised. Formerly, general practitioners (GP) used to be organised in small groups of GPS in which they joined a rota system. Nowadays large-scaled GP cooperatives have been set up to provide out-of-hours primary care. The current organisation of out-ofhours primary cate is very similar to that in the UK and Denmark ${ }^{1,2}$. Many aspects of out-of-hours primary care have already been investigated, however, little is known about costs of current out-of-hours care as organised in GP cooperatives.

The organisation of out-of-hours care in the Netherlands varies from region to region. This is mainly due to local preferences and the rapid development of GP cooperatives. The GP cooperatives vary with respect to size of the population, number of participating GPs, accessibility, and location close to or separate from a hospital emergency department. (ED). In the Netherlands, there is currently debate on the position and the role of the GP during out-of-hours care, and how out-of-hours care should be organised. More specifically, the debate focuses on the cooperation and the positioning between GP cooperatives and EDs. The Dutch minister of Health has argued that GP cooperatives should seek close collaboration with hospital emergency departments, and favours an integrated model in which the GP cooperative and the ED work closely together at the same site ". Many GPs however, are still reluctant to go towards a closer relationship with the hospitals' EDs, mainly because they are afraid to loose their identity and autonomy as GP. Obviously, it is essential that this discussion is supported with objective data on differences (advantages or disadvantages) between the out-of-hours care models.

In a recent publication we showed that different models of out-of-hours care, i.e. integrated versus separated out-of-hours system, have different implications on the utilisation of out-of-hours primary care " In the integrated system the GP cooperative is located at the site of the hospital emergency department (ED) and sees all non-referted patients who atrend the out-of-hours care facility. This implicates that no self-referred patient can enter the ED without first having been seen by a GP of the GP cooperative. The separated system has a GP cooperative located away from the hospital ED, and patients can choose to attend the primary care facility or the hospital ED. We found that the integrated model has the potential to reduce the number of patients utilising hospital emergency care with approximately $50 \%{ }^{5}$. As a consequence, substantially more patients are seen at the integrated GP cooperative compared to the separated GP cooperative 4,5 
In addition to information on utilisation of out-of-hours care, we have also investigated patient satisfaction in South of the Netherlands, covering a region with one integrated cooperative and four separated cooperatives. Detailed analysis, which was published in an internal report ${ }^{7}$, showed that there were only few differences between cooperatives and they were not directly related to the way out-of-hours care was organised in relation to the hospital ED. However, in their comments, some patients mentioned to prefer the integrated cooperative, because primary and hospital emergency care facilities are available at the same site.

So far, little is known about the differences in costs between an integrated out-of-hours care model and a separated out-of-hours care model. One would expect that reallocating patients during out-of-hours from hospital emergency care to primary care facilities may have effect on the costs of the GP cooperatives and the hospital ED. It is expected that the reduction of patients using ED care may cause a reduction in costs of the ED. The necessity of information on costs to support the discussion on the out-of-hours care organisation of preference is evident.

The objectives of this study are to determine the costs of two differently organised GP cooperatives (integrated versus separated), and to determine the effect of setting up a GP cooperative integrated with the $E D$ on these costs.

\section{METHODS}

To gain insight in costs of a separated GP cooperative and an integrated GP cooperative we studied two cooperatives in the Southern part of the Netherlands. As an example of a separated model we chose the GP cooperative in the Heerlen region, and as a representative of an integrated cooperative we studied the GP cooperative in Maastricht (see Figure 1). Also, data on use of out-of-hours primary care was collected.

\section{Setting}

\section{The separated GP cooperative}

The separated GP cooperative was set up in March 1999. It started with taking care of a population of approximately 100,000, but expanded in 2002 to a population of 285,000 . In this region one hospital ED is open during out-of-hours. The distance from the Heerlen GP cooperative to this ED is approximately $5 \mathrm{~km}$. At the moment about 120 GPs participate in the separated GP cooperative. The GP cooperative is open from $5 \mathrm{pm}$ to 8 am 
on weekdays, and from 5 pm on Friday to 8 am on Monday. In the evenings the GP cooperative is staffed with five GPs, and during the night only two GPs are present. During daytime in the weekends, the GP cooperative is staffed with seven to eight GPs.

Patients are stimulated to make a phone call before attending the cooperative. This allows the GP cooperative to triage patients at urgency levels of their medical complaints in order to prioritise treatment. This process of telephone triage is performed by doctor's assistants. In the evenings there are five to six doctor's assistants at the cooperative, and during the night there are only two. During the day in the weekends, eight or nine doctor's assistants are present.

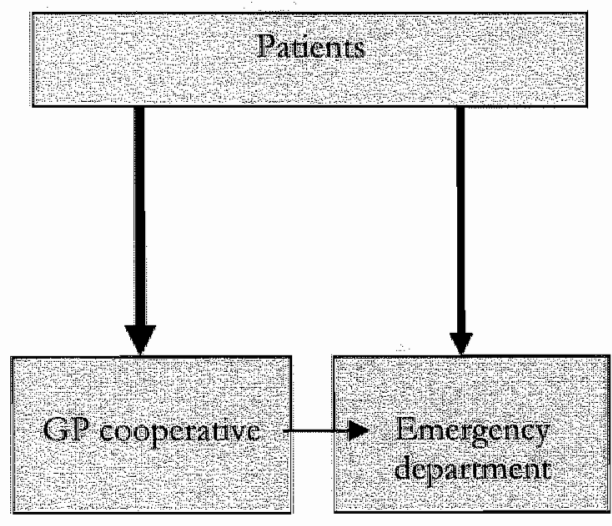

Separated out-of-hours care

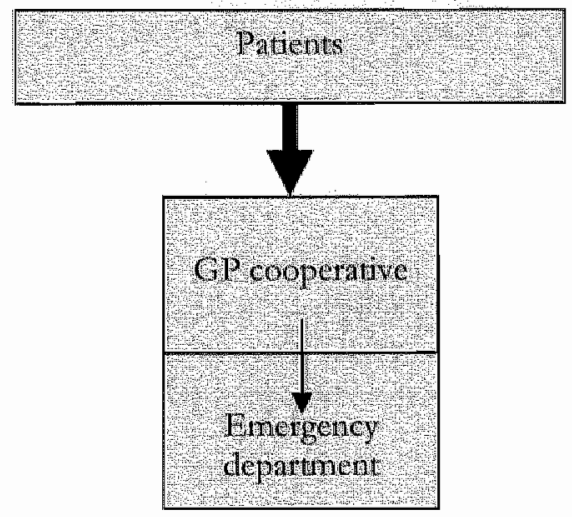

Integrated out-of-hours care

Figure 1. Organisation of out-of-hours care (patients with refertal or brought in by ambulance bypass this system and go directly the roD).

\section{The integrated GP cooperative}

The integrated GP cooperative was set up in January 2000. During the first yeat, this GP cooperative covered only the population of the city of Maastricht (approximately 120,000 inhabitants). In August 2001 the surrounding area of Maastricht joined the GP cooperative, increasing the coverage area to 190,000 inhabitants. Only one ED is open for this region which is located at the same site as the GP cooperative. All patients attending the integrated out-of-hours care facility without referral are first seen by a GP, who refers, if necessary, the patient to the ED. At the moment 83 GPs participate in the integrated GP cooperative. The GP cooperative is open from 5 pm to 8 am on weekdays, and from $5 \mathrm{pm}$ on 
Friday to 8 am on Monday. In the evenings the GP cooperative is staffed with three GPs on weekdays and four on weekends. During the night only two GPs are present. In the daytime on Saturday and Sunday, the GP cooperative is staffed with four GPS.

In the integrated out-of-hours care model patients are also stimulated to make a phone call first before attending the cooperative. However, patients are also allowed to attend without an appointment, although this is not preferred and discouraged. At the integrated cooperative telephone triage is performed by doctor's assistants and medical students. In the evenings on weekdays four doctor's assistants or medical students are present. At night on weekdays and weekends there is just one person who performs telephone triage. The number of doctor's assistants and medical students that is present during the daytime and evening on Saturday and Sunday varies between five and six.

Both GP cooperatives have installed management with a director or coordinator. The management of the integrated GP cooperative operates independently of the hospital. Patients contacting these two GP cooperatives can receive three types of consultations; telephone self-care advice, consultation at the GP cooperative, or a home visit. If necessary, patients are referred to the ED. GPs who perform home visits have a car with chauffeur at their disposal.

\section{Costs of both GP cooperatives}

Information on costs was gathered from the annual accounts of the year 2003 of the two GP cooperatives involved in this study. Costs have been divided in five categories: personnel, GPs' salary, accommodation, coordination and organisation, and other costs (including transportation, interest, cleaning, computers, communication, and overhead). Total costs per capita were calculated by dividing the total sum of costs by the number of inhabitants in the GP cooperative's coverage area. This was also repeated for the five costs categories.

\section{Primary care utilisation duting out-of-hours}

Information on use of primary care during out-of-hours at both GP cooperatives was collected from the annual reports. Per type of consultation, i.e. telephone advice, consultation at the GP cooperative, or home visit, number of patient contacts were registered. 


\section{Cost calculation of emergency department}

To study the effect of an integrated GP cooperative on costs of an ED, we assessed the costs of the ED of the University Hospital Maastricht. For this matter, the annual accounts of 1999 and 2000 were used (a year before and a year after the reorganisation of out-of-hours primary care). We did not assess the costs of the ED in the Heerlen region. During the years this study was conducted, two of the three former EDs in this region were closed. This will have caused considerable bias, which would make it impossible to assess changes in costs telated to the set up of the separated cooperative without the interference of the closing of EDs.

Table 1. Anmual costs of an integrated GP cooperative and a separited GP cooperative in 2003 .

\begin{tabular}{|c|c|c|c|c|}
\hline & \multicolumn{2}{|c|}{$\begin{array}{l}\text { Integrated noodel } \\
2003\end{array}$} & \multicolumn{2}{|c|}{$\begin{array}{l}\text { Sepratated nodel } \\
2003\end{array}$} \\
\hline & Total & $\begin{array}{l}\text { Per capita } \\
(n=100,000)\end{array}$ & Total & $\begin{array}{l}\text { Percapira } \\
(m=285,000)\end{array}$ \\
\hline $\begin{array}{l}\text { Personiel/ } \\
\text { management }\end{array}$ & 6761,484 & 6401 & $61,125,56$ & 6360 \\
\hline & 6840,740 & C4.42 & C $1,287,311$ & 6452 \\
\hline dationg & 6105,893 & 60.56 & 6129,011 & 60,45 \\
\hline $\begin{array}{l}\text { Coordination atud } \\
\text { organisation }\end{array}$ & 671,970 & 60.38 & 6122,754 & 60.43 \\
\hline & 6399480 & (2.11) & 6440,250 & 01.54 \\
\hline Total & $62,179,567$ & 011.47 & $63,004,987$ & 610.5 \\
\hline
\end{tabular}

\section{RESULTS}

The total costs of out-of-hours primary care in the separated GP cooperative have been found to be $€ 3.0$ million. In the integrated cooperative this was $€ 2.2$ million. In the separated model the costs of outof-hours primary care ate $€ 10.54$ per capita per year and in the integrated model $€ 11.47$ per capita per year. This difference is mainly the result of a difference in costs of personnel and 'other' costs per capita (Table 1). In the integrated cooperative the costs for personnel are $€ 4.01$ per capita, while in the separated cooperative these costs are $€ 3.60$ per capita. The category 'other' (including transportation, interest, cleaning, computers, communication, and overhead) in the integrated cooperative costs $€ 2.10$ per capita, and $€ 1.54$ in the separated cooperative. The costs of the GP salary are practically the same for both cooperatives; $€ 4.42$ per capita in the 
integrated model, and $€ 4.52$ per capita in the separated model. In total, about $75 \%$ of the costs of both GP cooperatives are based on personnel (including GPs' salary).

T able 2. Uhilsation of out of hours prinatey care in 2003

\begin{tabular}{|c|c|c|c|c|}
\hline & Whogred & cooperatue & \multicolumn{2}{|c|}{$\begin{array}{l}\text { Seproted } \mathrm{PP} \text { cooperative } \\
2003\end{array}$} \\
\hline & (5) $(10)$ & $\mathrm{n} / 1000 / \mathrm{gear}$ & $n(\gamma /))$ & n/1000/ year. \\
\hline Tolephone & $13187(24,004)$ & 69 & $27399(36.09 \%)$ & \\
\hline $\begin{array}{l}\text { consultation } \\
\text { Consultation at }\end{array}$ & $36438(66.3 \%)$ & 102 & $39207(51.5 \%$ & 138 \\
\hline $\begin{array}{l}\text { GP cropletatye } \\
\text { Hone visit }\end{array}$ & $5350(9.7 \%)$ & 28 & $9460(124 \% 6)$ & 33 \\
\hline $7 \mathrm{ngl}$ & $54975(1000 \%)$ & 289 & $76072(100 \%)$ & 267 \\
\hline
\end{tabular}

K Number of patrent contacts per thousand whabiants per year.

T able 3, Costs of he hospital emergency department before and after the establishment of the nicegrated CP cooperatue.

\begin{tabular}{|c|c|c|c|}
\hline 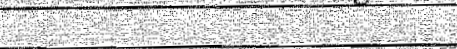 & 1990 (befine) & $2000($ ated & Difference \\
\hline Personinela & $6,250,611$ & 11250,611 & 601 \\
\hline Adinunisitation & $\mathrm{C} 25,996$ & 1022,770 & $-6,3,226$ \\
\hline Oprumunisation & 67,453 & 68,405 & +6952 \\
\hline Interios. & 63,078 & e 2,408 & 4670 \\
\hline Meclication, bandages, casts, etc & e200,675 & 0185,624 & $-415,051$ \\
\hline Diagnostics & 1725,135 & $\mathrm{C} 726,400$ & $+C 1,265$ \\
\hline Orerheral's & $61,380,774$ & $61,380,774$ & 80 \\
\hline Othet & 14,107 & 414254 & +6147 \\
\hline Torl & $(3,607,836$ & $63,591,247$ & $-616,582$ \\
\hline
\end{tabular}

Suffing of the ED remained unchanged, therefore, costs have been kept the same.

6 Overherd costs hine been kept the same for both year:

In total, about fifty-five thousand patient contacts wete registered in 2003 with the integrated GP cooperative. The separated GP cooperative registered apptoximately seventy-six thousand patient contacts during outof-hours (Table 2). This implies that the integrated GP cooperative (289 contacts / 1000 inhabitants / year) has about $8 \%$ more patient contacts compared with the separated GP cooperative (267 contacts / 1000 inhabitants / year). Over $66 \%$ of all contacts with the integrated GP cooperative consist of patients attending the GP cooperative for a consultation. In the separated GP cooperative about half of all contacts consist of consultations at the GP cooperative. Relatively more patients receive telephone advice in the separated model $(36 \%)$ than in the 
integrated model (24\%). Approximately $10 \%$ of all patient contacts at the integrated cooperative were home visits, which was not very different from that of the separated cooperative, where about $12 \%$ of all contacts were home visits.

The total costs of the ED in the integrated system, before the GP cooperative was established, were $€ 3.6$ million (Table 3 ). In the year after the integrated GP cooperative was set up, the costs were slightly reduced (minus $€ 16,582$ ) but remained atound the $€ 3.6$ million. The reduction was mainly caused by a reduction in costs related to the use of medication, bandages, plaster casts, and splints. These costs decreased from $€ 200,675$ to $€ 185,624$.

\section{DISCUSSION}

The results of this study show that the primary care cooperative integrated with the ED is slightly more expensive, but has relatively more patient contacts, compared with the GP cooperative separate from the hospital EDs. There was no substantial change in costs of the ED at the integrated system after the GP cooperative had been set up, mainly because the organisation of the ED had not been changed despite the reduction of patient contacts.

The main category of costs of the GP cooperatives is that of personnel (doctor's assistants, management, and GPs), which is responsible for over three quarters of all costs. These costs could be in some way dependent on the model of out-of-hours primary care; differences in organisation may have specific effects on utilisation of out-of-hours primary care. As a consequence, staffing of the cooperative may have to be adjusted tesulting from different demands. However, the costs for GPs are the same for both cooperatives; even slightly higher in the separated system. In contrast, costs of personnel (management, administration, and doctor's assistance) have been found to be higher in the integrated GP cooperative. However, this is probably the result of the scale advantage of the separated cooperative; the region covered by the separated cooperative is much larger than that of the integrated cooperative. Because costs like management, administration, but also accommodation have a less strong relationship with the size of the area, as compared to staffing of doctor's assistants and GPs, they will be relatively lower in a cooperative covering a larger area. Therefore, it scems that costs of out-of-hours care are more dominated by the size of the population the GP cooperative covers than the organisational structure of out-of-hours care, i.e. integrated versus separated. In this study we found 
that approximately $8 \%$ more patients attended the integrated GP cooperative compared with the separated GP cooperative. In that case, it is reasonable to suggest that the higher expenses (9\% higher) of the integrated cooperative are justified by the fact that at this GP cooperative generally mote patients are seen.

With respect to the ED of the integrated model no changes occurred in costs after the GP cooperative had been set up. Unfortunately we have not been able to use costs of the EDs in the separated setting to compare with the potential change we analysed in the integrated ED setting. Nevertheless, the before - after analysis we used provided a good indication of whether costs of this ED have changed over time. Because staffing of the ED remained unchanged, despite the substantial decrease of number of patients that utilised hospital emergency care, the costs of this department did not change. Staffing of the ED before and after the establishment of the GP cooperative did not change due to hospital regulations that prescribe a sufficient staffing in case of major traumata. Although costs of the ED remained the same, the regional Health Insurance Fund has cut the hospital's annual budget with approximately $€ 1.36$ million. This budget reduction was mainly based on the fact that fewer patients attended the ED after the GP cooperative had been set up. For every patient attending the $\mathrm{ED}$, the costs of a so-called first administrative consult (FAC) are reimbursed by the Health Insurance Company. Because fewer patients attended the ED, fewer FACs could be reimbursed, and consequently the hospital's budget was reduced.

Considering the utilisation of primary care in both settings, it is reasonable to suggest that the integrated primary care GP cooperative is equally cost efficient as the separated GP cooperative. After all, the higher costs $(9 \%$ more) of the integrated GP cooperative are compensated by the larger number of patients ( $8 \%$ more) utilising out-of-hours primary care at the integrated GP cooperative. However, the ED at the integrated system has become less cost efficient because they see fewer patients at the same costs. For that matter, it would seem wise to consider keeping staff, like nurses, doctor's assistants, and management, no longer separated in an integrated model.

Obviously, preference with elther one of these two organisational models for out-of-hours care should not only be based on costs. Patient sarisfaction and preferences with either one of these two systems should also be accounted for, but also the opinions of GPs should be considered. GPs also have to be satisfied with the organisation of out-of-hours care. First, because quality of care may be reduced in case of dissatisfied staff ${ }^{8}$. But second, because GPs have a strong saying in how out-of-hours care should be organised. Now that we have some indication that costs of out- 
of-hours primary care are only moderately dependent on the organisational structure, one could say that patients and GPs opinions, and other quality of care aspects should prevail in the decision of out-of-hours care organisation of preference. Nevertheless, from a financial point of view, based on the savings that occurred because the hospital's budget was reduced with 1.36 million because of decreased utilisation of $\mathrm{ED}$ care, the integrated out-ofhours care system should be preferred.

In conclusion, the costs of out-of-hours primary care appear to be more dependent on the size of the population the cooperatives cover than on the way the GP cooperative is organised, i.e. separated versus integrated. In addition, locating the GP cooperative at the same site as the ED was found to have little effect on costs of the ED. Nevertheless, savings have occurred at the side of the Health Insurance Funds, which may prove to be beneficial to the community.

\section{REFERENCES}

1. Hallam L, Cragg D. Organisation of primary care serwices outside normal working hours. BMJ. 1994;309:1621-3.

2. Christensen MB, Olesen F. Out of hours service in Denmark: evaluation five years after reform. BMy. 1998;316:1502-5.

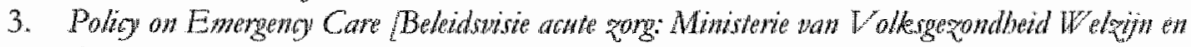
Sport?. The Hague: Ministry of Health Care, The Netherlands; 2003.

4. Van Uden CIT, Winkens RAG, Wesseling GJ, Crebolder HFJM, Van Schayck CP. Use of out of hours services: a comparison between two organisations, Emerg $M e d]$. $2003 ; 20: 184-7$

5. Van Uden GJT, Winkens RAG, Wesseling GJ, Fiiolet JFBM, Van Schayck CP, Crebolder HFJM. The impact of a family physician cooperative on the caseload of an cmergency department. The Maratricht integrated out-of-hours setrice / Gen Intent Med 2005:accepted.

6. Van Uden CJT, Ament AJHA, Hobma SO, Zwhetering PJ, Ctebolder HIJM. Piltient satisfaction with out-of-hours primary care in the Netherlands. $B M C$ Heall Serw Res. $2005,5: 6$.

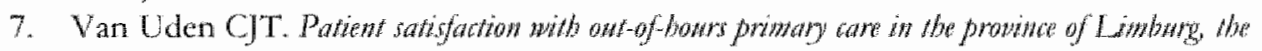

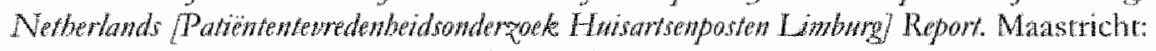
Universiry Hospital Maastricht; February 32004.

8. Williams ES, Skinner $\mathrm{AC}$. Outcomes of physician job satisfaction: a narrative revicw, implications, and directions for future research. Health Care Manage Ren 2003;28:119. 39. 


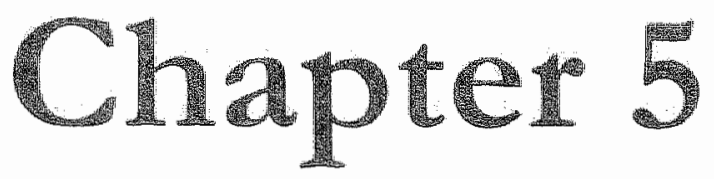

\section{General practitioners' satisfaction with and attitudes to out-of-hours services.}
C.J.T. van Uden ${ }^{1,2}$
Submitted for publication
F.H.M. Nieman ${ }^{3}$
G.B.W.E. Voss ${ }^{3}$
G. Wesseling ${ }^{1,4}$
R.A.G. Winkens ${ }^{1.2}$
H.F.J.M. Crebolder ${ }^{2}$

Deparment of Integrated Care, Unwersiry Hospital Maastricht

- Department of Genceal Practice, Masatrich University

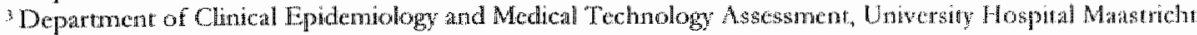

* Deparment of Respiratory Diseases, Universiry Hospilat Maastrictir 


\section{ABSTRACT}

Background: In recent years, Dutch general practitioner (GP) out-ofhours service has been reorganised into large-scale GP cooperatives. Until now little is known about GPs' experiences with working at these cooperatives for out-of-hours care. The purpose of this study is to gain insight into GPs" satisfaction with working at GP cooperatives for out-ofhours care in separated and integrated cooperatives.

Setting: A GP cooperative separate from the hospital Accident and Emergency (A\&E) department, and a GP cooperative integrated within the A\&E department of another hospital. Both cooperatives are situated in adjacent geographic regions in the South of the Netherlands.

Methods: One hundred GPs were interviewed by telephone; fifty GPs working at the separated GP cooperative and fifty GPS from the integrated GP cooperative. Opinions on different aspects of GP cooperatives for outof-hours care were measured, and regression analysis was performed to investigate if these could be related to GP satisfaction with out-of-hours care organisation.

Results: GPs from the separated model were more satisfied with the organisation of out-of-hours care than GPs from the integrated model (70 vs. 60 on a scale score from 0 to $100 ; P=0.020$ ). Satisfaction about out-ofhours care organisation was related to opinions on workload, guarantee of gatekeeper function, and attitude towards out-of-hours care as being an essential part of general practice. Cooperation with medical specialists was much more appreciated at the integrated model $(77$ vs. $48 ; P<0.001$ ) versus the separated model.

Conclusions: GPS in this study appear to be generally satisfied with the organisation of GP cooperatives for out-of-hours care. Furthermore, GPS working at the separated cooperative seem to be more satisfied compared to GPs working at the integrated cooperative. 


\section{INTRODUCTION}

During the last decade, out-of-hours care by genetal practitionets (GP) in the Netherlands has changed substantially. Formerly, GPs performed out-of-hours care in small locum groups in which they joined a rota system. In recent years, large GP cooperatives have been set up following British and Danish examples ${ }^{1,2}$. Currently, about 124 GP cooperatives are operational in the Netherlands, taking care of more than $90 \%$ of the Dutch population during out-of-hours.

In the current Dutch out-of-hours primary care, roughly two types of organisation models can be distinguished; a separated model and an integrated model. In the separated model the GP cooperative is located separate from the hospital's accident and emergency (A\&E) department, indicating that there is no functional integration of out-of-hours services. In this model patients with a medical problem can choose between attending the GP cooperative or the A\&E department, during out-of-hours. In the second organisation model the GP cooperative is integrated with the hospital A\&E department. In this model, all patients utilising out-of-hours primary and emergency care without referral are first seen by a GP or practice nurse. It is known that a substantial number of self-referred patients at the A\&E department exhibit minor injuries or non-urgent ailments that can be treated by a GP ${ }^{3,4}$. As a consequence, GPs of the integrated model will generally have to handle more patients than GPS at the separated model ${ }^{5}$. Patients with a refertal or brought in by ambulance always bypass this system and will be directed to the emergency department without interference of the GP on call.

The initiative of the out-of-hours primary care reorganisation has come mainly from the medical profession itself, motivated by increased dissatisfaction with the former out-of-hours services. However, as indicated by a recently published systematic review, thete is little evidence available on current GPs' satisfaction with out-of-hours services ". The authors of this review identified only one study with respect to GPs' satisfaction with out-of-hours care. That study showed high levels of satisfaction with cooperative based primary care services ". However, only a part of the GPs interviewed actually participated within this service. Other studies have reported of beneficial effects to GPs with the introduction of GP cooperatives for out-of-hours care, like improved GPs' health " or decreased levels of stress ?. We have also identified one Dutch study that showed increased satisfaction after reorganising out-of-hours care from practice based to cooperative based ${ }^{10}$. No further information is available on GPS' satisfaction with cooperative based out-of-hours care. 
There were two important reasons to conduct this study. First, because GP satisfaction has been shown to be an important contributor to quality of care ${ }^{11}$. GP satisfaction, besides patient satisfaction and costs, should be taken into account when evaluating out-of-hours care services. Second, during the time of the study, the integrated GP cooperative was still in its trial period and insight had to be gained in experiences and opinions of GPS working at this cooperative to support the decision whether this way of organising out-of-hours care should be continued.

The purpose of this study is to gain insight in the satisfaction of GPS with out-of-hours primary care organised in cooperatives. In addition, this study investigates potential differences in the relationship of satisfaction and other out-of-hours care related opinions between GPs working in an integrated model and GPs working in a separated model.

\section{METHODS}

This study investigates two specific elements: GPs' satisfaction with the organisation of two types out-of-hours care and the GPs" opinions related to working at either of two GP cooperatives. Two differently organised outof-hours cooperatives are involved; a separated model and an integrated out-of-hours care model in two adjacent geographic regions in the Netherlands.

\section{Setting}

The separated cooperative is located in the centre of the city of Heerlen, the Netherlands, about $5 \mathrm{~km}$ and $9 \mathrm{~km}$ away from the only two $A \& \mathbb{E}$ departments in this region. This cooperative was first set up in 1999, and covered at that time a population of approximately 100,000. In 2001, more GPs joined the cooperative and the population was increased to 278,000 . The number of participating GPS increased to 120 . In this system patients are stimulated to make a phone call before attending the GP cooperative. This allows the GP cooperative to triage patients at urgency levels of their medical complaints in order to prioritise treatment. During out-of-hours, patients with a medical problem can choose which out-of-hours service to attend, i.e. the GP cooperative or the hospital A\&E department.

The integrated GP cooperative is located in the city of Maastricht, the Netherlands, at the region's only A\&E department of the University Hospital Maastricht. This cooperative was set up in January 2000. During the first one and half year, this cooperative covered only the population of the city of Maastricht (approximately 120,000). In August 2001, the 
surrounding area of Maastricht also joined the cooperative, increasing the coverage area to 190,000 inhabitants. In total, 83 GPs participate in the integrated GP cooperative. At this GP cooperative patients are allowed to attend the cooperative without an appointment, although it is preferred that they make a phone call first. All patients attending the integrated out - ofhours care facility without referral are first seen by a GP, who refers, if necessary, the patient to the A\&E department.

At both GP cooperatives, telephone triage is performed by doctor's assistants who are supported by guidelines and protocols, and are supervised by a GP. GPs of these cooperatives perform telephone consultations, consultations at the cooperative, and home visits. Regarding home visits a chauffeured care is at their disposal. Both regions comprise rural as well as urban areas.

\section{Development of the questionnaite}

Topics relevant to out-of-hours primary care were identified in interviews with three GPs participating in the two GP cooperatives under study. We have developed a set of items to enable us to measure and test multi-item scales. The items are related to relevant themes with respect to working at a GP cooperative. In total the questionnaire consisted of 86 items. (Some items are excluded from the analysis because they are only of local interest.) We investigated opinions on: overall satisfaction with the GP cooperative for out-of-hours, reorganisation of out-of-hours care, perceived workload, out-of-hours care as being an essential part of primary care, anonymity of care, gatekeeper function, availability of patient dossiers, cooperation with medical specialists during out-of-hours, and safety. We used a Likert five point scale (strongly agree, agree, neutral, disagree, strongly disagree) to tecord responses.

\section{Sample}

In both GP cooperatives (separated and integrated) a ranclom sample of 50 GPs was taken. In case one of these GPs was not able or refused to participate, we had a substitution list of 25 GPs for each cooperative. This list was a random sample of the remaining GPs who were not selected by the first sampling.

The questionnaire was administered by telephone to ensure high response rates. Two research assistants administered the questionnaire and received instructions, prior to the study, by $\mathrm{FN}$. The study was conducted from November 2001 to February 2002. 


\section{Statistics}

Beforehand, the 86 items of the questionnaire were divided into four blocks. These blocks represented 'satisfaction with out-of-hours care organisation", "perceptions and subjective evaluations on working conditions in the present organisation', 'opinions and beliefs on professional philosophy', and 'evaluation of the cooperation with medical specialists at the local hospital'. The most important block concerns the one in which satisfaction with out-of-hours care organisation was measured: this was operationalised with 12 items. Principal component analysis with oblimin rotation was performed on the items of this block and after removal of items with weak factor loadings (lower than |0.60|) and/or ambiguously loading items (on more than one factor) two factors remained in analysis. Four irems measured satisfaction with the current cooperative and three items measured satisfaction with the state of affairs before the cooperative was set up (out-of-hours care in a rota system). Next, per intended scale the test stability of each factor was measured by Cronbach's alpha, and again items could be removed from this scale, if this did increase the value of the alpha coefficient. Next, scale constructions were performed under specific rules for missing item data: in summating to a total for each case scores had to be valid on at least half of the items, if the number of items was even, and on at least half of the items plus one half, if the number of items was uneven. Otherwise, scale scores were set to 'missing'. Finally, a transformation of the total scale score to a 0-100 score was made ${ }^{12}$. After that, the remaining three blocks were analysed in a similar way. In total this procedure produced ten scales.

The relationship between individual scales and overall satisfaction was analysed using multiple regression analysis. In case of missing data, listwise deletion of missing cases was applied. To test differences between GPs from either two GP cooperatives we performed independent Student's trests per scalc. A P-level of less than 0.05 , was considered to be statistically significant. All data were analysed using SPSS-pc, version 10.0.5.

\section{RESULTS}

In total 100 GPs participated; 50 GPs per each cooperative. One respondent of the Maastricht GP cooperative (integrated model) refused to participate and was substituted by a GP from the reserve list. The mean dutation of the interviews was $22( \pm 6.6)$ minutes. The characteristics of the respondents of both models do not differ statistically (Table 1). 
Table 1. Characteristics of tespondents.

\begin{tabular}{|c|c|c|c|}
\hline & & $\begin{array}{l}\text { Gl cooperative } \\
\text { Heerlen }(\mathrm{n}=50)\end{array}$ & $\begin{array}{l}\text { GI cooperanivs } \\
\text { Marastroht }(\mathrm{n}=50)\end{array}$ \\
\hline Mge & & $448,0 \pm 75$ & $4473 \pm 6.6$ \\
\hline Gender & Male & 12 & +43 \\
\hline & Female & 8 & 1 \\
\hline Emploved & Patt-time & 11 & 16 \\
\hline & Pullame & $(\div, 39$ & 234 \\
\hline Size ot practice (GPs) & Mean (tange) & $2.50-9$ & $2011-7)$ \\
\hline Participanon in GP & Tully & $4+37$ & $(37$ \\
\hline coopetative & Parly & 43 & 13 \\
\hline
\end{tabular}

Table 2. Scales scores for GPs opinions on diferent aspects of out-of-hours primary care.

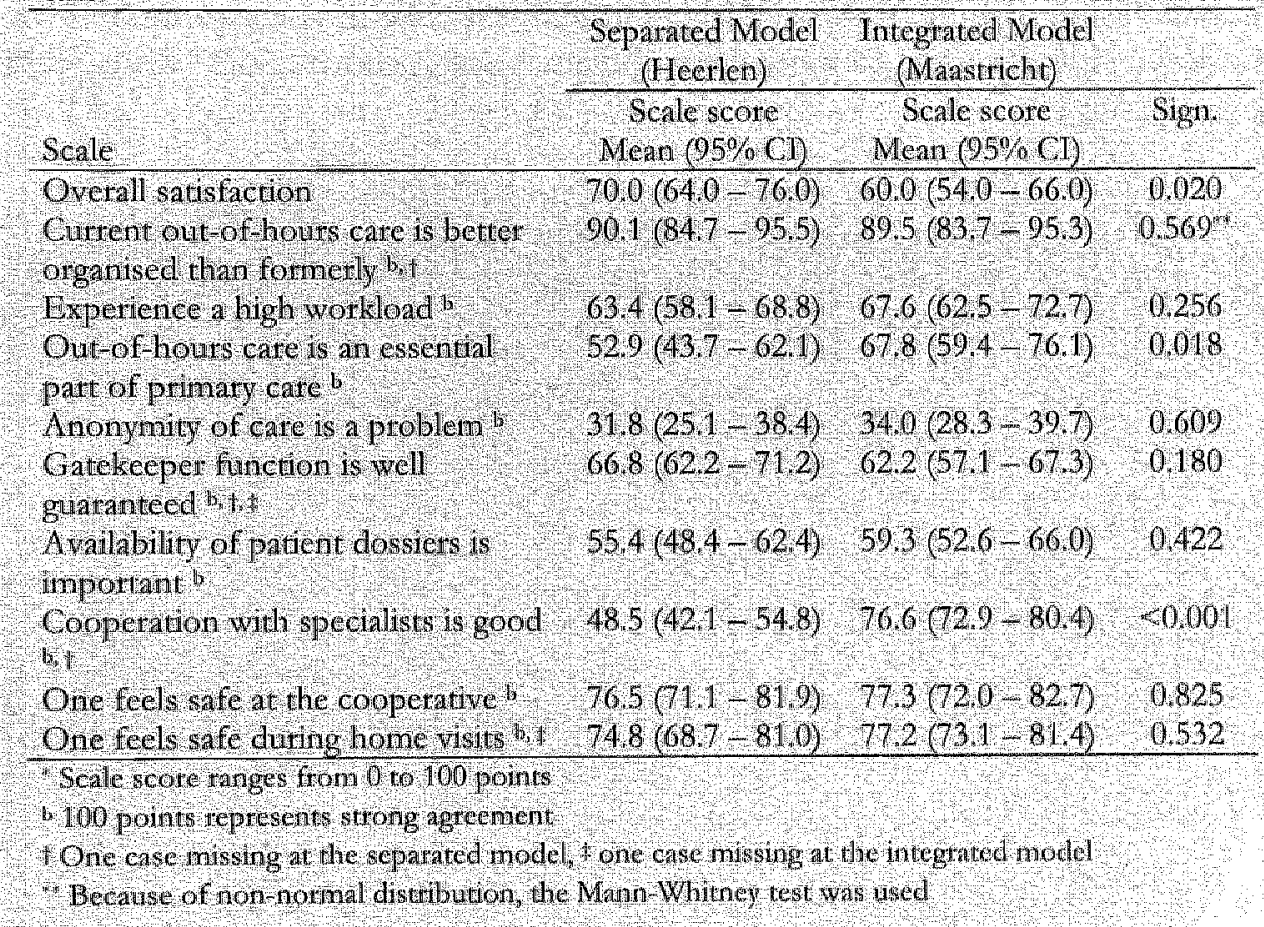

We tested ten scales related to aspects of current out-of-hours primary care (Table 2.). Internal reliability of these scales was considered appropriate; Cronbach's alpha's ranging from 0.74 to 0.97 . An overvicw of all scales and related items is presented in Appendix 1 (see page 68). 
GPs' overall satisfaction score with the current organisation of out-ofhours care was 65 points (95\%CI: $60.7-69.3$ ) on a scale from 0 (absolutely not satisfied) to 100 (highly satisfied). However, GPs from the separated model were more satisfied compared to their colleagues of the integrated model (scale score 70.0 vs. $60.0 ; P=0.020$ ). GPs from both cooperatives reported that the new organisation of out-of-hours primary care is better compared to the former practice-based out-of-hours care (mean scale score 89.8). Most GPs experience a high workload (mean scale score 65.5). A minority of all interviewed GPs think that the anonymity of patient care many patients are not known to the GP because care is organised on largescale - endangers adequacy of out-of-hours primary care (mean scale score 32.9). Furthermore, a small majority feels that the patient's medical file should be available at the cooperative (mean scale score 57.4). In both cooperative models (integrated and separated) of out-of-hours care, GPs think that their gatekeeper's role to secondary care is sufficiently guaranteed (mean scale score 64.0). Most GPs feel relatively safe at the cooperative or during out-of-hours home visits (mean scale score 76.9 and 76.0 respectively).

Table 3. Regression analysis with overall satisfaction with the otganisation of out of: hours cate as dependent varable $(0=$ not satisfied, $100=$ very satisficd $)\left(n=98, R^{2}=\right.$ $0,36)$

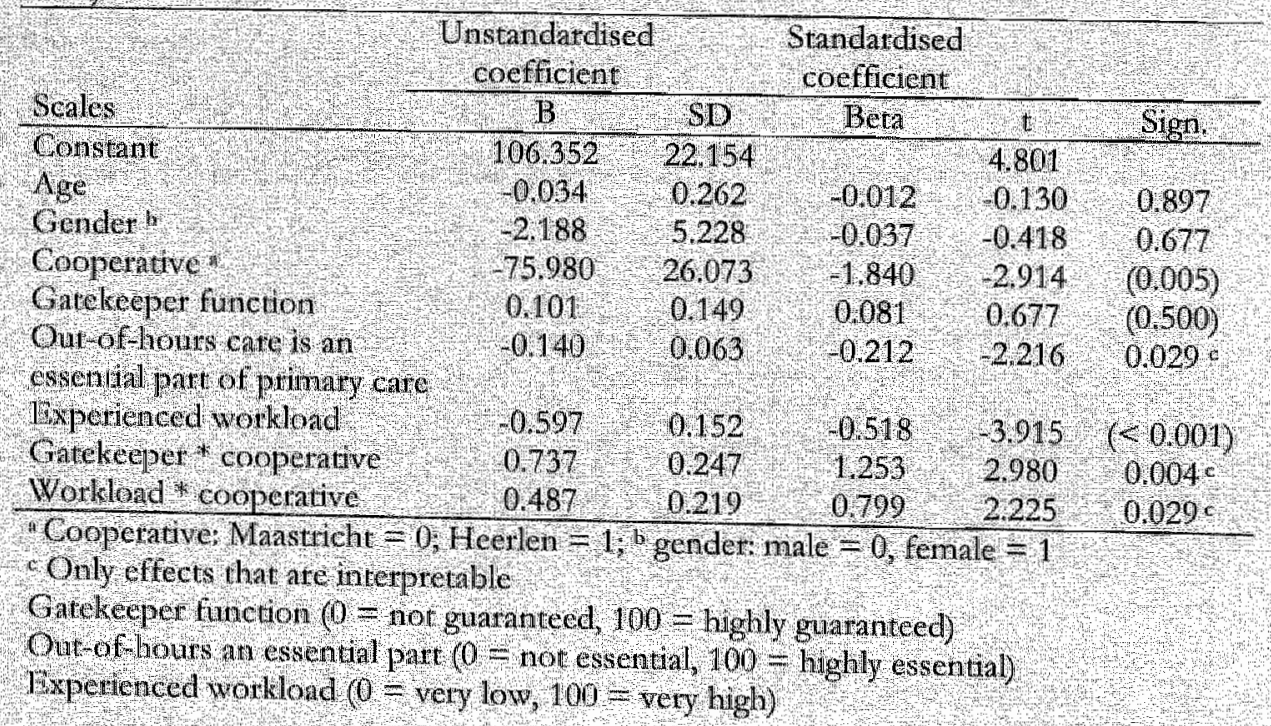


GPs from the separated model were neutral about out-of-hours care as being an essential part of their job as a GP, in contrast with the integrated model GPs who were more convinced that out-of-hours care is an important part of their job (scale score 52.9 vs. $67.8 ; P=0.018$ ). GPs at the integrated model experience a better cooperation with medical specialists during out-of-hours care (scale score 76.6 vs. $48.5 ; P<0.001$ ).

The regression analysis identified three scales that are significantly related to overall satisfaction (Table 3.). Effects on satisfaction for two of these scales, experienced workload and whether the GP thinks that his gatekeeper function is well guaranteed during out-of-hours, are different for both cooperatives. Experienced workload is mainly related to overall satisfaction of GPs from the integrated model. Whereas, the GP's opinion about the gatekeeper function is mainly related to overall satisfaction of GPs from the separated model. Increased experienced workload will lead to a decreased overall satisfaction, and the better the GPs valued the guarantee of their gatekeeper function during out-of-hours the higher their overall satisfaction will be.

Table 4. Regression analysis results on overall satisfaction with the organisation of out of hours care as dependent valiable for both GP cooperatives separately $(0=$ not satisfied, $100=$ very satisfled).

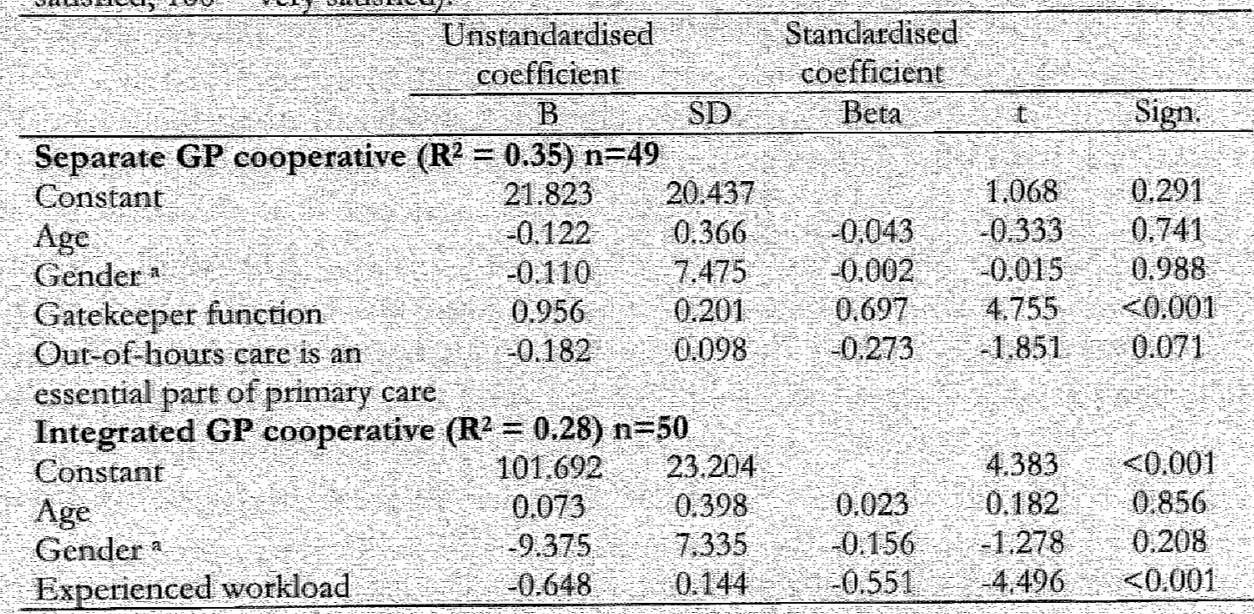

Gender, male -0, temale $=1$

Gatekeeper function $(0=$ not guaranceed, $100=$ highly guatanced)

Out-of hours an es sential pant $(0=$ not essential, 100 - lighly essematial)

Experienced workload $(0$ - very $10 w, 100=$ ver high) 
The thitd scale that is significantly related to overall satisfaction is the GP's opinion about out-of-hours care as being an essential part of his task as a GP. GPS who indicated that they believed that out-of-hours care was an essential part of their job as a primary care physician had a lower overall satisfaction with respect to current out-of-hours care. Neither gender nor age was significantly related to overall satisfaction. The regression model explained $36 \%$ of the variation in overall satisfaction.

Subgroup regression analysis for GPs of the integrated and separated model separately (see Table 4), showed that for the GPs of the integrated model workload was the main factor that influenced overall satisfaction (variance explained: $34 \%$ ). With respect to the GPs of the separated model, the guarantee of the gatekeeper function was of great importance to the overall satisfaction (variance explained: $35 \%$ ).

\section{DISCUSSION}

$G P S$ in this study are generally satisfied with the way out-of-hours primary care is currently organised. However, GPs from the separated cooperative are more satisfied that GPs working at the integrated cooperative. Mainly three factors are related to overall satisfaction. These are: experienced workload, guarantee of the gatekeeper function, and attitude towards out-of-hours care as being an essential part in general practice.

To out best knowledge, this is the first study to investigate GPs' satisfaction with out-of-hours care as organised in separated and integrated primary care cooperatives. One British study and one Dutch study have looked into GPs satisfaction with out-of-hours care ${ }^{7}{ }^{10}$. However, these studies solely focused on separated out-of-hours care models. The Dutch study showed that $70 \%$ of the GPs were satisfied with cooperative based our-of-hours care ${ }^{10}$, and the British study found that $92 \%$ of the GPs were satisfied with the way out-of-hours care was arranged ${ }^{7}$. Since these studies used different ways to measure satisfaction it is difficult to compare them with our results.

The results of this study indicate a difference in satisfaction between $G P_{s}$ from the separated and integrated cooperative. A possible explanation for this difference could be the fact that the integrated cooperative has to deal with a larger number of patients compared to the separated cooperative 5. In this study however, experienced workload of GPs from the integrated cooperative did not differ from that of the GPs of the separated one. Obviously workload is also dependent on staffing of the cooperative. We presume that the difference in satisfaction might well be explained by other 
factors, which we have not investigated in this study. At the time of the study the integrated model was still in its experimental phase; housing in the integrated cooperative was generally not considered to be optimal. In this phase of the experiment the waiting room was very small and quickly overcrowded. Also, the space in the doctor's offices was quite limited and contained only room for one bed and no desk. In addition, at this time also patients' and GPs' privacy were not as sufficiently guaranteed as in the separated model. These factors may have had an effect on GP's overall satisfaction with out-of-hours services.

Three opinions were found to be significantly related to GP satisfaction with the organisation of out-of-hours care. The two opinions that weighted most heavily on satisfaction were experienced workload and gatekeeper function.

We found that the GPs' opinion on the gatekeeper function during outof-hours was related to satisfaction with the organisation of out-of-hours care specifically for GPs of the separated GP cooperative. The fact that this opinion is not related to satisfaction with the organisation in the integrated cooperative is probably due to the fact that this is not an issue at this cooperative, because the GP's gatekeeper function is fully guaranteed; all patients entering the out-of-hours centre are screened by a $G P$ and if necessary referred to a medical specialist. In the separated model however, the patient can still bypass the GP and attend the emergency department of the hospital without a GP's referral. GPs who feel to have too little grip on these self-referring patients appear to be less satisfied with their arrangements of out-of-hours care.

We have not been able to investigate GPs' satisfaction prior to the reorganisation from practice based out-of-hours care to cooperative based out-of-hours care, whilst GPs' dissatisfaction with practice based out-ofhours care was one of the important reasons why primary care in the Netherlands was reorganised. Nevertheless, this study shows that GPs feel that current out-of-hours primary care is better organised compared to former practice-based out-of-hours care. These results are in line with previous research ${ }^{10}$. However, this is not surprising considering the effort that has gone into reorganising the out-of-hours services and the prior dissatisfaction. All those who were in favour of the change of the out-ofhours system will obviously be satisfied with the fact that out-of-hours care has been reorganised, and feel that the new system is better than formerly.

A distinct feature of the integrated model is the close cooperation between primary and hospital emergency care. This offers possibilities to improve communication and to exchange expertise. "This is reflected by the high satisfaction score of GPS from the integrated model with the cooperation with the medical specialists of the hospital. Because GPs and 
medical specialists now work at the same site, it is easier to consult each other. Furthermore, GPs who have referred a patient to one of the medical specialists have access to feedback, i.e. they can check on the patient a few minutes later to see if they were right in their diagnosis. Nevertheless, region-specific differences may also have accounted for this difference, because in the region with the integrated cooperative there is a longer tradition in cooperation between primary and secondary care.

We investigated GPs' opinions on working at two contrasting models of out-of-hours primary care, i.e. a separated and an integrated GP cooperative, in order to gain insight in GPs' preferences for either one of these models. Until November 2001, the Maastricht GP cooperative for out-of-hours care was the only cooperative in the Netherlands that was integrated with a hospital A\&E department. Consequently, the Mastricht out-of-hours care organisation was the only service at the time of the study that could be used as an example of integrated out-of-hours care.

There are limitations to generalise the results of the study to other regions. First, results of the study reflect the opinions of GPs at only two cooperatives in the South of the Netherlands. Second, the integrated GP cooperative was still in its trial phase and may therefore have not been a good representative of a well-established GP cooperative. Nevertheless, this is the first study to address GP satisfaction with an integrated GP cooperative and may therefore, despite the limited generalisability, give some indication of relevant aspects of integrated out-of-hours care for further research and care development.

Currently, three regions in the Netherlands are working according to an integrated out-of-hours care system. However, at the moment GPs in other regions consider adopting this organisational structure. Furthermote, the current Dutch minister of health care has stated to be in favour of an intensive collaboration between primary and emergency care, for this will probably reduce costs ${ }^{13}$. The results of this study can support the current discussion in the Netherlands on the organisation of out-of-hours primary care.

Future research should focus on the economic efficiency of both models and patient preference with respect to the organisation of out-of-hours primary care, because these are important features to take into account when developing out-of-hours care.

In conclusion, GPs seem to be generally satisfied with out-of-hours primary care organised in GP cooperatives. 


\section{REFERENCES}

1. Hallam L, Cragg D. Organisation of primary care services outside normal working hours. BMT. 1994;309:1621-3.

2. Olesen F, Jolleys. JV. Out of hours service: the Danish solution tamined. BMJ. 1994;309:1624-6.

3. Lee A, Lau FL, Hazlett CB, et al. Factors associated with non-utgent utilization of Accident and Emergency services: a case-control study in Hong Kong. Sor $S a \mathrm{Mrd}$. 2000;51:1075-85.

4. Dall J, Green J, Reid F, Glucksman E. Primary care in the accident and emergency department: I. Prospective identification of patients. BMJ. 1995;311:423-6.

5. Van Uden CJT, Winkens $\mathbb{R A G}$, Wesseling GJ, Crebolder HFJM, Van Schayck CP. Use of out of hours services: a comparison between two organisations. Emheng Med J. $2003,20: 1847$.

6. Leibowitz R, Day S, Dunt D. A systematic teview of the effect of different models of after-hours primary medical care services on clinical outcome, medical workload, and patient and GP' satisfaction. Fan Praw. 2003;20:311-7.

7. Salisbury C. Evaluation of a general pracrice out of hours cooperative: a questionnaire survey of general practitioners. BMJ. 1997;314:1598-9.

8. Fletcher J, Pickard D, Rose J, et al. Do out-of-hours co-operatives improve general practitioners' health?' BrJ Gen Prat. 2000;50:815-6.

9. Heaney D, Gorman D, Porter M. Self-recorded stress levels for general practioners before and after forming an out-of-hours primary care centre. BrJ Gen Prot. 1998:48:1077-8.

10. Giesen PHJ, Haandrikman LGR, Broens S, Schreuder JLM, Mokkink HGA. GP cooperatives: Does it beneft the GP? [Centmale huisartsenposten: wordt de husarts er beter van?]. Herisarts Wet 2000;43:508-10.

11. Williams ES, Skinner $A C$. Outcomes of physician job satisfaction: a narrative review, implications, and directions for funure research. Health Care Manage Rev. 2003;28:11939.

12. McKinley RK, Cragg DK, Hastings AM, et al. Comparison of out of hours care provided by patients" own general practitioners and commercial deputising services: a randomised controlled trial. TI: The outcome of care. BMJ. 1997.314:190-3.

13. Policy on Emergency Care [Beleidsvisic acute zorg: Ministerie van Volksgezondlheid Welzijn en Sport]. The Hague: Ministry of Health Care, The Netherlands; 2003. 
Appendix 1. GP questionnuife Descripuon of scales and items. Original items are in Dutchts

Seale 1 Overall salisfaction with OP cooperadve (Cronbach's $\alpha=090$, mean (SD) $=$ $650(216)$

I am very satisfied alsont the functioning and the structure of the GP cooperarive (t)

1 am pleased with the current (j) cooperative (t)

I am wery satisfied with the current organisation of out-of hours primary care $(t)$

Scale 2. Current out of hours care is betiet organised than fommeny (Cronbach's $\alpha$ = 0.92 , mean $(S D)=89.8(195)$

Out-of hours care was better organised before the set up of GP copperatives (t)

I prefer the fornet organisation of out of hours primaty eare ()

The curtent organisation ff out of hours care is not an improvenent compared to the former organisation $(9)$

Scale 3. Ixperienced a high workload (Gronbachs $\alpha=0.67$, mean (SD) $=655(18.4)$ The workload at the (GP cooperalve is too high (t)

Out-of hours care duing daytine on Saluth y and Sunday is very aggravating ( + )

Usually, out of liours service is mich too aggtavating (t)

1 do not experience such a high woullord a dhe $(\mathrm{P}$ cooperatre ()

Perfouning our of hours care ts absolutely not apgravating ( )

Outof hours cane during daytime in the weekends is not too high ()

Scale 4 . Out o l hours care is an essentul part of primary care (Gronbachs $x=0.97$ nean $(\mathrm{SD})=60.3(31,7)$

The se days, olut-bf hours cate should no longer be an essential part of prinary care ()

Oulof hours carc is definitely an essential part of primary care (+)

Out-of hours care should a ways be a part of general practice $(t)$

There is no 1 lace anymore for out of hours care in generd practice (c)

Scale 5. Anonyniry of care is a problen (Crombach $\mathrm{B} \alpha=0,90$; nean $(\mathrm{DD})=32.9$ (21.8)

Because the GP of he coppernive and the patient are not familiat with each other there ti a 1 isk for inadeguatc reabment (t)

Because of anonynity of care theie is o nib that diagnos lies and crea tment are not adequately adjusted for the patients needs (t)

One of the big disadvartages of the GP couperavive is the anonymity of care, because The (GP is not tamiline with the protent $(t)$

Because the GP of the cogpentive and the patient are not famillar with each other there is it tisk for inadequicy of care (t)

\footnotetext{
* The promistomal translation inou Lnglish is neant to inform the reader of the content of the scrles and cannot be seen as a de finite one
} 
Appendix 1. (contuued). GP questionnaire. Description of scales and terns.

Scale 6. Garekeeper function is well guaranted (Cronbachs $\alpha=0.74$, mean $(S D)$ ) $645(16.8)$

I think the GP gatekeeper function at the GP copperative is well guaranteed $(t)$

I an afraid that the QP gatekeeper function during our-of hours will disappenr ( )

1 believe that in the neas future the GP gatekepet function will be pur under ron much pressure ()

I think the GP garekeeper function at he QP cooperative is well protected (t)

Scale 7. Availability of patient dossiers is important (Crombach's $\alpha=0.93$, nean $(S D)=$ $57.4(241)$

As fat as I ana concerned, I do not need the availability of tiny colleagues patient dossiers ()

1 think it is a serious problem that my colleagues' parient dossiers ane not at my disposal

(1)

The avalability of patient dossiers of the other particpating GPs during out of hours is absolutely annecessaty ( $)$

During out of hours I am hindered in my practice, because of lack of information about my colleagues patients $(t)$

Scale 8. Cooperation with medical specialists is good (Crohbach's $\alpha=0.94$, mean (SD) $=62.7(23.0)$

Sometimes, the cooperation between GPs and nedieal specialists is not so good $(-)$

I think that duting out of hours the understanding letween $\mathrm{P}$ s and medical specialists is sometimes prent bad ()

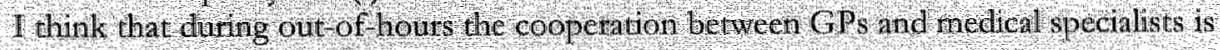
always tine (t)

Genevally, the cooperation berween myself and the nedical specialists of the hospital is good (t)

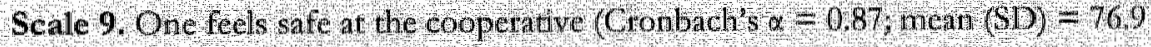

(18)

Sometimes, I feel ansafe at the GP cooperatue during out of hours ()

During ny shifts at the GP cooperalive, I never feel unsafe ( 1 )

Regularly, I feel unsafe at the GP cooperntive duing out-of houts ( )

Scale 10. One feels safe during home visits (Cronbach's $\alpha=0.84$, nean $(S 1)=760$ $(18.4)$

Regularly, I feel unsafe when performing home visits during out-of hours $(-$ Sametimes, I feel unsafe when perfouming home visits luring ouit of hours () Usually, I feel safe when performing home visios during our of hours ( $)$

* The provisional translation into English is meant w inform the reader of the content of the scales and cannot be seen as a definite one. 


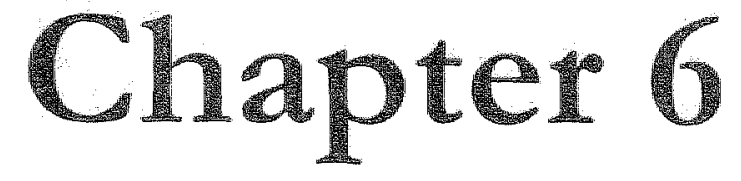

Does setting up out-of-hours primary care cooperatives outside a hospital reduce demand for emergency care?

\begin{tabular}{l|l} 
C.J.T. van Uden ${ }^{1.2}$ & Emergency Medicine Journal 2004; 21:722-723 \\
H.F.J.M. Crebolder & ${ }^{2}$
\end{tabular} 


\section{ABSTRACT}

Objective: To investigate whether the reorganisation of out-of-hours primary care, from practice rotas to GP cooperatives, changed utilisation of primaty and hospital emergency care.

Methods: During a four-week period before and a four-week period after the reorganization of out-of-hours primary care in a region in the South of the Netherlands all patient contacts with genetal practitioners and hospital accident and emergency (A\&E) departments were analysed.

Results: We observed a $10 \%$ increase in patient contacts with out-ofhours primary cate, and a $9 \%$ decrease in patient contacts with out-of-hours emergency care. The number of self-referrals at the A\&E department was reduced by approximately $4 \%$.

Conclusions: The reorganisation of out-of-hours primary care has led to a shift in patient contacts from hospital emergency care to primary care. 


\section{INTRODUCTION}

The organisation of out-of-hours primary care in the Netherlands has changed substantially during the last decade. Formerly, general practitioners (GPs) provided out-of-hours care to their patients in small groups of GPs (6 to $8 \mathrm{GPs}$ ), utilising a rota system. In recent years, large GP cooperatives have been set up following British and Danish examples ${ }^{1,2}$. Generally, 40 to 120 GPs participate in these services, providing care for populations ranging from 80000 to 300000 . Currently, GP cooperatives in the Netherlands cover over $90 \%$ of the population.

There has been debate on how the establishment of these cooperatives influences utilisation of emergency care services by patients with non-urgent health problems, i.e., problems that are not life threatening and do not require immediate care ${ }^{3}$. In the Dutch healthcare system the GP acts as a gatekeeper to secondary care. As a rule, patients need a GP's referral to utilise hospital services. However, to attend an emergency department a referrall is recommended but not strictly required. Research shows that over $40 \%$ of all patients attending the emergency department present with nonurgent problems that can be managed in general practice". Non-urgent patients have been recognised to be one of the main contributors to the problem of overcrowding at the emergency department ${ }^{5}$.

In the Netherlands most cooperatives are situated separately from the local hospital's emergency department. Based on patient interviews, Coleman et al. ${ }^{6}$ suggested that alternative facilities have little effect on the use of emergency services by patients with non-urgent problems. However, no data are available to support this assumption. In an earlier study we have shown that GPS working at a cooperative within the A\&E department handle relatively more patients as compared to their colleagues in a cooperative separate from the A\&E department. In addition, this integrated organisation reduced the number of self-referrals at the A\&E department? Still, it remains unclear to what extent cooperatives separate from the $A \& E$ department have an effect on emergency services utilisation. The organisation and positioning of GP cooperatives has mainly been the result of local preferences.

The objective of this study is to gain insight into the impact of GP cooperatives on the use of hospital emergency services and primary carc during out-of hours. 


\section{METHODS}

This study was conducted in the South of the Netherlands in the province of Limburg, a region with about 400000 inhabitants, of whom approximately $70 \%$ live in rural areas. The area's size is about $840 \mathrm{~km}^{2}$, with roughly 190 houses per square kilometer. In this region, 173 GPs are registered. Until September 2001 , out-of-hours primary care was organised in 24 small pracrice rotas. At that point in time, out-of-hours care was reorganised and three large GP cooperatives were created. All cooperatives are located near, but function fully independently of, the only three hospital's emergency departments. The public was informed about the outof-hours care reorganisation by posters at their own GP's practice and by the GPs" answering services.

Out-of-hours are defined as between $5 \mathrm{pm}$ and $8 \mathrm{am}$ on working days and from 5 pm Fidiay to 8 am Monday.

During a four-week period in May and June 2001 (before the reorganisation) and during the same period in 2002 (after the reorganisation) we investigated all patient contacts with out-of-hours primary and emergency care. During the first assessment period there were two bank holidays; during the second period there was one bank holiday. To improve comparability between these two periods, we excluded all patient contacts from 8 am to $5 \mathrm{pm}$ on one of the two bank holidays during the first assessment period. In the 2001 study period, GPs in this region were asked to register all patient contacts when they were on call. With respect to patient contacts with emergency care, contacts between $8 \mathrm{am}$ and $5 \mathrm{pm}$ were excluded.

In the registration period in 2002 we extracted the data from the GP cooperatives' computer system. Data from the emergency departments were extracted from the hospitals" computer systems.

Eighty-three percent (143/173) of all GPs participated during the first assessment period. To estimate total number of patient contacts with outof-hours primary care during this period, a correction factor was applied to all absolute numbers; absolute numbers were divided by the number of participating GPs and multiplied by the totall number of GPs working in that area.

Chi-square tests were used to test for relative changes. The level of significance was set at 0.05 . 
Table 1. Number of patient contacts with out-of houts care diring the tho fowit werk: assessments before and afrer the reorganisation 2001 numbers adjusted for $(j)$ ? Barticipation):

\begin{tabular}{|c|c|c|c|}
\hline & $\begin{array}{l}\text { Before }(2001) \\
\text { n }(\%(95 \% \mathrm{Cl}))\end{array}$ & $\begin{array}{l}\text { Arter }(2002) \\
\mathrm{n}(\%(95 \% \mathrm{Cl})\end{array}$ & $\begin{array}{l}\text { Alosolinte } \\
\text { change } \\
\left(n / \sigma_{0}\right)\end{array}$ \\
\hline 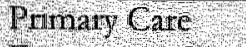 & $8496(72,1(71,3,729)$ & $9326(75.7749 .765)$ & $1+830(9.80 \%)$ \\
\hline ncy Care & $3285(27.9(271,287)$ & $2993(24,3(23.525,1)$ & $(292(6,9 \%)$ \\
\hline PI: & 11781 & $2+12319$ & $+530(46 \%$ \\
\hline
\end{tabular}

\section{RESULTS}

The total number of patient contacts during out-of-hours increased by $4.6 \%$ (see Table 1). Before the reorganisation (2001) the GPs registered 7023 patient contacts during out-of-hours. Adjusted for the GP response rate, the total number of patients for that period was estimated to be 8496 . In the year after the reorganisation of out-of-hours primary care (2002) there were 9326 patient contacts with the three GP cooperatives, an increase of $9.8 \%$.

Before the reorganisation the emergency departments of the three hospitals registered 5454 patient contacts, of which $3285(60.2 \%)$ were during out-of-hours. After the reorganisation the total number of patient. contact with these A\&E departments was found to be 5062 with 2993 $(59.1 \%)$ contacts during out-of-hours. This indicates a decreased demand for emergency care during notmal hours of $8.2 \%$ and a decrease during outof-hours of $8.9 \%$.

In $2001,47.6 \%(2598 / 5454)$ of all patients at the emergency departments during and outside office hours were self-referred, whereas atter the reorganisation $44.3 \%(2242 / 5062)$ of the patients were self-referted; a relative reduction of $3.3 \%(P<0.001 ; 95 \% \mathrm{Cl}:-5.2-1.4)$. The absolute reduction in the number of self-referrals was $13.7 \%(356 / 2598)$.

During out-of-hours, there was a $3.6 \%$ shift $(P<0.001)$ from patients utilising emergency care to primary care $(P<0.001 ; 95 \%$ CI: $2.5-4.7)$.

\section{DISCUSSION}

Although the total demand for out-of-hours care has increased, we observed a decreased demand for emergency care after the reorganisation of primary care out-of-hours care in the study region. It seems likely that the reduction of the urilisation of emergency care has mainly been caused by a 
reduction in self-referred patients with non-urgent problems. As a consequence, more patients are being managed by the GPs, due to increased overall demand and the shift of primary care patients from the A\&E department to the GP cooperatives. As more information becomes available to the public about how and when to use out-of-hours medical services, we expect the current shift to grow. Since the second assessment was performed shortly after the reorganisation, the public was probably not accustomed to this model of healthcare delivery; thus, the reorganisation's full effect on out-of-hours medical care may not be fully appreciated.

It is likely that the number of patient contacts with primary care before the reorganisation has been slightly underestimated, as GPs may not have registered all patient contacts during out-of-hours. If this is the case, the overall increased utilisation of out-of-hours care may be somewhat smaller. However, our conclusion on the decreased use of emergency care remains unaffected.

Although not investigated in this study, the shift in patient contacts from emergency care to primary care is likely to reduce $\cos \mathrm{ts}^{3,8}$.

Future research is warranted to investigate the cost of these out-of-hours services, quality of care, and satisfaction with these services of patients and care providers.

In conclusion, the reorganisation of out-of-hours primary care into GP cooperatives has reduced utilisation of hospital emergency care and increased utilisation of primary care.

\section{REFERENCES}

1. Hallam $L_{x}$, Cragg $D$. Organisation of primary care services outside normal working hours. BMJ. 1994;309:1621-3.

2. Olesen I. Jolleys JV. Out of hours service: the Danish solution examined. BMJ. $1904 ; 309: 1624-6$.

3. Murphy $\Lambda$ W, Bury G, Plunkett P.K, et al. Randomised controlled trial of general practitioner versus usual medical care in an urban accident and emergency deparment: process, outcome, and compatative cost. BMJ. 1996;312:1135-42.

4. Dale I, Green J, Reid F, Glucksman E. Primary care in the accident and emergency departinent: 1. Prospective identification of patients. BM]. 1995;311:423-6.

5. Tatovich DM. Emergency medicine. BMJ. 2002;324:958-62.

6. Coleman P, Irons R, Nicholl J. Will altemative immediate care services reduce demands for non-urgent treatment at accident and emergency? Emerg Med].
$2001 ; 18: 482-7$.

7. Van Uden GT, Winkens RAG, Wesseling GJ, Crebolder HFJM, Van Schayck CP. Use of out of hours services: a comparison between two organisations. Emerg Med J. 
8. Dale J, Lang H, Roberts JA, Green J, Glucksman E. Cost effectiveness of trearing primary cate patients in accident and emergency. a compatison between general practitioners, senior house officers, and registrars. BMJ. 1996:312:1340-4. 


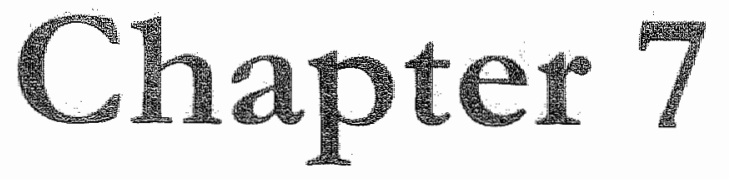

\section{Patient satisfaction with out-of-hours primary care in the Netherlands}

\begin{tabular}{l|l} 
C.J.T. van Uden ${ }^{1,2}$ & BMC Health Services Research 2005; 5:6 \\
A.J.H.A. Ament & \\
S.O. Hobma & \\
P.J. Zwietering & \\
H.F.J.M. Crebolder &
\end{tabular}

\footnotetext{
Department of Integrated Care, Uniwersity llospital Masastricht

Department of General Practice, Manstrich University

${ }^{3}$ Department of Health Organization Policy and Economics, Masastricht Universiry
} 


\section{ABSTRACT}

Background: In recent years out-of-hours primary care in the Netherlands has changed from practice-based to large-scale cooperatives. The purpose of this study is to determine patient satisfaction with current out-of-hours care organised in general practitioner (GP) cooperatives, and gain insight in factors associated with this satisfaction.

Methods: From March to June 2003, 2805 questionnaires were sent to patients within three weeks after they had contacted the GP cooperative in their region. The study was conducted in the province of Limburg in the South of the Netherlands. One-third of these questionnaires was sent to patients who had only received telephone advice, one-third to patients who attended the GP cooperative for consultation, and one-third to patients who received a home visit. Four weeks after the first reminder, a nonrespondents telephone interview was performed among a random sample of 100 patients. Analyses were performed with respect to the type of consultation.

Results: The total response was 42.4\% (1160/2733). Sixty-seven percent of patients who received telephone advice only reported to be satisfied with out-of-hours care. About $80 \%$ of patients who went to the GP cooperative for consultation or those receiving a home visit, reported to be satisfied. Factors that were strongly associated with overall satisfaction included, the doctor's assistant's attitude on the phone, opinion on GP's treatment, and waiting time.

Conclusion: Patients seem generally satisfied with out-of-hours primary care as organised in GP cooperatives. However, patients who received telephone advice only are less satisfied compared to those who attended the GP cooperative or those who received a home visit. 


\section{INTRODUCTION}

In recent years, out-of-hours primary care in the Netherlands has been substantially reorganised. Formerly, general practitioners (GPs) used to perform these services in small locum gtoups ( 6 to $8 \mathrm{GPs}$ ) in which they joined a rota system. Nowadays, out-of-hours care is organised in largescaled GP cooperatives (45 to 120 GPs) following examples in the UK and Denmark ${ }^{1,2}$.

The initiative of reorganising out-of-hours care has come mainly from the profession itself, motivated by increased dissatisfaction with the organisation of former out-of-hours primary care services. This dissatisfaction was mainly due to the high perceived workload (after out-ofhours service a regular day of work followed), and poor separation between work and private life. The main advantage of the reorganisation was the substantial reduction of number of hours a GP has to be on call. Furthermore, the organisation of out-of-hours care became much more professional by installing management, employing doctor's assistants, and using chauffeured cars. Studies have indicated that GPs appear to be generally satisfied with out-of-hours care organised in cooperatives".

Not only did things change for doctors, but also patients expetienced some important changes in out-of-hours primary care. Generally, the reorganisation caused a shift from more personal care to more anonymous care, with increased distance to the GP. Formerly, when patients needed primary care outside office hours, the probability of being seen by their own or a local GP with whom they were familiar, was higher. In addition, when patients contacted the GP during out-of-hours in the past, they were most likely to speak to the GP himself on the phone. Nowadays, the phone is staffed by a doctor's assistant who decides what action should follow the patient's call. Moreover, out-of-hours care used to be deliveted by local GPs, indicating short distances to the GP's practice. In large-scale GP cooperatives, the distance to a GP outside office hours will have increased substantially for most parients.

We expected that patient satisfaction would have been reduced after the reorganisation, because factors that guaranteed personal out-of-hours care at a short distance, that may be important to patients, were changed substantially. Furthermore, in Denmark it has been shown that after the out-of-hours primary care reform parient satisfaction dropped significantly ${ }^{4}$ 5

Patient satisfaction with out-of-hours primary care has quite often been investigated, especially in the $\mathrm{UK}^{4 \cdot 1 !}$. Mostly, comparisons have becn made between different types of out-of-hours services. Several of these studics focused on out-of-hours primary care as organised in GP coopcratives. 
These studies have shown that patients are generally satisfied with out-ofhours primary care organised in GP cooperatives $5,8,11$. Nevertheless, parients receiving telephone advice only, appear to be less satisfied compared to those attending the cooperative or those receiving a home visit. In addition, it has been shown that the patient's expectation about their contact with the GP coopetative strongly affects the patient's overall satisfaction with out-of-hours care ${ }^{12}$. Other variables that appear to be related to overall satisfaction are, access to a car, age, and waiting time ${ }^{8}$.

Insight in patient satisfaction with out-of-hours care supplies the health care provider with important information on the patient's perception of the cquality of that care. During the last years, Dutch GP cooperatives have often received negative publicity in newspapers. The reorganisation has had some important implications for patients, and therefore research on their opinions about current out-of-hours care is warranted. The purpose of this study is to determine patient satisfaction with current out-of-hours care, and to determine how satisfaction is related to different aspects of the patient's contact with a GP cooperative.

\section{METHODS}

\section{Setting}

The study was conducted in the province of Limburg in the South of the Netherlands. With respect to out-of-hours primary care, the province is organisationally divided in five regions. Two of these regions each have two GP cooperatives (NL and ML), one region (OZL) has one GP cooperative with two satellite centres, and in the other two regions (WM and MHD) only one GP cooperative is operational. All cooperatives but one $(\mathrm{MH})$ are organisationally separate from the emergency department of the local hospital, and are located nearby the hospital. This implies that patients may choose between attending the emergency department and the GP cooperative for medical problems during out-of-hours. The $\mathrm{MH}$ cooperative is located at the emergency department of the region's only hospital and sees all patients needing out-of-hours care, except for those having a referral for emergency care.

In total, these seven GP cooperatives cover a population of about 1.1 million people (the total Dutch population is over 16 million people), and are fully operational since the $1^{\text {st }}$ of September 2001 . 


\section{Development of the questionnaire}

To determine relevant issues for the questionnaire we interviewed GPs and managers involved with out-of-hours primary care. In addition, we analysed the process for a patient contacting the GP cooperative for all three loci of care (telephone advice, consultation at the cooperative, and home visits) separately to make sure that all facets of the GP cooperative a patient faces would be incorporated in the questionnaire. Moreover, we also analysed unpublished Dutch questionnaires in this field, and the patient satisfaction questionnaire developed by Mckinley et al. ${ }^{13}$. Based on these three analyses, we identified a number of relevant elements (initial scales). Next a set of items was developed to enable us to produce multi-item scales. Subsequently, this list was sent to the patient organisation in our province, the two largest health insurance funds, and to the five GP cooperative organisations for commentary. These organisations were asked to critically review the list of items, and to add or remove items if they considered it necessary. After receiving all commentary the questionnaite was adjusted and was submitted to five people not involved in the development but with experience with out-of-hours primary care to check for clarity of the questions.

Finally three questionnaires were constructed for each of the three types of consultations (telephone advice, consultation at the cooperative, and home visit). The three questionnaires differed on items related to the specific type of contact, but general items were the same for all three questionnaires. In this way it was possible to avoid complex skip sections which lengthen the questionnaire and can reduce the response rate. We used a balanced Likert five point scale (strongly agree, agtee, neutral, disagree, strongly disagree) to record responses.

The questionnaire related to telephone advice contained six initial scales measuring: accessibility of the cooperative by phone, doctor's assistant's attitude, questions asked by the assistant, advice given by the assistant, urgency of patient's complaint, and overall satisfaction.

The questionnaite related to consultations at the cooperative contained ten initial scales: accessibility of the cooperative by phone, doctor's assistant's attitude, questions asked by the assistant, urgency of patient's complaint, waiting time at the cooperative, waiting room, distance to the cooperative, GP's attitude, treatment by GP, and overall satisfaction.

The questionnaire related to home visits contained eight initial scales: accessibility of the cooperative by phone, doctor's assistant's attitude, questions asked by the assistant, urgency of patient's complaint, waiting time until GP arrives, GP's attitude, treatment by GP, and overall satisfaction. 
In addition, patient characteristics such as, age, gender, level of education, and health insurance (as a measure of social economic status) were recorded. Patients were also asked which type of consultation they expected prior to their contact with the GP cooperative, and whether they thought that the right diagnosis had been made.

\section{Sample}

From March to June 2003 a sample of 2805 patients - who had contacted the GP cooperative in their region - received a questionnaire by mail. Patients received this questionnaire within three weeks after they had contacted the GP cooperative. Sampling was performed per GP cooperative within the four-month period. With respect to patients who received telephone advice only and those who attended the GP cooperative, a computer program randomly selected each fourth patient contact with the GP cooperative backwards from the moment of sampling. Since the number of home visits is limited, all 150 patients, who were visited by a GP from the cooperative, prior to the moment of sampling received a questionnaite. These procedures assured that the time between receiving the questionnaire and the contact with the GP cooperative was not more than three weeks.

Per region 450 questionnaires were sent out; 150 to patients who received only telephone advice, 150 to patients who visited the GP cooperative, and 150 to patients who received a home visit. Because of parallel research, more questionnaires were sent out in one of the regions (WM): 1005 questionnaires equally distributed among the three types of patient contact with the GP cooperative. The study size was chosen based on previous research by McKinley et $a .^{7,13}$, who presented a study sample of about 1400 patients. We estimated that about half of all questionnaires would be returned, and therefore distributed 2805 questionnaires.

The study was approved by the Institutional Medical Ethics Board.

\section{Reminder and non-respondents interview}

Three to four weeks after the questionnaire had been distributed, a reminder was sent to patients who had not returned the questionnaire, with the exception of the WM area. Four weeks after the last reminder, a random sample of 100 patients who had not responded, was contacted by phone. They were asked about their reasons not to return the questionnaire, and about their opinion on the contact they had with the GP cooperative. This interview was performed during office hours, during a three-week period. 


\section{Statistics}

Principal components analysis with oblimin rotation was used to test whether the items could be assumed to measure similar aspects or components of patients' opinions about their contact with the GP cooperative. Next, Cronbach's alpha coefficient was calculated to estimate the internal consistency as a measure for reliability for each component. Finally, scale scores were calculated per component by summing the scores per item and expressing the total result as a percentage of the maximum score for each scale ${ }^{13,14}$. Scale scores could range between 0 and 100 .

The relationship between individual variables and ovetall satisfaction was analysed using multiple regression analysis, with subscale satisfaction scores as covariates. Variables that did not significantly contribute to the regression model were excluded from the final model. In case of missing data, listwise deletion of missing cases was applied. All data were analysed using SPSS-pc, version 10.0 .5 .

Table 1, Patient characteristics.

Thephone advice Consultation at the Hone ristic GP coopetative

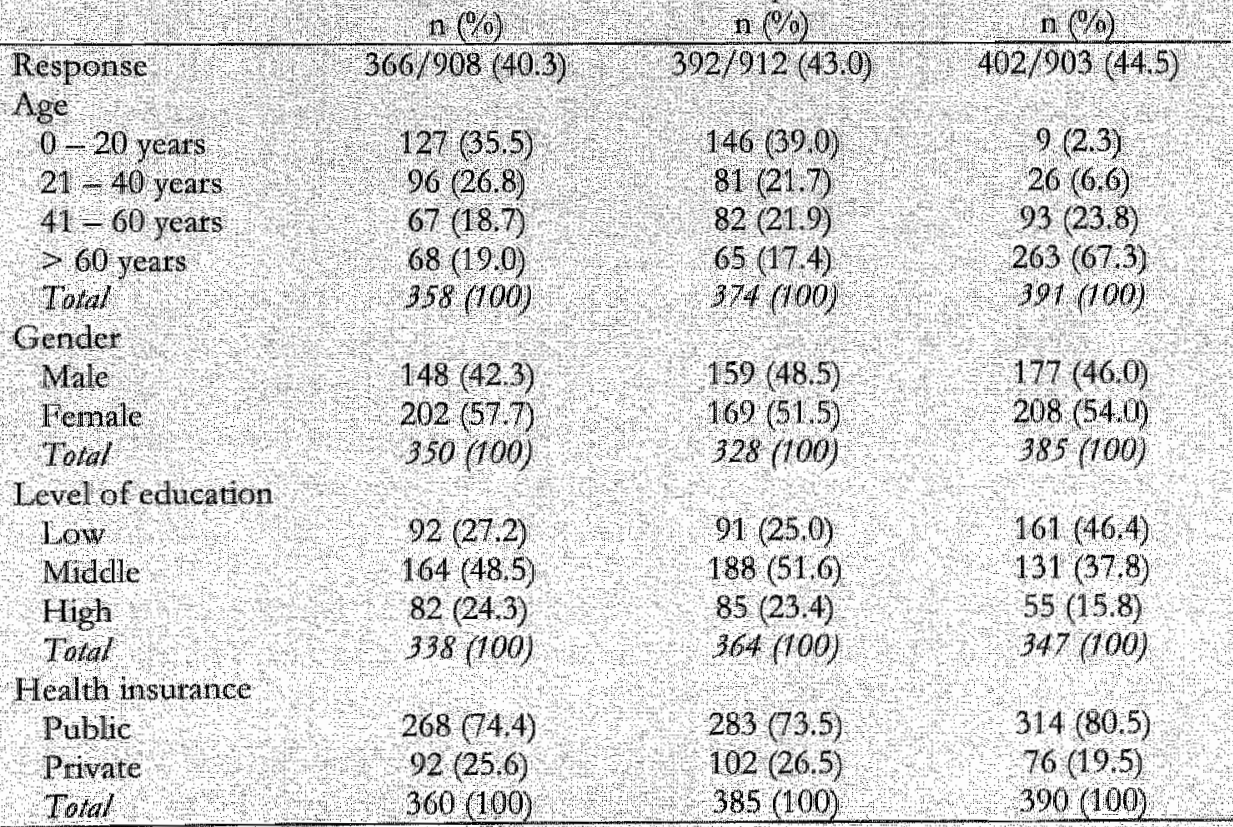




\section{RESULTS}

\section{Patient characteristics}

Seventy-two of the 2805 questionnaires were excluded, either because they could not be delivered (patient had moved or gave a wrong address), the patient had died, or the patient was sent a double questionnaire (multiple contacts). Eventually the response was 42.4\% (1160/2733). Generally more women responded to the questionnaire, and about threequarter of the respondents had public health insurance (table 1). The age of respondents of those who received telephone advice only was comparable with those who attended the GP cooperative for a consultation. The respondents who received a home visit were generally older; two-third was over sixty years of age.

\section{Telephone advice}

Forty percent (366/908) of the patients who had received telephone advice only, returned the questionnaire. $67 \%$ of these patients responded to be satisfied $(44.3 \%)$ or very satisfied $(22.3 \%)$ with their contact with the GP cooperative, and $57 \%$ thought that the current out-of-hours care was an improvement compared to the former situation. We identified the same six scales that were initially set to represent patients" opinions on aspects of primary out-of-hours care (table 2). All six scales had Cronbach's alpha coefficients between 0.64 and 0.93 . Detailed information on the scales and items can be found in appendix 1 (page 94).

Overall satisfaction in this group was significantly related to five scales, with a variance explained of $62 \%$ (see table 3 .). When patients judged that the right diagnosis had been made overall satisfaction was higher. We found that satisfaction also increased with age. When patients were satisfied with the accessibility of the cooperative by phone, the doctor's assistant's attitude on the phone, and the doctor's assistant's advice overall satisfaction was higher.

\section{Consultation at the GP cooperative}

Forty-three percent $(392 / 912)$ of the patients who attended the GP cooperative returned the questionnaire. Approximately $80 \%$ of these patients reported to be satisfied $(54.6 \%)$ or very satisfied $(26.3 \%)$ with their contact with the GP coopetative, and $61 \%$ thought that the current out-ofhours care was an improvement compared to the former situation. We 
Table 2. Deschption of scales represenung parient opmon on diferent thpect of out of hours prinary care

\begin{tabular}{|c|c|c|c|}
\hline Scales * ? & Cases & $\begin{array}{l}\text { Cronibrichis } \\
\text { alpha }\end{array}$ & $\begin{array}{l}\text { Scale score. } \\
\text { Mean } I \mathrm{SI})(95 \% \mathrm{Cl})\end{array}$ \\
\hline \multicolumn{4}{|l|}{ Telephone advice } \\
\hline Accessibility by phone & 364 & 072 & $76.5+18.9(7.4678 .5)$ \\
\hline Doctor's assistant's aiturude & 363 & 091 & $72.8 \pm 22 \cup(70.5751)$ \\
\hline Questions asked by assistan & 361 & 0.64 & $586+25,4(56,0-61,3)$ \\
\hline Adnce given by assistant & 351 & 0.93 & $337 \pm 273(50,856.5)$ \\
\hline Uigency of complains & 363 & 0,86 & $69.1 \pm 24.5(60.6-717)$ \\
\hline Qverall satisfaction & 361 & 0.93 & $64.2-26,1(61,5-66.9)$ \\
\hline \multicolumn{4}{|c|}{ Consulation at the GP conpertative } \\
\hline Accessibling lby phone & 385 & 0.73 & $79.3 \pm 176(77581.1)$ \\
\hline Doctor's assistani's atritude & 386 & 0.88 & $79.8+16.3(782.81 .4)$ \\
\hline Questions asked by assistant & 384 & 0.65 & $65.5 \pm 230(61.265 .8)$ \\
\hline Urgency of complaint & 384 & 0779 & $7201215(608741)$ \\
\hline Warling time at cooperative & 387 & 0.62 & $61.5+25.8(58.0 .64 .1)$ \\
\hline Waing room & 381 & 0.60 & $65.6 \div 20.3(635.67 .6)$ \\
\hline Distance to coopetative & 388 & 075 & $66.7 \pm 212(64.5 .68 .8)$ \\
\hline Treamnent by $\mathrm{Cl}$ ) & 377 & 093 & $81.0=18.9(79) 1.829)$ \\
\hline Overall sarisfaction & 392 & 1,88 & $73.7+19.8(71.7-75.6)$ \\
\hline \multicolumn{4}{|l|}{ Mone $\mathrm{Not}$} \\
\hline Accessibility by phone & 391 & 086 & $8019+18.4(79,1827)$ \\
\hline Doctor's assistant's atitude & 393 & 0.90 & $80.6 \pm 18.6(78.7 .82 .4)$ \\
\hline Quesuirns asked by issistant & 383 & 0.73 & $522+26,6(56.5-619)$ \\
\hline Utgencr of complant & 383 & 0.78 & $86.7 \pm 16.1(85.188 .3)$ \\
\hline Treatment by CP & 380 & 096 & $84.4+107(82,486.4)$ \\
\hline Waiting thie until GP arrives & 369 & 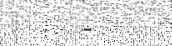 & $6004307(56863)$ \\
\hline Orerall saris facion & 300 & 0.92 & $74.6122,4(72.476,9)$ \\
\hline
\end{tabular}

TScale scores range from 0 to 100, whete O represents yery dissatished thd 100 represents highly satisfed

identified nine scales that represent patients' opinions on aspects of primary out-of-hours care (table 2), with Cronbach's alpha coefficients between 0.62 and 0.93 . Two initial scales have been merged into one scale; these were patient's opinion on the GP's attitude and the treatment by the GP. All other identified scales were the same as the initial scales. Detailed information on the scales and items can be found in appendix 1 (page 94).

Seven variables proved to be predictors of overall satisfaction, with a variance explained of $51 \%$ (see table 4.). Patients, who expected prior to their contact with the cooperative that they were going to be asked to come to the GP cooperative, were generally mote satisficd. Those who believed 
Table 3, Regression analysis with oyerall satisfaction with out-of-hours primary care as dependent varable of patients who recedred only telephone advice (adjusted R = 0.615)

\begin{tabular}{|c|c|c|c|c|c|}
\hline & $\begin{array}{l}\text { Unsta } \\
\text { coe }\end{array}$ & $\begin{array}{l}\text { dised } \\
\text { nts }\end{array}$ & $\begin{array}{l}\text { Standardised } \\
\text { terefficients }\end{array}$ & & \\
\hline & $\bar{B}$ & SIE & $B$ era & t & Sign. \\
\hline Constant & 2.404 & 4.302 & & -0.559 & \\
\hline 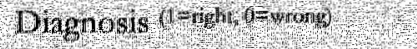 & 12.345 & 2.64 & 10200 & 4668 & $<0.001$ \\
\hline Patient's age? & 0.077 & 0.036 & 0,076 & 2128 & 0034 \\
\hline Arecessibility by lhotie & 01155 & 0.054 & 0.412 & 2.859 & 0.005 \\
\hline Doctor't assistant 6 antivide : & 0.401 & 0.067 & 0.355 & 5960 & $<0,001$ \\
\hline Doctor's assisvints ad wice & 0267 & 0.055 & 0.282 & 4.840 & $-0,001$ \\
\hline
\end{tabular}

Vartables that did not significantly contribule to the regression nodel $\mathrm{Panent}$ s gender, ype of heal hi insurance, level of education, expectation about type of consultation, patient's pereerved ugency of his or her complaint, and opinion on the guestions a sked by the doctor s assistant.

a seale score ranges from 0 to 100 , where 0 represents very dissativfied and 100 represents highly sarisfied.

Table 4. Regression analysis w th overall satisfaction with our -of hours primary care as dependent variable of paients who went for consultation to the $G \mathrm{P}$ cooperative. (adjusted $R^{2}=0.501$.

\begin{tabular}{|c|c|c|c|c|c|}
\hline & $\begin{array}{l}\text { Unsan } \\
\text { cone }\end{array}$ & $\frac{\text { dised }}{\mathrm{nts}}$ & $\begin{array}{c}\text { Standardused } \\
\text { coerfigtens } \\
\text { Beta }\end{array}$ & 1 & \\
\hline (Constant) & 5.249 & 5187 & & 1,012 & \\
\hline Expectation abour connet & 4,313 & 2113 & 0.978 & 2.042 & 0042 \\
\hline blly by phone s? & 0,095 & 0.47 & 0,088 & 2022 & 0.044 \\
\hline Doctor's assistints s artukide : & 0.165 & 0055 & $1 9 \longdiv { 3 8 }$ & 2981 & 0,005 \\
\hline Utgerncy own complaint t? & 0,072 & 0,036 & 0,178 & 2008 & 0.045 \\
\hline Whing lime? & 0181 & 0.030 & 0241 & 6050 & 20001 \\
\hline Dustance to cogperative & 0.176 & 0.035 & 1192 & 4965 & <0.001 \\
\hline ClPs realunent & 0.454 & 0042 & 0,441 & 10756 & $<0,001$ \\
\hline
\end{tabular}

Varibles that did not ignificanty contribute to the tegression nodel Patent s age and gender, ype of health insuinnce, level of edication, dhagrosis 0 -right, 0 -wrong), and opurion on the grestions asked by the doctor's assistant

a Selle scone tanges fom 10 to 100 , where 0 represents very dissausfied and 100 represents highly saris tied.

b scale tanges from 0 wo 100 o represents not urgent and 100 represents very argent acoording to the patient.

Indicates whether the patient neceived the vpe of contact (relephone ad wice, consultation at the cooperative, or home visi) he or she expected $(1=$ in accordance wh expectation, $0=$ not in accotdance with expectation) 
that their medical problem was urgent wete less satisfied. Long waiting times and dissatisfaction with the distance to the cooperative also reduced overall satisfaction. When patients were satisfied with the accessibility of the cooperative by phone, the doctor's assistant's attitude on the phone, and the GP's treatment overall satisfaction was higher.

Table 5. Regression analysis with overall safisfaction with our-of hours primary care as dependent variable of patents who received a home visit from a $\mathrm{GP}$ from the cooperative; (adjusted $\mathbb{R}^{2}=0.506$ )

\begin{tabular}{|c|c|c|c|c|c|}
\hline & \multicolumn{2}{|c|}{$\begin{array}{l}\text { Unstandardised } \\
\text { coefficients }\end{array}$} & $\begin{array}{l}\text { Standardised } \\
\text { coefficients }\end{array}$ & \multirow[b]{2}{*}{ t } & \multirow[b]{2}{*}{ Sign. } \\
\hline & B & $\mathrm{SE}$ & Beta & & \\
\hline (Constant) & -11.650 & 5.213 & & 2.235 & \\
\hline Diagnosis $(1-$ rght, $0=$ =verong & 11.948 & 2,461 & 0.207 & 4.856 & $<0,001$ \\
\hline Accessibility by phone & 0.232 & 0.059 & 0.198 & 3.246 & $<0.001$ \\
\hline Doctor's assistani's attitude & 0.329 & 0.061 & 0.282 & 5.364 & $<0.001$ \\
\hline GP's trearment : & 0.260 & 0.050 & 0.233 & 5.155 & $<0.001$ \\
\hline $\begin{array}{l}\text { Waiting time untl GP } \\
\text { arrives }{ }^{*} t\end{array}$ & 0.154 & 0.030 & 0.218 & $5: 183$ & $<0001$ \\
\hline
\end{tabular}

Yariables that did not significantly contribute to the regression model Patient's age and gender type of health insurance, education level, expectation about type of consultation, urgency of own conplaint, and opinion on the questons asked by the doctor's assistant.

- Scale seore ranges from 0 to 100 , where 0 represents very dissatisfied and 100 represents highly satisfied,

Single item scale

\section{Home visits}

Almost forty-five percent (402/903) of the patients that received a home visit by a GP from the cooperative returned the questionnaire. About $81 \%$ of these patients reported to be satisfied $(42.8 \%)$ or very satisfied $(38.8 \%)$ with their contact with the GP cooperative, and $61 \%$ thought that the current out-of-hours care was an improvement compared to the former situation. We identified six multi-item scales that represented the patient's opinion on different aspects of out-of-hours primary care, with Cronbach's alpha coefficients between 0.73 and 0.96 . Two initial scales have been merged into one scale; these were patient's opinion on the GP's attitude and the treatment by the GP. All other identified scales were the same as the initial scales. Detailed information on the scales and items can be found in appendix 1 (page 94).

We found that five variables predicted overall satisfaction, with a variance explained of $51 \%$ (see table 5.). Similar to the group of patients 
who had received telephone advice only, patients who receive a home visit were generally more satisfied when they believed that the GP of the cooperative had made the right diagnosis. When patients were satisfied with the accessibility of the cooperative by phone, the doctor's assistant's attitude on the phone, and the GP's treatment overall satisfaction was higher. In addition, when patients were satisfied about the waiting time until the GP arrives, overall satisfaction increased.

\section{Overall satisfaction}

The means of the three loci of care, adjusted for age, sex, insurance status, and education level, show that there is no difference between overall satisfaction in the group of patients who visited the GP cooperative (75.1 \pm 1.31 ) and those who received a home visit $(72.5 \pm 1.37$ ) (Table 6). However, patients who received telephone advice only $(66.2 \pm 1.30)$, were significantly less satisfied compared to the other two groups of patients.

Table 6. Adjusted neans for ovetall satir faction.

\begin{tabular}{|c|c|c|c|}
\hline a & Mean & SD & $959 \% 01$ \\
\hline Telephone advice & 662 & 1,313 & $63.6-68.7$ \\
\hline Consultation at GP cooperative & 751 & 1,31 & 725.77 .6 \\
\hline Mome visit & 72.5 & 1,37 & $69.8-75,2$ \\
\hline
\end{tabular}

\section{Non-response}

Out of 100 randomly selected patients, who had not returned the questionnaire, we were able to reach 63 by phone. Of these 63 nonrespondents $35(55.6 \%)$ were male and $28(44.4 \%)$ were female. Many of them reported that they had forgotten to teturn the questionnaire $(40 \%)$. A minority said not to be interested $(6.7 \%)$ or did not find it needful $(6.7 \%)$. Most non-respondents $(46.7 \%)$ gave other reasons like, no time, too difficult, or had lost the questionnaire.

Of these patients, about $71 \%$ reported to be satisfied or very satisfied about their contact with the GP cooperative.

\section{DISCUSSION}

The results of this study indicate that patients were generally satisfied about their contact with the GP cooperative. Patients who received 
telephone advice only, however, were less satisfied compared to those who attended the GP cooperative and those who received a home visit. A small majority believes that current out-of-hours care is an improvement compared to the former situation.

The response rate in our study is not as high as presented previously by others who investigated patient satisfaction with out-of-houts primary care ${ }^{5}$ $7.9,11$. Reasons for patients not to return the questionnaire in our study were assessed through the non-respondents interview. We found that most patients gave reasons that were not directly related to their contact with the GP cooperative. Therefore, we assume that this reduced response rate may have had little effect on the outcome of our study. In addition, the overall satisfaction in the non-respondents group did not differ much from that of the respondents.

In the process of determining relevant aspects of out-of-hours cate to patients, we consulted the province patient organisation and studied discussions on out-of-hours care in newspapers. We have not used patient interviews, although this might have identified other relevant domains of out-of-hours care. However, we think that the current questionnaire captures many relevant domains of out-of-hours care to patients as well as to health professionals.

Based on results of a Danish study 4, 5, we expected overall patient satisfaction to be low because our study took place relatively shortly after out-of-hours care had been reorganised. However, we have not assessed patient satisfaction before the reorganisation, and therefore it remains unclear whether satisfaction has changed. Nevertheless, this study showed that more than half of the patients believe that the reorganisation has improved out-of-hours primary care.

We have no reason to believe that the results of this study cannot be generalised to other regions in the Netherlands. Most GP cooperatives in the Netherlands are comparable, with respect to organisation and population size, to those in this study. In addition, the region in our study includes both rural and urban areas. Despite the similarities with out-ofhours primary care in other countries such as Ireland, the UK and Denmark, there are also differences with respect to the way these cooperatives are organised, and therefore care should be taken when generalising these results to other countries.

We identified various factors that are closely related to overall satisfaction. These factors give important insight in aspects of the GP cooperative that really matter in the patient's opinion on out-of-hours care. The patient's opinion on the doctor's assistant's attitude on the phone proved to be the strongest predictor of overall satisfaction with respect to those having received telephone advice and those that received a home visit. 
Also for those attending the GP cooperative, this factor was a relatively strong predictor; in this group the patient's satisfaction with the GP's treatment was by far the strongest predictor of overall satisfaction. Thus, it appears that the patients' impression of the first contact they have with the cooperative, which is mostly through telephone, strongly influences overall satisfaction.

In accordance with other studies we found that patients who received telephone advice only, are generally less satisfied with the out-of-hours service, compared to those attending the GP cooperative and those receiving a home visit ${ }^{4,5,8,9,11}$. Patient's expectation of care is assumed to be an important factor that influences overall satisfaction ${ }^{12}$. In our study, only $35 \%$ of the patients with telephone advice expected that they would receive this type of consultation. In contrast, $85 \%$ of the patients that were asked to attend the cooperative or received a home visit found this type of consultation in line with their expectations. This difference in expectation of care may very well explain the difference in overall satisfaction.

It is questionable whether extra information to the public on the process of the telephone triage process will adjust patients' expectations. Similar to what Salisbury et al. ${ }^{8}$ suggested, we believe that a shift to an out-of-hours care organisation based predominantly on telephone advice may decrease patient overall satisfaction. Therefore, proper information about the telephone procedure at the GP cooperative is desirable ${ }^{15}$. This information can be supplied by the doctor's assistant on the phone, and by written information through folders and posters in GP practices.

\section{CONCLUSIONS}

This study has shown that patients are generally satisfied with out-ofhouts care, but that patients with telephone advice only ate less satisfied than those attending the cooperative or receiving a home visit. The patient's opinion on several aspects of out-of-hours care can predict overall satisfaction, with different predictors regarding the three types of consultations. However, the accessibility by phone and the doctor's assistant's attitude on the phone ate always significantly related to overall satisfaction, regardless of the type of consultation. This implies that when trying to improve overall satisfaction one should always focus on at least these two factors. The questionnaire used in this study has potential for use as a standardised instrument for assessing satisfaction with out-of-hours care in The Netherlands for either research or service monitoring. 


\section{REFERENCES}

1. Hallam I, Cragg D. Organisation of primary care services outside nomal working hours. BMJ. 1994;309:1621-3.

2. Olesen 1 , Jolleys JV. Out of hours service: the Danish solution examined. BMJ. 1994;309:1624-6.

3. Leibowitz $\mathbb{R}$, Day $S$, Dunt D. A systematic review of the effect of different models of after-hours primary medical care services on clinical outcome, medical workload, and patient and GP satisfaction. Fan Prat. 2003;20:311-7.

4. Hansen BI, Munck A. Out-of-hours service in Denmark: the effect of a structural change. BrJ Gen Pract. 1998;48:1497-9.

5. Christensen MB, Olesen F. Out of hours service in Denmark: evaluation five yeats after reform. BMJ. 1998;316:1502-5.

6. Cragg DK, McKinley RK, Roland MO, et al. Comparison of out of houts care provided by patients" own general practitioners and commercial deputising services: a randomised controlled trial. I: The process of care. BMJ. 1997;314:187-9.

7. McKinley RK, Roberts C. Patient satisfaction with out of hours primary medical care. Qual Health Carr. 2001;10:23-8.

8. Salisbuty C. Postal survey of patients' satisfaction with a genetal practice out of hours cooperatuve. BMJ. 1997:314:1594-8.

9. Shipman C, Payne F, Hooper R, Dale J. Patient satisfaction with out-of-hours scrvices; how do GP co-operatives compare with deputizing and practice-based arrangements? I Public Healib Med. 2000;22:149-54.

10. Murphy AW, Bury G, Phnkert PK, et al. Randomised controlled trial of general practitioner versus usual medical care in an urban accident and emergency department: process, outcome, and comparanive cost. BMI. 1996;312:1135-42.

11. Pickin DM, O'Cathain A, Fall M, Morgan AB, Howe A, Nicholl JP. The impact of a general practice co-operative on accident atud emergency services, patient satisfaction and GP satisfaction. Fom Pract. 2004;21:180-2.

12. McKinley RK, Stevenson K, Adams S, Manku-Scott TK Meeting patient expectations of care: the majot determinant of satisfaction with out of-hours primary medical care? Fam Pract. 2002;19:333-8.

13. McKinley RK, Manku-Scott T, Hastings AM, French DP, Bakker R. Reliability and validity of a new measure of patient satisfaction with out of hours primary medical care in the United Kingdom: development of a patient questionnaine. BMF. 1997;314:193 8.

14. McKinley RK, Cragg DK, Hastings AM, et al. Comparison of out of hours care provided by patients' own general practitioners and commercial deputising services: a randomised controlled trial. II: The outcome of care. BMJ. 1997;314:190-3.

15. Payne F, Shipman $C$, Dale J. Patients' experiences of receiving telephone advice from a GP co-operative. Fan Prat. 2001;18:156-60. 
APPendt 1. Patien sarts faction questionnaire Description of scales and tems.

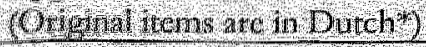

\section{Sedit I. Aecessibility by phonets}

1. Was easy w find the phone number of the GP cooperadiret (t)

Tt was easy to get hrough on the telephore (t)

The time und the doctor's gssistant picked up the phone was short (1)

\section{Scale 2. Doctor's assistant's attitudetch}

The doctor's assistant was filendly on the phone (t)

The doctor's assistant had enough tme to talk to me on the phone (t)

The doctor's assistant secmed to understand the problem (t)

The dicetor's assistant took diny problem seriously $(t)$

The informalion given by lie doctor's assistant was very clear ( 1 )

\section{Scale 3. Questions asked by the doctor's assistants con}

The doctors assistant aked too many questions ()

1 thought it was aninoyng that the doctor's as sistant statted with nioting ny personal dat before asking abour my complaints ()

\section{Scalle 4 . Urgency of complaint of}

I believed ny problem was very severe $(t)$

T thought ny prolstem necded tanmediate care (t)

\section{Seale 5. Advice given by doctor's assistant}

The doctor's assigianr's infomation about my problem was good (t)

The advice lie doctor's assistann gave nie was very use ful $(t)$

The telephone advice by the doctor's assistane had teassuted ne (t)

The telephore advice by the doctor's assistant was sufficient considering my problem (t)

T hought the doctor's assistant was 49 gr to grve me telephonc advice only $(t)$

\section{Soale 6. Waiting time at the eboperativec}

I thought I had to wain too long at the registratern desk ()

I thought thad 10 wath toolong before the GP came to see ne ( )

\section{Seale 7. Waiting toome}

There was enowgh naterlal (magazues et cetera) in the waiting roon to entertain the palientes (fit)

The waning room looked very clean (t)

\section{Scale 8. Distance to the GP cooperative}

I think the travel time from ny holise to the GP cooperative is too long (a) The GP cooperative is edsy accessible (1)

* The provisional translation into English is neant to wiform the reader of the content of the scales and cannot be scen as a definite one. 
Appendix 1 (contrived) Patient satisfaction gue stionnaire Description of scales and items (Orignalinems are in Dutch*)

Scale 9. Treament by the GPC:

The GP look ny problen seriously (1)

The $G$ P was friendy $(t)$

The GP gave ne elear information abour ny problem (t)

The advice the GP gave ne was very use ful (t)

The GP lad enough time for me duming the consultation (t)

I was very pleased with the treatment by the (IP (t)

Seale 10. Waiting time vintil GP arrivesv

Thought it rook too long for the GP wa arrive()

\section{Scale 11, Overall satisfaction,}

I and satisfied abour this contact with the CP cooperative (t)

I an satisficd about the time it took to help ne (t)

I think the GP cooperative functions rery well $(t)$

Satsfaction ratung on a scale from 1 to 10 regarding the functioning of dhe $\mathrm{GP}$ cooperativet

Satisfaction ratung on a scale from 1 to 10 regarding the telephone procedure at the GP cooperativel:

* The provisional translation into English is meant to nform the readef of the content of the seales and cannot be seet as a definite one.

Tscale for the patiens group who teceived relephone advice only

G seale for the patienis group who attended the (A cooperative for a consultation.

i scale for the patents group who trecevied a hone visit

"this item was excluded fiom the scale telated topatients who attended the GP cooperatue

Athis icem was excluded from the scale related to patients who recened a hone wisi

These tems have been divided by wwo to teach the same range as the other trent. 


\section{Chapter 8}

\section{Telephone triage during out-of-hours primary care: patients' and doctors' opinions.}

C.J.T. van Uden, ${ }^{1,2}$

Submitted for publication

M.W.A. Hübben ${ }^{\hat{3}}$

S.O. Hobma ${ }^{2}$

P.J. Zwietering ${ }^{2}$

M. Elferink ${ }^{3}$

E. van Cromvoirt ${ }^{3}$

A.J.H.A. Ament ${ }^{3}$

${ }^{3}$ Deppartment of Health Organisation Policy and Economics, Mastricht Universitg 


\section{ABSTRACT}

Objective: The purpose of this study is to gain insight in patients' and gencral practitioners' (GP) opinions on telephone triage with and without computer based decision support software (the Telephone Advice System (TAS)) at GP cooperatives for out-of-hours primary care.

Methods: Patients and GPs of two GP cooperatives were sent a questionnaire in which they were asked about their opinions on aspects of telephone triage. At one GP cooperative the doctor's assistants performing telephone triage use TAS, and at the other GP cooperative the telephone triage process is supported by written protocols and guidelines.

Results: Patients who contacted the cooperative that uses TAS were generally more satisfied about the telephone advice, but less satisfied about the accessibility of the GP cooperative by phone. GPs of the cooperative that uses TAS were more satisfied about their role as telephone GP, but were equally satisfied about the information given by the doctor's assistant to supervise and authorise the handling of the call. GPs of both cooperatives were also equally satisfied about the selection of consultations.

Conclusions: The use of TAS seems to increase patient satisfaction with telephone advice. However, according to GPs' opinions, the selection of consultations at the cooperative that uses 'TAS is equal to that of the GP cooperative that uses written protocols and guidelines to support the telephone triage process. 


\section{INTRODUCTION}

Currently, out-of-hours primary care in the Netherlands is organised in large-scale general practitioner (GP) cooperatives. This organisational structure of out-of-hours care is comparable to that in countries such as the United Kingdom and Denmark. The GP cooperatives have been set up to provide care outside office hours for populations ranging from 40,000 to 300,000 people. Generally, the number of participating GPs within these cooperatives varies between 20 and 150 . In former times, out-of-hours primary care was delivered by small groups of GPs (generally 6 to 8 GPs) who used a rota system to provide care for populations tanging from ten to twenty thousand patients. GPs' dissatisfaction with the former organisation of out-of-hours care was the most important factor to reorganise these outof-hours services. At the moment, there are more than $120 \mathrm{GP}$ cooperatives in the Netherlands covering over $90 \%$ of the Dutch population.

The GP cooperatives in the Netherlands use telephone triage to prioritise patient treatment. During telephone triage the urgency of the patient's problem is assessed and a decision is made about the appropriate action to be taken. This decision includes giving self-care advice without seeing the patient, advising patients to attend their own GP the next day, referring patients to a $G P$ at the cooperative, or ordering home visits. At most Dutch GP cooperatives the telephone is staffed by a doctor's assistant. In addition, this doctor's assistant is supervised by a GP, who can be consulted in case of doubt and who authorises all calls handled by the doctor's assistant.

The telephone triage process is an important and critical link in the chain of out-of-hours primary care. It is essential that patients receive adequate and timely care, and therefore, telephone triage must be safe and effective. At all GP cooperatives in the Netherlands, triage protocols and guidelines are available to support the doctor's assistant. To further support the triage process some GP cooperatives have started using computer based decision support tools. One of these tools which has been introduced in the Netherlands is the Telephone Advice System (TAS). This system was originally developed in the United Kingdom and has been translated and adapted to the Dutch situation. It was found that trained nurses using TAS are capable of independently handling about $50 \%$ of the calls, which proved to be safe and effective $e^{2,3}$. Moreover, Dale et al. ${ }^{3}$ showed that the decisions taken by nurses were remarkably consistent.

The suggested advantage of telephone triage using TAS above using written protocols and guidelines is the standardisation and structuring of the triage process. It has been shown that during telephone triage without computer based decision software, doctor's assistants start with formulating 
a hypothetical diagnosis and then look at symptoms to validate this diagnosis (backward reasoning) ${ }^{4}$. However, it is preferable to start with collecting symptoms and subsequently make a diagnosis based on these symptoms (forward reasoning). Computer based decision softwate structures this process of telephone triage and supports the process of forward reasoning. It has also been argued that the self-care advice given by the doctor's assistant when using TAS will be more standardised and consistent, and the GP who supervises the telephone triage process has more structured and relevant information about the patient's medical problem to authorise and check the handling of the cail.

In the Netherlands, the use of TAS at GP cooperatives has not yet been formally evaluated. The use of TAS has been introduced to support safety, adequacy and transparency of telephone triage for patients. However, patient experiences with Dutch GP cooperatives using TAS has not been investigated. As also indicated by a recent review, there is still lack of knowledge about patient satisfaction with telephone triage.

To support the quallity of the telephone triage process, TAS requires all relevant information about the patient's medical problem to be collected and registered in the computer system. This assumes that the GP who supervises the telephone triage process is given more insight in call handling by the doctor's assistant, compared to the situation where no computer based decision software is used. Moreover, if calls are indeed better selected and more information is available about the triage process, GPS will probably be more comfortable with the supervision of telephone triage and be more satisfied with the selection of consultations at the GP cooperative and home visits.

The purpose of this study was to gain insight in patients' and GPs' experiences with the telephone triage when TAS is used.

\section{METHODS}

In this study we compared patients' and GPs" opinions on different. aspects of telephone consultation and triage with respect to a GP cooperative using protocols and guidelines to support the triage process (Sittard) with a GP cooperative that uses the Telephone Advice System (Tilburg).

\section{Description of the cooperatives}

The GP cooperative in the Sittard region covers a population of about 175,000 patients. The cooperative is located at the site of the region's only 
hospital. In total $78 \mathrm{GPs}$ participate within this cooperative, excluding deputy GPs. The staffing of the cooperative varies between two GPS and one doctor's assistant during the night, and four GPs and three doctor's assistants during the weekends. All phone calls are taken by the doctor's assistant, who registers the patient personal details and assesses the urgency of the patient's medical problem and prioritises treatment. Protocols and guidelines are available to support this telephone triage process. There is always one GP present who supervises the telephone triage, the so-called telephone GP. The other GPs working at the cooperative are performing consultations at the GP cooperative, or making home visits in the region.

The GP cooperative in the Tilburg region covers a population of about 250,000 patients. In Aptil 2003 a small cooperative joined the Tilburg region, the GP cooperative of Waalwijk, and the total population increased to 330,000 patients. With respect to patients' opinions, we interviewed patients of the Tillburg and Waalwijk cooperative. With respect to GPs' opinions we interviewed only GPs of the Tilburg cooperative. In Tilburg and Waalwijk respectively, 108 and 40 GPs participate within the cooperative. The Tilburg cooperative is centrally located in the area, however not close to any hospital. The Waalwijk cooperative is located at the local hospital. The staffing of the Tilburg and Waalwijk cooperarive varies between three GPs and one doctor's assistant during the night, and six GPs and eight doctor's assistants during the weekends. Comparable to the Sittard GP cooperative, these GP cooperatives have three functions or roles for GPs; telephone triage supervision, consultations at the cooperative, and performing home visits. During telephone triage at the Tilburg cooperative the doctor's assistants are supported by a computerised decision support tool; the Telephone Advice System (TAS).

\section{Patient questionnaire development}

Patient opinion on the handling of the phone call was investigated using a postal questionnaire. The development of the questionnaire is described in detail elsewhere. In this study we only analysed patient opinion on aspects that are relevant with respect to telephone triage. These are: accessibility of the GP cooperative by phone, doctor's assistant's attitude, questions asked by the doctor's assistant, advice given by the doctor's assistant, and score for telephone procedure on a ten-point scale. Responses were recorded using a Likert five point scale (strongly agree, agree, neutral, disagree, strongly disagree). 


\section{GP questionnaire development}

To investigate GPs' opinion on different aspects related to telephone triage, we developed a new questionnaire, because no such questionnaire was available at that time. Relevant topics were identified in interviews with GPs participating in out-of-hours care. We have developed a set of items to enable us to measure and test multi-item scales. In total the questionnaire consisted of 71 items. (Some items are excluded from the analysis because they are only of local interest.) We investigated opinions on: specificity of the triage process (did the patient correctly teceive self-care advice or should a doctor have been consulted), appropriateness of patient contacts, the function of telephone GP, how well telephone consultations have been selected, the available information to supervise doctor's assistant's telephone triage, selection of patients attending the cooperative, and selection of home visits.

We used a Likert five point scale (strongly agree, agree, neutral, disagree, strongly disagree) to record responses.

\section{Procedure patient questionnaire}

From March to June 2003 questionnaires were sent to patients who contacted the GP cooperative for out-of-hours care. We distributed 1005 questionnaires per GP cooperative, with 335 sent to patients who received telephone advice only, 335 to patients who attended the GP cooperative, and 335 to patients who received a home visit. Patients were randomly selected: backward from the moment of sampling each fourth patient contact with the GP cooperative was selected. Only with respect to patients receiving a home visit each patient contact was selected backward from the moment of sampling until 335 patients were selected. The time between distributing the questionnaire and the patient's contact with the cooperative was no more than 3 weeks.

\section{Procedure GP questionnaire}

All GPS of the cooperative without TAS (Sittard) and those of the cooperative with TAS (Tilburg) received a questionnaire by mail. In total 95 questionnaires were distributed to the GPS in Sittard and 108 to GPs of Tilburg. In the Sittard area the questionnaires were distributed in December of 2002, and in Tilburg in June of 2003. Three weeks after questionnaires were distributed, a reminder was sent to those GPS who had not returned the questionnaire. 


\section{Statistics}

With respect to the patient questionnaire, scales were constructed as described earlier ${ }^{6}$. Regarding the GP questionnaire, principal components analysis with oblimin rotation was used to test whether the items could be assumed to measure similar aspects or components of GP opinions about the different aspects of telephone triage and the GP cooperative. Next, Cronbach's alpha coefficient was calculated to estimate the internal consistency as a measure for reliability for each component. Finally, scale scores were calculated per component by summing the scores per item and expressing the total result as a percentage of the maximum score for each scale? Scale scores could range between 0 and 100 . To test differences between patients or GPs from either two GP cooperatives we performed independent Student's t-tests per scale. A P-level of less than 0.05 was considered to be statistically significant. All data were analysed using SPSS version 10.0.5.

Table 1. Pallent characteristes.

\section{Telephone advice}

Sittard

\section{Gender}

Male

Temale

Age

Insumace

public

Private

Tiiburg

Gender

Male

Fenale

Age

Insurance

Public

Privale

$348(23.9)$

$73(777 \%$
Consult at GP

cooperative

n -129 . $n=1 / 8$

$52(41)(60 \%)$

$50(44,2 \% 0)$

$63(55,8 \%)$

$66.1(161)$

$32.8(24,0)$

$86(60,490)$

$82(73,2 \%)$

$36(30600)$

$30(26.8 \%)$

$1=130$

$55(43,7 \%)$

$71(56,3 \%)$

$05(50.8 \%)$

$63(49290)$

$32.7(22.5)$

$03.3(17.9)$

$87(68.0 \%)$

$4132,06)$
$109(83.8 \%)$

$21(102 \%)$ 


\section{RESULTS}

\section{Patient questionnaite}

The response to the patient questionnaire did not differ between regions. In Sittard 378 questionnaires were returned, of which $356(36.2 \%)$ were usable. In Tilburg 371 questionnaires were returned and 360 (36.2\%) were usable. The patient group who had received telephone advice only, had the

Table 2. Patient opinions on different aspects of telephone triage.

\begin{tabular}{|c|c|c|c|c|c|}
\hline \multirow{2}{*}{ (2) } & \multicolumn{2}{|c|}{ Sittard } & \multicolumn{2}{|c|}{ Tiburg } & \multirow[b]{2}{*}{ Sign } \\
\hline & Mean (SD) & $95 \% \mathrm{Cl}$ & Mean (SD) & $95 \% \mathrm{Cl}$ & \\
\hline Telephore advice & $n=109$ & & $n=97$ & & \\
\hline $\begin{array}{l}\text { Accessibility by } \\
\text { phone }\end{array}$ & $763(20.4)$ & $72.4-80.2$ & $68.3(23.6)$ & $63.5-73.1$ & 0.011 \\
\hline $\begin{array}{l}\text { Docter's assistant's } \\
\text { ardinale }\end{array}$ & $75.6(20.3)$ & $71,8-79.5$ & $77.9(17.1)$ & $74,4-81,4$ & 0.395 \\
\hline $\begin{array}{l}\text { Questions askiked by } \\
\text { he assistant. }\end{array}$ & $62.7(24.9)$ & $580-67.5$ & $62.5(23)$ & $57.8-67.2$ & 0.945 \\
\hline $\begin{array}{l}\text { Advice given by } \\
\text { assistant }\end{array}$ & $54.9(25.9)$ & $49.8-6010$ & $62,4(23.8)$ & $57.5-67.2$ & 0.037 \\
\hline $\begin{array}{l}\text { Score for telephone } \\
\text { procedure }\end{array}$ & $7.0(1,75)$ & $67-7.3$ & $6.6(1.98)$ & $6.2-7.0$ & 0.123 \\
\hline $\begin{array}{l}\text { Consultation at (j] } \\
\text { cooperative }\end{array}$ & $n=129$ & & $n=129$ & & \\
\hline $\begin{array}{l}\text { Accessibility by } \\
\text { phone }\end{array}$ & $771(19.8)$ & $73.6-80.5$ & $66.9(228)$ & $62.9-70.9$ & $<0001$ \\
\hline $\begin{array}{l}\text { Doctor's assistant's } \\
\text { attitude }\end{array}$ & $79.1 .17 .6)$ & $76.0-82.2$ & 78.0 .18 .0 & $74.9-81.2$ & 0.648 \\
\hline $\begin{array}{l}\text { Questions asked by } \\
\text { the assistant }\end{array}$ & $60.6(24.9)$ & $56.3-65.0$ & $59.8(25,4)$ & $55,3-64.3$ & 0.788 \\
\hline $\begin{array}{l}\text { Seore for telephone } \\
\text { proce uret }\end{array}$ & $7.2(1.8)$ & $69-7.5$ & $6.4(2.3)$ & $0.0-6.8$ & 0.001 \\
\hline Honge visits: & $\mathrm{n}=116$ & & $n=133$ & C.t? & 20 \\
\hline $\begin{array}{l}\text { Accessibility by } \\
\text { phone. }\end{array}$ & $757(21.8)$ & $71.7-79.7$ & $75.3(21.7)$ & $71.5-790$ & 0.865 \\
\hline $\begin{array}{l}\text { Doctor's assistants } \\
\text { atrifude }\end{array}$ & $779(21.2)$ & $74.0-81.8$ & $79.3(15.3)$ & $76.7-81.9$ & 0.554 \\
\hline $\begin{array}{l}\text { Questions asked by } \\
\text { the assistant }\end{array}$ & $62.1(26.6)$ & $57.1-67.0$ & $54.6(27.3)$ & $49.9-59.3$ & 0.034 \\
\hline $\begin{array}{l}\text { Score for telephone } \\
\text { procedure }\end{array}$ & $7.3(1.2)$ & $7.0-7.7$ & $71(2.0)$ & $6.7-7.4$ & 0.295 \\
\hline
\end{tabular}


lowest response rate of approximately $31 \%$. The response rates of the other groups of patients ranged between $35 \%$ and $40 \%$.

Patient characteristics as presented in Table 1 showed little variation between regions. However, patients who received a home visit appear to be generally older compared to patients who received telephone advice only or who attended the GP cooperative. In general, more women than men contacted the GP cooperatives in both regions.

With respect to patients who received telephone advice only and those who attended the GP cooperative, we found that patients who contacted the Sittard GP cooperative were more satisfied about the accessibility of the cooperative by telephone compared to patients who contacted the Tilburg GP cooperative (with TAS) (Table 2.). Patients receiving telephone advice at the Tilburg GP cooperative, were more satisfied about that advice compared to patients of the Sittard GP cooperative. Patients who attended the Sittard GP cooperative for a consultation were more satisfied about the telephone procedure. Patients who received a home visit of the Sittard GP cooperative were more satisfied about the questions that were asked by the doctor's assistant on the telephone compared to patients of the Tilburg GP cooperative.

\section{GP questionnaite}

Of the 95 questionnaires sent to GPs of the Sittard cooperative 77 were returned, of which 74 could be used. Three GPs said to have returned the questionnaire, however, these were not received by the researcher. Consequently, the corrected response rate is $82 \%$. In the Tilburg region, 84 of the 108 questionnaires were returned. One GP said to have returned the questionnaire, which was, however, not received by the researcher. The corrected response rate in this region is $79 \%$.

Characteristics of GPs of the Sittard GP cooperative, with respect to age, gender, and distribution of part-time and fulltime workers, were comparable to that of GPs of the Tilburg cooperative (Table 3.).

Generally, GPs of both cooperatives are equally satisfied about the specificity of triage. This indicates that they do not see many patients at their own practice who received self-care advice during out-of-hours, while they should have been seen by a GP of the GP cooperative (Table 4.). GPs from both cooperatives were equally dissatisfied about the appropriateness of many patient contacts during out-of-hours.

Although satisfaction scores are low for both GP cooperatives, GPs of the Tilburg GP cooperative were more satisfied about their role as telephone GP compared to their colleagues of the Sittard cooperative. Both 
Table $3.9 \mathrm{P}$

characterisucs:

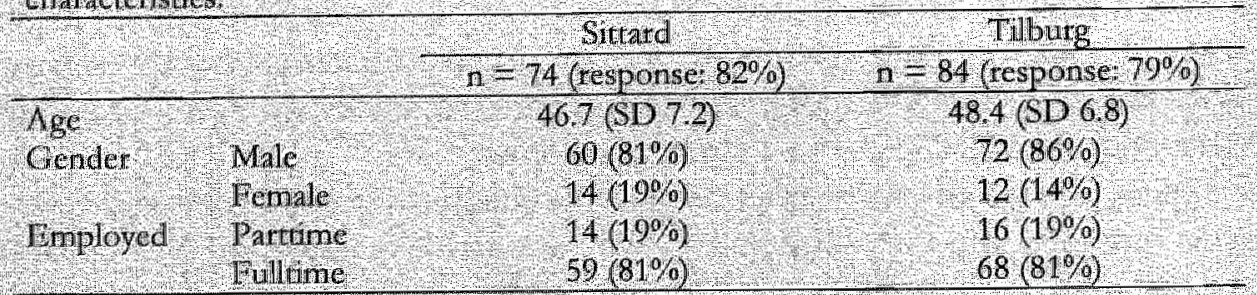

Table 4 . GP's opinions on different aspect related to telephone Hage and wonking at the GP cooperative.

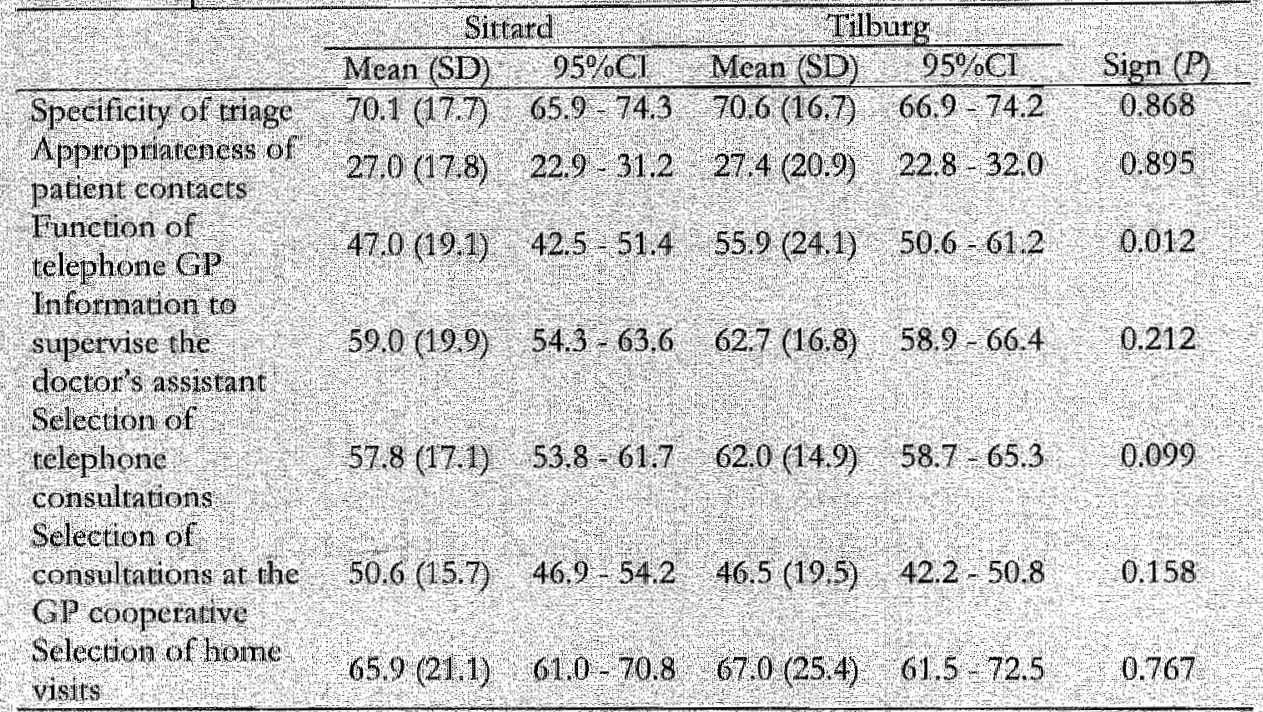

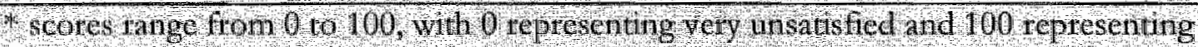
very sansfied doout the related sclle

groups of GPS were equally satisfied about the information they received to supervise the telephone triage process.

GPs of the Sittard GP cooperative and the Tilburg GP cooperative were equally satisfied with the selection of telephone consultations, consultations at the GP cooperative, and home visits. 


\section{DISCUSSION}

This study showed that, regarding the GP cooperative where TAS is used, patients were more satisfied about the telephone advice and less satisfied about waiting times on the phone. GPs of this cooperative were more satisfied about their role as supervisor of the telephone triage and consultation process.

The response rates to the patient questionnaires were relatively low. However, these were low for both cooperatives. Therefore, it is unlikely that this may have caused systematic differences between the study populations of both regions. This assumption is supported by the comparability of patient characteristics of the respondents of both regions. Nevertheless, care should be taken when extrapolating the results to the total population because of possible selection bias.

Patients in our study were more satisfied about the advice given by the assistant at the GP cooperative that uses TAS. Most likely, patients perceived the advice given by the assistant to be of a higher professional standard, because individual items show that the advice has reassured them more, was more helpful, and was found to be sufficient. Although no causal relationship between this finding and the use of TAS can be established, it is reasonable to suggest that the patient opinion on advice is related to the use of standardised advice dictated by TAS. This is in line with previous findings that showed that self-care advice given by doctor's assistants using TAS is more standardised and consistent ${ }^{3}$. Because the use of TAS is more time consuming than telephone triage without computer based decision software, the time per call increases. As a consequence, the Tilburg GP cooperative had to increase the number of personnel performing telephone triage. Considering patient dissatisfaction with the accessibility of the cooperative by phone, this has insufficiently improved waiting times on the phone.

At the cooperative where TAS is used, parients who received a home visit were less satisfied about the number of questions asked during telephone triage. As described before, the triage process with 'TAS generally takes longer because more questions are being asked. In the eyes of the patient many of these questions may seem inappropriate or unnecessary and the patient just wants the doctor to come as soon as possible. Especially, because most of the time this patient group has severe and urgent problems, and expects a home visit as soon as possible.

The GPS in Tilburg are more satisfied about their function as telephone GP. Analysis of the scale's items (see Table 5) showed that this is not so much caused by experienced workload, but just has to do with whether they enjoy their task as telephone GP. Another factor that may play a role but 
which has not been investigated is the GP's confidence in the triage process when TAS is used. However, despite the fact that it is assumed that when using TAS the telephone triage process becomes more transparent and therefore easier to supervise, there is no difference in satisfaction about the information the telephone GP receives about every call to supervise this process.

Surprisingly, we found no differences in GPs' opinions on the selection of telephone consultations, consultations at the GP cooperative, and home visits. We expected on forehand that the use of TAS would lead to a more accurate selection of these consultations. However, the results indicate that GPs are of the opinion that the selection process at both GP cooperatives is not strict enough, especially with regard to selection of consultations at the GP cooperative. This implies that the GPs feel that the triage process at both cooperatives lacks sensitivity. In addition, GPs of both cooperatives were equally satisfied about the specificity of the telephone triage process. Meaning that they believed that many patients correctly receive self-care advice and were not referred for a consultation with a doctor during out-ofhours.

An important effect of computerised decision tools on telephone triage is that it should improve safety and effectiveness of the triage process. This has been addressed by other studies, which have shown that telephone triage using TAS is safe and effective ${ }^{2,3,5,8}$. Nevertheless, results of these studies are also dependent on training, professional level of the person who performs triage, and the setting. Therefore, these results cannot be generalised without restrictions to the Dutch situation. Future research is warranted to investigate the safety and adequacy of telephone triage at Dutch GP cooperatives.

In contrast to many other countries, $2,9.12$, telephone triage in the Netherlands, specifically during out-of-hours primary care, is still in its infancy. Many Durch cooperatives have employed doctor's assistants or nurses to perform this triage, which implies variability in level of education [13]. To increase the structure and adequacy of triage, written protocols and guidelines are available to support the telephone triage process. However, these materials may not be sufficient, because telephone triage is a very complex procedure and requires specific skills ${ }^{14-18}$. Therefore, structured telephone triage supported by computer based decision tools may have great beneficial effects, as it will provide an adequate base to structure and support the telephone triage process. In many other countries where telephone triage and consultation is more established, the use of computer based decision tools is widespread ${ }^{5,19}$. This study did not find many differences in patient and doctor opinions on triage aspects between a GP cooperative that uses computer based decision software and one that uses 
only written protocols and guidelines. However, more aspects have to be investigated to come towards a conclusion on preference of triage system. Nevertheless, there is great potential for the use of computer based decision tools at Dutch GP cooperatives considering the need for increased transparency and adequacy of telephone triage ${ }^{13}$.

In conclusion, patients are more satisfied about the telephone advice they receive when TAS is used. In addition, GPS are more satisfied about their function of telephone GP, but are equally satisfied or dissatisfied about the selection of consultations.

\section{Acknowledgements}

We would like to thank prof. dr. Harry Crebolder for providing helpful comments on drafts of this manuscript. A part of this study was financially supported by TWA Medicinfo BV Tilburg, the Netherlands.

\section{REFERENCES}

1. Leibowitz R, Day S, Dunt D. A systematic review of the effect of different madels of after-hours primary medical care services on clinical outcome, medical workload, and patient and GP satisfaction. Fam Pratt. 2003;20:311-7.

2. Lattimer V, George S, Thompson F, et al. Safety and effectiveness of nurse telephone consultation in out of hours primary care: randomised controlled trial. The South Wiltshire Out of Hours Project (SWOOP) Group. BMJ. 1998;317:1054-9.

3. Dale J, Ctouch R, Lloyd D. Primary care: nurse-led telephone triage and advice out-ofhours. Nurs Stand. 1998;12:41-5.

4. Crouch R, Dale J. Decision support for telephone advice. J Acaid Emerg Med. 1997;14:201-2.

5. Bunn $F$, Byrne $G$, Kendall $S$. Telephone consultation and triage: effects on health care use and patient satisfaction. Cocbrame Database Syst Rev. 2004:CD004180.

6. van Uden CJT, Ament AJHA, Hobma SO, Zwietering PJ, Crebolder HNIM. Patient satisfaction with out-of-hours care in the Netherlands. BMC Healds Serv Res. 2005;5:6.

7. McKinley RK, Manku-Scott 'T, Hastings AM, French DP, Baker. R. Reliability and validity of a new measure of parient satisfaction with out of hours primary medical care in the United Kingdom: development of a patient cuestionnaire. BMJ. 1997;314:193-8.

8. Dale J, Williams S, Foster T, et al. Safety of telephone consultation for "non-serious" emergency ambulance service patients. Q Hal Sof Healh Care. 2004;13:363-73.

9. Nurse telephone-triage. Lawer. 2001;357:323.

10. Fortune T. Telephone triage: an Irish view. Awad Emerg Nurs. 2001;9:152-6.

11. Niemann S, Meer A, Simonin C, Abel T. Medical telephone triage and patient behaviour: How do they compare? Smiss Med Whely. 2004;134:126-31.

12. Turner VF, Bentley PJ, Hodgson SA, et al. Tellephone triage in Western Australia. Med J Akst. 2002;176:100-3.

13. General Practitioner Cooperatives in the Netherlands J Huisarssenposten in Nederland: Inspectie voor de Gerondheidszorg]. The Hague: Health Care Inspectorate; 2003. 
14. Car J, Sheikh A. Telephone consultations. BMJ. 2003;326:966-9.

15. Car J, Ireeman GK, Partridge MR, Shekh A. Improving quality and safety of telephone based dclivery of care teaching telephone consultation skills. Qual Saf Teath Care. 2004;13:2-3.

16. Crouch $\mathrm{R}$, Dale J. Telephone trage-how good ate the decisions? (Part 2). Nowr Stand. $1998 ; 12: 33-9$.

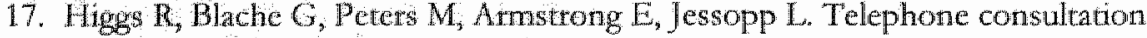
requires approprtate training. BMJ. $2003 ; 327: 53$.

18. Foster Jinessopp L, Dale J. Concerns and confidence of general practitioners in providing telephone consulltations. Br J Gen Prat. 1999;49:111-3.

19. Crouch $\mathrm{R}$, Dale). Telephone triage--identifying the demand (Part 1). Nurs Stand. $1998 ; 12: 33-8$. 
Appendix 1. (Original items are in Dutch*)

Scale 1. Triage (Cronbach's alpha $=0.84$ )

Regularly, I see patients in ny pracrice who received a self-care advice during out-ofhours, while they should have been referted to a GP. ()

Often, $I$ see patients in my own practice who vere only reassured during out-of-hours, while action should have been taken. ()

Regulatly, I see patients in my practice who have not received adequate eare during our of hours because of fincorrect telephone triage. ()

Scale 2. Appropriateness of patient contacts (Cronbach's alpha $=0.69$ )

Many patient contacts during out-of hours are inapproptiate ()

The number of inappropriate patient contacts during out-of hours is a thenet to the quality of care of patients requiring acute primary care ()

Scale 3. Function of telephone GP (Cronbach's alpha $=0.80$ )

It is rice to perform the work of the telephone GP ( $($ )

Regularly, the work of the telephone GP is frastrating ( )

The expenenced workload of the telephone $\mathrm{GP}$ is too high $(\mathrm{)}$

Scale 4. Selection of telephone consultations (Cronibach's alplas $=0.75$ )

The telephone consultations that $I$ receive as a telephone GP are very well selected by the doctor's assistant $(+)$

The assessment of urgency of the telephone consultations is good (t)

The number of calls passed through ly the doctor's assistant to the telephone $G P$, is too muich ()

Scale 5. Information to supervise the doctor's assistant (Cronbach's alpha $=0.78$ )

I sufficiently trust the information given by the doctor's assistants to authorise the call they handled $(+)$

I receive enough information about the eall handled by the doctor's assistant to authorise $(+)$

Scale 6. Selection of consultations at the $\mathbf{G P}$ cooperative (Cronbach's alpha $=0.79$ ) The consultations at the GP cooperative ne very well selccted $(+)$

The urgency of parients' complaints referred to the GP cooperative is well assessed( + ) Too many patients are referred to the GP cooperative for a consultation ()

Scale 7. Selection of home visits (Cronbach's alpha $=0,75$ )

The home visits are very well selected $(+)$

The doctor's assistant otders too many home visits (-)

The urgency of complaints of patients who receive a home visit are well assessed $(+)$

The telephone GP orders too many home visits (-)

Scale 8. Overall satisfaction (Cronbach's alpha $=0.80$ )

I am satisfied about the current arrangements of out of -hours care $(+)$

1 am satisfied abour the organisation and functioning of my GP coneperative $(+)$

* The provistonal translation into English is meant to inform the reader of the content of the scales and cannot be seen as a definite one. 


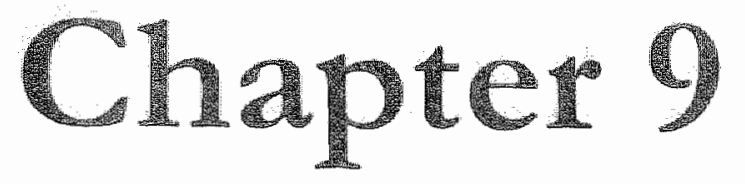

\section{Follow-up care by patient's own general practitioner after contact with out-of-hours care. A descriptive study.}
C.J.T. van Uden ${ }^{1,2}$
P.J. Zwietering ${ }^{2}$
S.O. Hobma ${ }^{2}$
A.I.H.A. Ament ${ }^{3}$
G. Wesseling "4
C.P. van Schayck ${ }^{2}$
H.F.J.M. Crebolder ${ }^{2}$

Submitted for publication

\footnotetext{
Deparment of Integrated Cate, Unwersigy Hospital Mastrich

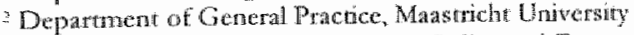

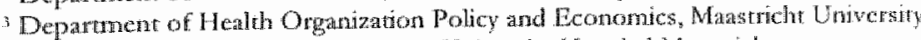

"Deparment of Resplatrony Diseases, Lniversity Hospital Magatricht
} 


\section{ABSTRACT}

Background: Little is known about the care process after patients have contacted the GP cooperative for out-of-hours care. The objective of this study was to determine the dimension of follow-up care after contact with a GP cooperative for out-of-hours care, and to gain insight into factors that are related to this follow-up care.

Methods: 2805 patients who contacted a GP cooperative for out-ofhours care were sent a questionnaire. They were asked whether they had attended their own GP within a week after their contact with the cooperative, and for what reason. To investigate whether other variables are related to follow-up care, a logistic regression analysis was applied. Variables that were entered in this analysis were patient characteristics (age, gender, etc.) and patient opinion on correctness of diagnosis, urgency and severity of the medical complaint.

Results: The response rate was $42 \%$. In total, $48 \%$ of the patients received follow-up care with their own GP. Only $20 \%$ was referred or advised to attend their own GP. Others attended because their medical condition worsened or because they were concerned about their complaint. Variables that predicted follow-up care were the patient's opinion on the correctness of the diagnosis, patient's health insurance, and severity of the medical problem.

Conclusion: Almost half of all patients in this study who contacted the GP cooperative for out-of-hours care attended their own GP during office hours within a week for the same medical complaint. Most important factor that predicted follow-up care at the patient's own GP after an out-of-hours contact was the patient's degree of confidence with the diagnosis established at the GP cooperative. Despite the limited generalisability, this study is a first step in providing insight into the dimension of follow-up care after a patient has contacted the GP cooperative for out-of-hours primary care. 


\section{INTRODUCTION}

During the last decade, out-of-hours primary care in the Netherlands has been reorganized from practice-based services to large-scale general practitioner (GP) cooperatives ${ }^{1}$. Currently, over $90 \%$ of the Dutch population is covered by more than $120 \mathrm{GP}$ cooperatives for out-of-hours primary care. The initiative for this reorganization has come mainly from the medical profession itself. Research has shown that similar reorganisations had beneficial effects in other countries like the UK and Denmark; GPs' satisfaction with out-of-hours services increased and the number of hours the GP has to be on call dropped substantially ${ }^{2}$. Also patients seem to be fairly satisfied with out-of-hours primary care delivered by GP cooperatives. However, patients seem to be less satisfied when receiving telephone advice only ${ }^{3-5}$.

GP cooperatives, being a new type of organisation in Dutch health care, are initiated to enhance the efficiency of current care provision. Besides the increased satisfaction of GPs, a further improvement of the efficiency may well be possible. Research into utilisation of out-of-hours services and patient flow can generate relevant insight into functioning of out-of-hours care organisations. Insight into how many patients utilise out-of-hours services, what type of consultation they receive, and which care process follows their contact with the GP cooperative can supply information about the efficiency of the out-of-hours care organisation. Utilisation of out-ofhours services and the type of consultations patients receive have been regularly investigated ${ }^{2}$. However, little is known about the care process after patients have contacted the GP cooperative for out-of-hours care. Only a few studies have included analyses on demand of follow-up care at the patient's own GP's practice, but show wide variability in numbers and outof-hours care settings. Mckinley et al. "found that $54 \%$ of all patients who received telephone advice only during out-of-hours provided by patients" own GP or by commercial deputising services, attended theit own GP during office hours with the same problem within two weeks after their outof-hours contact. For patients who received a home visit this proportion was $45 \%$. Two studies on GPs working at a hospital's emergency department reported that 22 to $26 \%$ of the patients went to theit own GP within three months after their contact with the GP at the emergency department ${ }^{7.8}$. Neither one of these studies, which used patient reports, do give insight into how many of these patients were advised to see their own GP for follow-up care, or attended at their own initiative. A study by Shipman et al. showed that GPS working out-of-hours in a practice-based setting referred about $17 \%$ of all patients to the patient's own GP the next day. This leaves unknown how many attended at their own initiative. 
The purpose of this study is to determine the dimension of follow-up care after contact with a GP cooperative for out-of-hours care, and to gain insight into factors that are related to this follow-up care.

\section{METHODS}

The study was conducted in the province of Limburg in the south of the Netherlands. In this province there are seven GP cooperatives operational, which cover a population of about 1.1 million. (Total population of the Netherlands is approximately 16 million.) From March to June 2003, 2805 patients from these seven GP cooperatives were sent a questionnaire within three weeks after they had been in contact with the GP cooperative. Of these 2805 questionnaires 935 were sent to patients who received telephone advice only, 935 to patients who attended the GP cooperative, and 935 to those who received a home visit. This study was part of a larger study on patient satisfaction with out-of-hours primary care. The study was approved by the institutional medical ethics board of the University Hospital Mastricht.

Patients were asked to report whether they had attended their own GP within a week after their contact with the GP cooperative for out-of-hours care for the same medical complaint. They were also asked about their reasons for this attendance.

To investigate whether other variables could predict follow-up care we also collected information on patient's age and gender, patient's education level (low, medium, high), and health insurances. Health insurance was used as a measure of the patient's socio-economic status: people with an income below a certain amount (some $60 \%$ of the population) are compulsorily insured under a public scheme (the Health Insurance Fund). Everyone else has to take out private insurance. Other variables that were collected included: whether the patient thought the diagnosis made by the GP of the cooperative was correct, urgency and severity of the medical complaint (as judged by the patient), patient's concern about his medical condition, whether the patient received the type of consultation (telephone advice, consultation at the GP cooperative, home visit) he or she expected, and the patient's opinion on performance of the GP cooperative on a 10-point scale $(1=$ very poor and $10=$ very good $)$. 


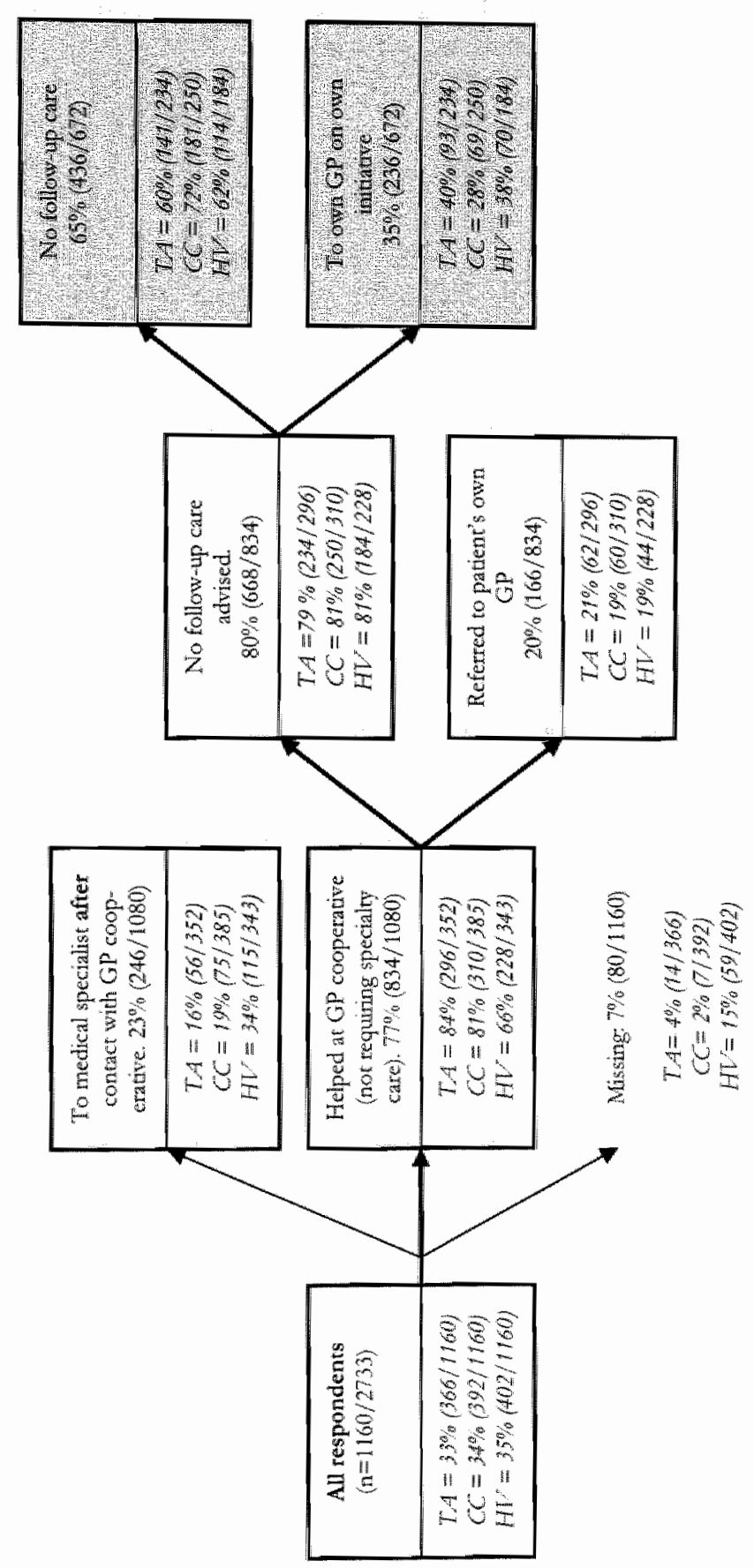

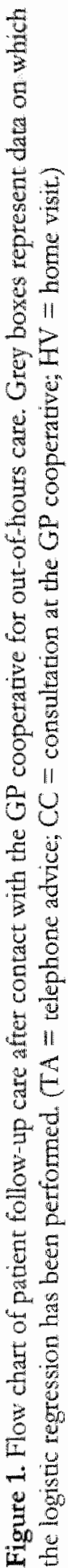




\section{Statistics}

Descriptive statistics were applied to gain insight into the extent and patients' reasons of follow-up care after contact with the GP cooperative. We performed logistic regression analysis to determine any other factors related to follow-up care. All other variables except for the patient's reason for attendance were entered in the analysis. Variables that did not significantly contribute $(P>0.10)$ to the predictive model were excluded by backward deletion. Patients included in the logistic regression analysis had either not attended their own GP, or had attended their own GP within a week but were not referred or advised to attend their own GP by the GP or doctor's assistant of the GP cooperative.

Table 1. Reaisons grven by patients for seeking follow ry 1 care with theit own general ptactitioner after their contact with the GP cooperalue for out of hours cate.

\begin{tabular}{|c|c|c|c|c|}
\hline & $\begin{array}{l}\text { Telephone } \\
\text { advice }\end{array}$ & $\begin{array}{l}\text { Consultation } \\
\text { at the (G) } \\
\text { copperatre }\end{array}$ & Home visis & Total \\
\hline & $1 \mathrm{n}(\%)$ & $n(\%)$ & $n(0)$ & $\mathrm{A}(\%)$ \\
\hline Referred or adnised by G'P & $62(10.1)$ & $60(46.5)$ & $44(38.6)$ & $166(41.7)$ \\
\hline Worsening of eomplaiti & $38(24.5)$ & $30(23,3)$ & $23(20,2)$ & $91(22.9)$ \\
\hline Wrong advice or trealment & $41(71)$ & $6(4.7)$ & $3(2.6)$ & $20(5.0)$ \\
\hline Worred & $26(16.8)$ & $15(11.6)$ & $26(22.8)$ & $67(16.8)$ \\
\hline Orher reasons & $18(11.6)$ & $18(14,0)$ & $18(15.8)$ & $54(13.6)$ \\
\hline Total & $155(1000)$ & $129(100,9)$ & $114(1000)$ & $398(1000)$ \\
\hline
\end{tabular}

\section{RESULTS}

Seventy-two of the 2805 questionnaires were excluded, either because they could not be delivered (patient had moved or had given a false address), the patient had died, or the patient was sent more than one questionnaire (in case of multiple contacts). Eventually the response was $42.4 \%$ (1160/2733). Of this group, 834 patients reported to have been helped by the GP or the doctor's assistant of the GP cooperative and did not receive care by a medical specialist at the hospital's emergency department (see figure 1). In total, $48.2 \%(166+236 / 834)$ of these patients reported to have attended their own GP within a week after their contact with the GP cooperative with the same medical problem. 19.9\% (166/834) attended their own GP on advice of the GP or doctor's assistant of the GP cooperative. About one-third of all patients not referred or advised to attend their own GP, still went to see their own GP within a week after their contact with the cooperative at their own initiative. 
Table 2. Varables related to not-advised follow- up care wiht the parien's own (i)

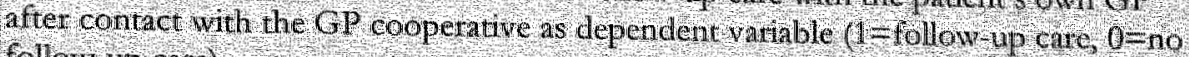
(ollow-ub crie)

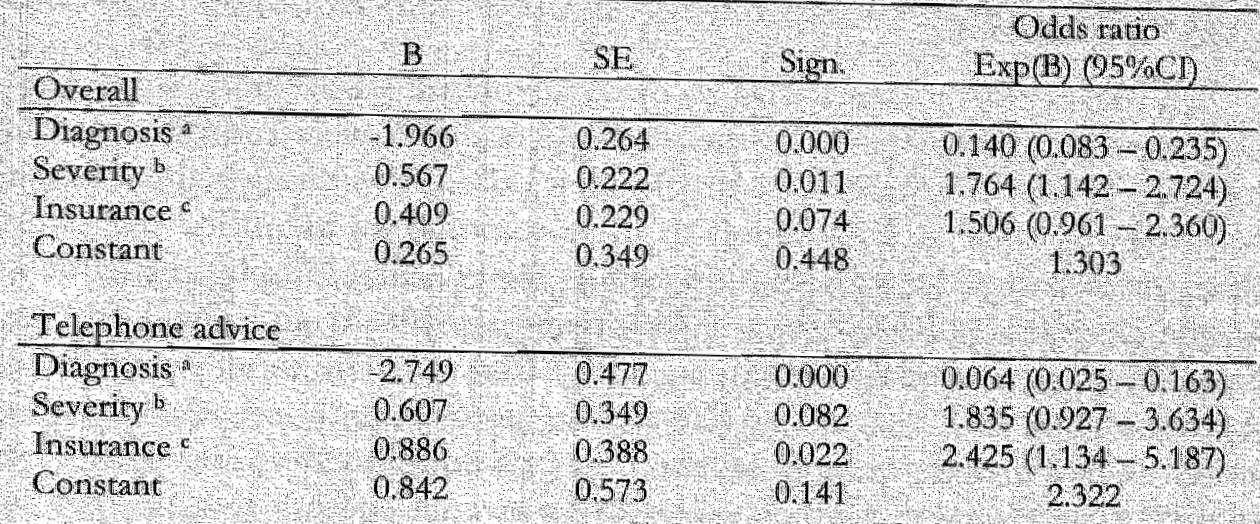

Consultation at the GP cooperative

\begin{tabular}{lcccc}
\hline Diagnosis a & 2.075 & 0.484 & 0.000 & $0.126(0.049-0.324)$ \\
Wormied d & 1.073 & 0.520 & 0.039 & $2.925(1056-8.100)$ \\
Constant & -0.083 & 0.651 & 0.899 & 0.920
\end{tabular}

Home visits

Diagnosis: $1=$ nght, $0=$ wrong

Berrentr. 1 - severe, 0 - not severe.

CInsurance: 1 = public insiuance, $0=$ prikate insurance.

d Wortied, $=$ wotned about own nedical complaht, $0=$ not wortied.

\section{Overall}

Of those patients who were not advised or referred to see their own GP within a week for the same problem but attended their own GP anyway, many of them reported that they had contacted their own GP because of worsening of their medical condition $(23 \%)$ or because they were worried about their complaint (17\%) (see "Table 1). In only frve percent of the cases, patients reported that wrong advice or treatment was the reason for them to attend their own GP after their contact with the GP cooperative.

Besides these reasons, we identified three other variables to predict follow-up care: the patient's opinion on the correctness of the diagnosis, the severity of the medical problem as judged by the patient, and the patient's health insurance (Table 2). The model with these three variables was more effective in predicting those who did not attend their own GP within a week: $94.0 \%$ of non-attenders and $32.7 \%$ of attenders were correctly 
predicted, with an overall success rate of $72.8 \%$. The variance in attendance accounted for overall was $13 \%$ (Cox and Snell test $R^{2}=0.13$ ).

\section{Telephone advice}

With respect to patients who teceived telephone advice only, worsening of complaint and worry about the medical condition were most frequently reported reasons for patients to attend their own GP without being advised or referred (Table 1). In addition to these reasons, we identified the same three variables to predict follow-up care as for the total sample: correctness of the diagnosis, the severity of the medical problem as judged by the patient, and the patient's health insurance (Table 2). The model with these three variables was also more effective in predicting those who did not attend their own GP within a week: $95.0 \%$ of non-attenders and $47.2 \%$ of attenders were correctly predicted, with an overall success rate of $74.5 \%$. The variance in attendance accounted for overall was $26 \%$ (Cox and Snell test $\mathrm{R}^{2}=0.26$ ).

\section{Consultation at the GP cooperative}

With respect to patients who went to the GP cooperative for consultation, again worsening of complaint and worry about the patient's medical condition were reported as most important reasons to attend the patient's own GP, without being advised or referted. Besides these reasons, we identified two variables to predict follow-up care: correctness of the diagnosis, and the patient's concern about his or her medical problem (Table 2). The model with these two variables was more effective in predicting those who did not attend their own GP within a week: $96.4 \%$ of non-attenders and $25.0 \%$ of attenders were correctly predicted, with an overall success rate of $76.8 \%$. However, the variance in attendance accounted for overall was small (Cox and Snell test $\mathrm{R}^{2}=0.11$ ).

\section{Home visits}

Like patients who received telephone advice only or visited the GP cooperative for consultation, patients who received a home visit reported that worry about their medical problem and worsening of the complaint were the main reasons for them to contact their own GP within a week after their contact with the GP cooperative. Only 3 patients $(2.7 \%)$ said to have attended their own GP within a week because they believed to have received incorrect advice or treatment by the home visiting GP of the GP cooperative. 
We also investigated other vatiables and their relationship with follow-up care, but none of the variables entered in the logistic regression analysis was able to predict whether the patient did or did not attend his or her own GP within one week after they had been visited by the GP of the cooperative at home.

\section{DISCUSSION}

This study showed that almost half of all respondents received follow-up care at their own GP's practice, within a week, for the same medical complaint for which they had contacted the GP cooperative. Although a substantial number of these patients $(40 \%)$ were referred or advised by the cooperative's GPS or doctor's assistants to do so, about $60 \%$ of these patients attended their own GP at their own initiative.

According to the Statistics Netherlands Database over the last four years, about $27 \%$ of all patients require follow-up care after they have seen their GP for a medical complaint ${ }^{10}$. The fact that in this study substantially more patients received follow-up care can be explained by several factors. First, the medical complaints presented during out-of-hours may be more severe compared to during office hours, and therefore require follow-up care more often. Second, the GP cooperative focuses mainly on medical complaints that cannot wait until the next day, all other non-urgent disorders are often referred to the patient's own GP the next day. Third, patients may not feel fully confident or are not fully satisfied with the way their complaint has been taken care of and want to check this with their own GP. Since we have not compared the situation during office hours with outside office hours, it remains uncleat which of these factors contributes the most to the difference in numbers of follow-up care.

In addition to the fact that patients have repotred to attend their own GP at their own initiative mainly because their medical condition worsened or that they were worried, we found that generally three other vatiables were related to follow-up care. The most important variable was whether the patient believed that the correct diagnosis has been made by the cooperative's GP or doctor's assistant. However, this variable might have been biased when the patient's own GP made another diagnosis than either the cooperative's GP or doctor's assistant, since patients may have more confidence in their own GP than in an unknown GP or doctor's assistant. We also found that health insurance was a predictor of follow-up care without referral. This may be explained by the fact that privately insured patients may not be fully reimbursed for these consultations. This implies some kind of financial incentive. In addition, research has shown that 
patients with lower socio-economic status more frequently attend their $G P^{11}$, which is in line with out findings.

For those who received a home visit, no model could be established that predicts follow-up care at the patient's own GP cooperative. We found that the correctness of the diagnosis as judged by the patient was a strong predictor for follow-up care regarding patients who received telephone advice only, or attended the GP cooperative. However, many patients who received home visits will already have a known diagnosis, which may give this variable limited predictive value in this patient category. Furthermore, in patients who received a home visit the patient's own GP may often take the initiative to visit the patient, possibly because of the severity of the complaint or co-morbidity, instead of the patient taking the initiative to contact the GP. Patients receiving home visits often suffer from more severe conditions and are significantly older than those helped by telephone advice and those who visited the GP cooperative. Also these two factors may give some explanation for not finding a model to predict re-attendance, because it is known that elderly people more frequently contact the GP and that the GP routinelly visits the patient to check on his or her condition.

An important limitation of the study is that the response rate to the questionnaire was only $42.4 \%$. Therefore, care should be taken with generalising these results to all patient contacts with GP cooperatives. It could be that the number of patients seeking follow-up care in this study has been overestimated or underestimated. However, the proportion of patients who went to their own GP for the same complaint was similar to that reported in the literature $e^{6}$. In addition, the number of parients who attended their own GP for the same medical complaint on advice of the cooperative's GP or doctor's assistant reported in this study $(19 \%)$, was fairly similar to that reported by Shipman et al. $(17 \%)$. In addition, this study did not provide insight into appropriateness of follow-up care, but is merely a first step in revealing the extent of follow-up care after contact with a GP cooperative. Therefore, it remains unclear whether the extent of follow-up care by the patient's own GP is appropriate or represents inefficient care. Future research is warranted to confirm our study findings and to investigate the appropriateness of follow-up care.

\section{CONCLUSIONS}

This study is a first step in providing insight into the dimension of follow-up care after a patient has contacted the GP cooperative for out-ofhours primary care. We showed that about half of all respondents who were helped at the GP cooperative attended their own GP for the same medical 
problem within a week. Onily a minority of the patients was referred or advised to do so. With respect to those that attended their own GP for the same problem on their own initiative, the perception that the correct diagnosis had been made at the GP cooperative was a strong predictor of non-attendance.

\section{REFERENCES}

1. Van Uden CJT, Winkens RAG, Wesseling GJ, Crebolder HFJM, Van Schayck CP. Use of out of hours services: a comparison between two organisations. Emerg Med J. $2003 ; 20: 184-7$.

2. Leibowitz $R$, Day $S$, Dunt D. A systematic review of the effect of different models of after-hours primary medical care services on clinical outcome, medical workload, and patient and GP satisfaction. Fam Pract. 2003;20:311-7.

3. Pickin DM, O'Cathain A, Fall M, Morgan AB, Howe A, Nicholl JP. The impact of a general practice co-operative on accident and emergency services, patient satisfaction and GP satisfaction. Fam Pract. 2004;21:180-2.

4. Salisbury C. Postal survey of patients' satisfaction with a general practice out of hours cooperative. BMJ 1997;314:1594-8.

5. Shipman C, Payne F, Hooper R, Dale J. Patient satisfaction with out-of-hours services; how do GP co-operatives compare with deputizing and practice-based arangements? Public Health Med. 2000;22:149-54.

6. McKinley RK, Cragg DK, Hastings AM, et al. Compatison of out of hours cate provided by patients" own general practitioners and commercial deputising services: a randomised controlled trial. II: The outcome of care. BMJ. 1997;314:190-3.

7. Dale J, Lang $H$, Roberts ]A, Green J, Glucksman E. Cost effectiveness of treating primary care patients in accident and emergency: a comparison between general practitioners, senior house officers, and registrars. BM]. 1996;312:1340-4.

8. Murphy AW, Bury G, Plunkett PK, et al. Randonised controlled trial of general practitioner versus usual medical care in an urban accident and emergency department: process, outcome, and comparative cost. BM]. 1996:312:1135-42.

9. Shipman $C$, Dale J. Responding to out of hours demand: the extent and nature of urgent need. Fam Pract. 1999;16:23-7.

10. Statine. Statistics Nerherlands. Avatlable at: htep://www clos nl/en/. Accessed July 19, 2004.

11. Kolk AM, Hanewald GJ, Schagen S, Gjisbers van Wijk CM. Predicting medically unexplained physical symptoms and health care urilizacion. A symptomp perception approach. I Psychosom Res. 2002;52:35 4.4. 
Chapter 10

General discussion 


\section{INTRODUCTION}

In the Netherlands, general practice out-of-hours care has been reorganised from small-scale practice rotas to large-scale general practitioner (GP) cooperatives. This reorganisation was an answer to the high workload and growing demand during out-of-hours ${ }^{1-6}$. Nowadays, many differences exist between these GP cooperatives. The objectives of the studies reported in this thesis were to determine the effect of the reorganisation of general practice out-of-hours care on care utilisation and to gain insight in the influence of different models and aspects of out-of-hours care on care utilisation, patient and doctor satisfaction, and costs.

In this thesis a distinction is made between two types of organisational structures of general practice out-of-hours care; integrated and separated out-of-hours care. The integrated system is where the GP cooperative works in close collaboration with the hospital emergency department (ED) and both facilities are joined into one facility. Although integration on all aspects may not be fully accomplished, the term 'integrated system' represents the essence of this type of organisation the best. Separated outof-hours care is where the GP cooperative works independently from the hospital ED, but may have some agreements on referring patients to one another. Often the GP cooperative is located at some distance from the hospital ED.

The findings reported in the individual chapters are summarised below. Subsequently, conclusions derived from the study findings on different aspects of general practice out-of-hours care are given, after which methodological strengths and weaknesses of the research presented in this thesis are discussed. The chapter ends with implications for health care professionals and policy makers, and recommendations for further research.

\section{SUMMARY OF FINDINGS}

Chapter 2 presents the consequences of reorganising out-of-hours primaty care from practice rotas to a GP cooperative integrated with the hospital emergency department (ED) on care utilisation in the city of Maastricht. In a before-after study we analysed all patient contacts during out-of-hours during two three-week periods. The results of the study show that after the set up of the GP cooperative the number of patients attending the ED was substantially reduced (minus $53 \%$ ), but the number of patients contacting a GP during out-of-hours was increased (plus 25\%). The shift in parient flow was mainly caused by patients with musculoskeletal disorders or skin problems. 
In chapter 3 the results of a study on differences in care utilisation and patient characteristics between two models of out-of-hours cate is presented. In this study a compatison was made between a model in which the GP cooperative was separate from the hospital ED and the mode described in chapter 2. We found that the integrated GP cooperative had more patient contacts during out-of-hours (279/1000/year) and less patient contacts at the ED (52/1000/year) compared with the separated model $(238 / 1000 /$ year and $(66 / 1000 /$ year $)$ respectively). However, the contact rate at the ED was not found to differ significantly between the rwo models. Moreover, relatively more patients attended the integtated GP cooperative for a consultation and less received telephone advice only, compared with the separated GP cooperative. About $50 \%$ of all patient contacts at the ED in the separated model during out-of-hours was still selfreferred.

In chapter 4 we investigated the costs of the two GP cooperatives that were presented in chapter 3 . We used annual accounts to assess costs of these GP cooperatives. The results of the study show that the integrated GP cooperative is $9 \%$ more expensive, but also has $8 \%$ more patient contacts. The differences in costs are probably mainly due to a scale advantage (arger population) of the separated GP cooperative. In addition, the substantial reduction of patient contacts at the ED as presented in chapter 2 , had litle effect on the costs of the ED itself, because staffing of the ED rematred the same. Nevertheless, production at this department was dectersed, and as a consequence the health insurer reduced the hospital's budget

Besides information on costs and care utilisation, we also investigated GPs' satisfaction with out-of-hours primary care, which is presented in chapter 5. This study was conducted at the same GP cooperatives of chapter 3 and 4. A telephone cuestionnaire was administered to a tandom sample of 100 GPs; 50 GPs per GP cooperative. We found that GPs were generally satisfied with the way out-of-hours care was organised, although GPs of the separated GP cooperative appeared to be more satisfied than their colleagues of the integrated GP cooperative. Moreover, satisfaction with out-of-hours care organisation was related to opinions on workload, guarantee of gatekeeper function, and attitude towards out-of-hours care as being an essential part of general practice.

Chapter 6 presents findings of a study on the effect of opening GP cooperatives separate from hospital EDs on care utilisation. This study was conducted at three regions during a four-week period before and a fourweek period after the set up of all three GP cooperatives. Data was collected on use of primary care and hospital emergency services during out-of-hours. The study results show an increase of out-of-hours primary 
care use of approximately $10 \%$, and a decrease in patient contacts with hospital emergency services of $9 \%$.

In 2003, we investigated patient satisfaction with out-of-hours primary care in the province of Limburg. The results of this study are presented in chapter 7. A self-developed questionnaire was distributed to 2805 patients, within three weeks after they had contacted the GP cooperative during outof-hours. One-third of the questionnaires were sent to patients who had received telephone advice only, one-third to patients who attended the GP cooperative for a consultation, and one-third to patients who received a home visit. Patients appeared to be generally satisfied with out-of-hours primary care, although patients who received telephone advice only were less satisfied. Patient satisfaction with out-of-hours care was related to the doctor's assistant's attitude on the phone, opinion on GP's treatment, and waiting time.

Chapter 8 reports on patient and GP opinions on telephone triage at two GP cooperatives. At one of these two GP cooperatives, telephone triage is supported with a computer based decision support tool (TAS), and at the other only written protocols and guidelines are used. The same patient satisfaction questionnaire was used as presented in chapter 7 . With respect to GPs, a new questionnaire was developed. The results indicate that patients who contacted the GP cooperative that uses TAS are more satisfied about the telephone advice they received. According to GPs, the selection of telephone consultations, consultations at the GP cooperative, and home visits is equally as good at both GP cooperatives. However, GPs are the least satisfied with the selection of consultations at the GP cooperative. GPs of both cooperatives are of the opinion to have sufficient information available to authorise and supervise telephone triage.

In chapter 9 we present a study on the extent of follow-up care by the patient's own GP after contact with a GP cooperative for out-of-hours care. We investigated how many patients attended their own GP within a week after they had contacted the GP cooperative, and for what reasons. Moteover, we also studied other variables that may be related to this followup visit. Forty-eight percent of the respondents reported to have attended their own GP after contacting the GP cooperative. Only $20 \%$ was referred or advised to attend their GP. Others attended because their medical condition worsened or because they were concerned about their complaint. Variables that predicted follow-up care were the patient's opinion on the correctness of the diagnosis, patient's health insurance, and severity of the medical problem. 


\section{METHODOLOGICAL CONSIDERATIONS}

The type of research as presented in this thesis has inevitably the burden of methodological limitations because of the very dynamic field in which it has to perform. Unlike, for example laboratory studies where research is conducted under well controlled conditions, the field of health services research is often confronted with changing circumstances and other influencing factors that cannot be eliminated in order to prevent confounding. Nevertheless, thoroughly investigating these circumstances and factors will provide researchers with sufficient knowledge on possible confounders, and enables them to judge the results in the light of these confounding factors.

The studies in this thesis were conducted while Dutch out-of-hours care was in the middle of its reorganisation. Only few GP cooperatives were already operational for some time, while many were still starting up. At the start of the study the GP cooperative in Maastricht was the only one in the Netherlands that had integrated the GP cooperative with the local hospital ED. The GP cooperative in Heerlen was the only other cooperative in the province of Limburg. Considering the circumstances, we chose to make comparisons between these two organisations as representations of integrated and separated out-of-hours care. Also in chapter 8 we studied only two cooperatives, one that uses a computer based decision tool to support telephone triage and one that uses written protocols and guidelines. A limitation of studying only two cooperatives is that they presumably do not exactly represent other GP cooperatives in the Netherlands. In addition, many other factors may be of influence on the outcomes of this study, for example the number of EDs open to the public and the composition of the population (rural versus urban). The question is whether the results from these studies can be generalised to other regions in the Netherlands, or are the GP cooperatives and circumstances so region specific that they hinder extrapolation of results. With knowledge about the region, the health care organisations, and the circumstances during and preceding the study, we are convinced that the results are sufficiently valid to represent the consequences of the organisation of out-of-hours care. Although the results in this thesis may not be literally translated into other regions in the Netherlands, they provide a good enough understanding of the effects of differences in organisation of out-of-hours care on different aspects as investigated in this thesis.

Another limitation of some of the thesis' studies is the low response rate on the patient questionnaires. Low response rates make it difficult to 
extrapolate study findings to other health care settings, because of uncertainty about the validity of the results.

Nevertheless, the patient satisfaction study showed that non-respondents were not different from the respondents. In addition, in the study on opinions on telephone triage a comparison was made between two patient groups and response rates were low for both settings. Also patient characteristics were similar. In contrast, the validity of the study's results presented in chapter 9 is threatened by the low response rate. Studies have shown that prevalence or incidence of medical conditions based on questionnaite research with low response rates is often misrepresented ${ }^{7}$. In this case where information on prevalence of follow-up care visits at the patient's own GP is gathered, it is unknown whether an underestimation, overestimation or the correct estimation has been made. A fact that supports the validity of our findings is that similar contact rates after out-ofhour care contacts with the patient's own GP have been found previously ${ }^{8}$. More research is needed to confirm our study findings.

The relevance of the results of studies on satisfaction or opinions is most often only tempotary. In turbulent times such as during the reorganisation of out of-hours primary care, not all circumstances may be perfect at a certain point in time. Satisfaction or opinions will easily be influenced by these imperfect local circumstances, despite that improvements may lie ahead which will not be accounted for at that moment. The tenability of the results of these studies wil therefore often be short; circumstances may have changed after the study has been conducted, and consequently do not really apply anymore. Nonetheless, this type of research supplies a good indication of people's opinions about aspects of care and quality of care at a given point in time. The results will supply health cate professionals and policy makers with valuable information that will help them to improve and develop (out-of-hours) care.

\section{CONCLUSIONS}

General practice out-of-hours care has been rapidly reorganised. This reorganisation was not so much directed by scientific knowledge about advantages and disadvantages of different models of out-of-hours care, but predominantly by local preferences. This has led to a diversity of out-ofhours care models in the Netherlands. Nevertheless, this enabled us to investigate the advantages and disadvantages of these different models on various aspects of out-of-hours care, such as utilisation of care, patient and GP satisfaction, costs, and telephone triage. 
From the study findings we conclude that setting up GP cooperatives has caused a small but significant shift from patients using hospital emergency care to patients using primary care during out-of-hours. However, when the GP cooperative is integrated with the ED, a more substantial reduction of patients utilising hospital emergency care is established. It seems that costs of general practice out-of-hours care are dominated by the size of the cooperatives population, and not so much by the organisational structure, i.e. integrated versus separated. Nevertheless, costs may be saved when the GP cooperative is integrated with the ED, because of reduced use of the ED.

Patients appear to be generally satisfied with out-of-hours primary care as organised in GP cooperatives, although some issues have been raised that are open to improvement. In addition, GPs are satisfied with the current organisation of out-of-hours cate, and prefer this organisation more than the former one.

It seems that patients and GPs do not perceive many differences in computer based telephone triage or telephone triage with protocols. However, more research has to be conducted to investigate the safety of either one of these triage systems.

GP cooperatives have been set up to enhance efficiency of out-of-hours primary care. Nevertheless, results from this thesis suggest some kind of inefficiency considering that half of all patients attend their own GP within a week after contact with the GP cooperative. More research is needed to confirm these findings.

\section{RECOMMENDATIONS FOR POLICY}

\section{GATEKEEPER AND INTEGRATION}

There has been much debate on the advantages and disadvantages of the role of the GP as gatekeeper to secondary care, nationally and internationally ${ }^{9-31}$. In Europe, twelve countries (Croatia, Denmark, Iceland, Ireland, Israel, Italy, the Netherlands, Norway, Portugal, Slovenia, Spain and the UK) have developed a health care system in which the GP acts as a gatekeeper and largely controls referrals to secondary care ${ }^{32}$. In the United States of America, about $40 \%$ of the population has a primary care physician who acts as a gatekeeper to specialist care ${ }^{26}$.

Evidence of the effectiveness of primary care gatekeeping is scarce ${ }^{33}$. Ferris et al. ${ }^{34}$ found little evidence of beneficial effects of GP gatekeeping on use of secondary care. Moreover, Feldman et $\mathrm{al}^{15}$. showed that the gatekeeper model was inefficient with respect to dermatological services. In 
contrast, other studies showed more clear positive effects of primary care gatekeeping with respect to referrals to specialty care ${ }^{35,36}$. Also, not all primary care physicians seem to be in favor of gatekeeping. However, some believe gatekeeping improves their role as care coordinator ${ }^{22}$.

Economically, on the other hand, primary care gatekeeping seems to be beneficial. In 1998, European countries with gatekeeping systems spent less on healthcare as a percentage of their gross national product than those allowing direct access to specialists ${ }^{37}$. Moreover, Delnoij et al. ${ }^{38}$ suggested that the introduction of gatekeeping in a health care system is likely to reduce health care costs.

The primary goal of GP gatekeeping should be to supply adequate care to patients at the right time at the tight place. The results of these studies show that the success of the gatekeeper function during out-of-hours is very much dependent on the organisation of out-of-hours care. Usually, in a GP gatekeeping system patients requite a GP's referral to utilise hospital services $^{39}$. However, all gatekeeping systems make an exception for emergencies that can be presented directly to the hospital $E D^{40}$. This is a major leakage of gatekeeping systems, especially during out-of-hours, when GP services are less available in some countries ${ }^{39,41}$. Several studies have indicated that a substantial number of patients attending the ED (ranging from $17 \%$ to $57 \%$ ) should actually have been seen in a primary care setting ${ }^{42-45}$. In addition, it may be difficult for medical staff at the ED to send non-urgent cases away without providing attention. Keeping the GP cooperative separated from the $\mathbb{E D}$ is unlikely to resolve this problem ${ }^{46}$. Reasons for skipping the GP cited most frequently by patients are convenience, lack of timely access to primary care providers, the belief that the medical complaint was very urgent, and the belief that radiography is necessary ${ }^{46-48}$. It seems therefore essential to combine these two out-ofhours care facilities at one single site.

Based on the study findings and the existing literature it is recommended to re-enforce the GP gatekeeper function during out-of-hours. This is best accomplished when GP cooperatives and hospital EDs are joined into one facillity, where the GP could be the first person of contact. In that case, the GP decides whether the patient can be treated in primary care or that a referral to specialty care is appropriate. However, this task of selecting patients for primary or hospital emergency care may in the future be substituted to other health care professionals, such as specialised triage nurses.

The positive result of diverting primary care patients away from the hospital ED towards out-of-hours general practice, indicating adequate care at the right place, deserves to be copied in other regions. Not only may this lead to cost savings as suggested in chapter 2 and 4, but also supplies 
patients with clarity about which facility to attend in case of a medical problem during out-of-hours. At this facility the patient is directly at the right place, no matter the urgency of the complaint. As suggested in chapter 4 , it may be more cost efficient to combine management of the $E D$ and $G P$ cooperative, and to deploy nurses of the ED at the GP cooperative to support GPs in treating non-urgent medical problems.

Additionally, the close collaboration between the ED and the GP cooperative will also enhance cooperation between individual health care providers. This will enable them to exchange expertise and to gain knowledge of each other's working methods. Knowledge about each others working methods has been suggested to enhance efficiency of care ${ }^{49}$. However, it does not seem preferable to exchange working methods, for they are believed to be complementary ${ }^{50}$.

\section{TELEPHONE TRIAGE}

Telephone triage is an aspect of out-of-hours primary care with great potential. In contrast to many other countries ${ }^{51-56}$, telephone triage in the Netherlands, specifically during out-of-hours primary care, is still underdeveloped. As shown by several studies, including one in this thesis, patients seem to be less satisfied when receiving telephone advice only ${ }^{57-61}$. However in times of increased demands and increased distances to health care providers, telephone consultation may serve as an adequate alternative in many cases. Because telephone triage is still relatively new in the Netherlands, effort has to be put in developing safe and adequate telephone triage systems. For that matter, it is essential to set standards or criteria for those professionals that perform telephone triage. Moreovet, a specific educational program has to be developed to adequately train these professionals, acknowledging the complexity and specific skills that are required for performing telephone triage ${ }^{62-66}$.

\section{WHERE DO WE GO FROM HERE?}

Future development of general practice out-of-hours care in the Netherlands will obviously not only be guided by scientific knowledge, such as presented in this thesis, but also by a variety of other factors. Besides GPs other actors such as patients, health insurers, and politics will play a role in out-of-hours care development. For that matter, it is important for Dutch general practice to develop a solid view on future out-of-hours care. Questions must be answered such as; "where does general practice go from 
here?": "do GPS still feel that they should be available during out-ofhours?", "do GPS still feel that it is important to perform these services, and for what reasons?"; and "what is the role of general practice within the spectrum of acute care during out-of-hours?" It is important to anticipate future development as much as possible and to realise how these potential developments fit in with the view GPs have on their own profession.

Developments in out-of-hours care in other countries may also have some influence on, or may be an omen of, the future of out-of-hours care in the Netherlands. For example, in the UK - a country that has been an example to the Dutch in developing of out-of-hours care - GPs have been given the opportunity to opt out of their 24-hour responsibility. Recently, out-of-hours primary care has become the responsibility of local primary care trusts, which can employ GPs or other professionals to perform these services. This leaves many GPS in the UK with the opportunity to concentrate fully on care during normal surgery hours, and not having to worry anymore about performing shifts on a regular basis. Is this an exclusive UK scenario, or is this the future picture of Dutch out-of-hours care?

The Dutch minister of Health has advocated more responsibility and direction for the health insurance companies in developing out-of-hours care. The minister also advocated integration of GP cooperatives and hospital emergency departments. Health Insurance companies may want to push GP cooperatives in collaboration with emergency departments, because integrating services may be more cost efficient (and may be conditional for adequate adjustment between primary and secondary acute care). It is clear that the findings of this thesis support this model. However, not all regions in the Netherlands may be suitable for this type of collaboration. In order to successfully organise cooperation or integration between secondary and primary care, all actors have to be accounted for. Moreover, local circumstances such as the number of hospitals in the region and population density will also play a role.

Presumably, also 'new' professionals will come on stage in general practice out-of-hours care. Actually, some have already been introduced, such as the doctor's assistant to whom telephone triage has been substituted. Perhaps in the future at places where patients can enter out-ofhours care facilities without an appointment, triage nurses may be introduced. But one may also think of allied health professionals to be introduced, for example physiotherapists who may deal with sports injuries. Many developments and changes are possible, but it is essential for GPs to have clarity about their role and position in acute care during out-of-hours, so that not all these changes are predominantly directed by ad-hoc decisions and external parties that impose certain measures. 
The role of GP cooperatives within general practice may also grow. For example in facilitating deputy services for daytime practices in case of holidays or illness. Moreover, GP cooperatives nowadays are set up exclusively for out-of-hours. It is reasonable to suggest that in the future they may also open during office hours and serve as a continuous backup for the local GP practices, or for patients who are not registered with a $G P$. When located at the hospital emergency department and open during office hours, the GP cooperative has the opportunity to coordinate care of patients attending the facility without referral not only outside (see chapter 2) but also inside office hours.

These considerations and determinants are elements to support the future development of one or more models of out-of-hours care. It is a matter of urgency for the professional and academic bodies of general practice to bring the stakeholders together to remain in charge of one's own future.

\section{RECOMMENDATIONS FOR FUTURE RESEARCH}

It is striking to see that so little research has been conducted in the Netherlands on out-of-hours primary care in the past. Only a few researchers have taken the challenge to investigate this part of genetal practice $^{67.73}$. Yet, since the rise of GP cooperatives, an exponential growth of research on this field has emerged. Despite this rapid expansion of research, we are still at the beginning of developing evidence based general practice out-of-hours care. Therefore, many aspects are still open for research. In this paragraph recommendations for future research will be given. Some recommendations have already been mentioned in the individual chapters of this thesis. The most compelling of these as well as some broader recommendations will be mentioned here.

This thesis has covered mainly process related issues with respect to general practice out-of-hours care. The time has come to explore aspects of out-of-hours primary care more in depth. One aspect that should receive high priority is the safety and effectiveness of telephone triage. In addition, it should be made clear what the exact demands and criteria are for: doctor"s assistants to adequately perform telephone triage. Telephone triage has been implemented in the Netherlands, without clear knowledge about safety and adequacy of telephone triage. As indicated by the Dutch Health Care Inspectorate the quality of telephone triage is failing, because of lacunas in telephone procedures, protocols, and structured supervision ${ }^{74}$. It should be made clear whether it is appropriate to use written protocols and guidelines, 
or that computer based decision support tools should be used. Does the latter significantly improve the quality of telephone triage?

Another important issue is the safety of directing primary care patients away from the hospital ED as is done in an integrated model for out-ofhours care. How effective is the triage process at the 'gate' in dividing patients into categories such as urgent or non-urgent, or as hospital emergency care or primary care. And if patients with obscure urgent problems slip through this triage process and end up in the non-urgent group, how fast will the GP recognize the urgency of the complaint and still refer the patient to hospital emergency care?

A third issue of significance is the GPs" vocational training. In the changing world of out-of-hours primary care, the occupational requirements of GPs have changed similarly. During out-of-hours the GP has several roles, which may require specific expertise. Knowledge about this and how this should be implemented in the GPs' vocational training and continuing medical education (CME) deserves attention.

A fourth issue that should deserve attention by researchers, but also by health professionals and policy makers, is the efficiency of care at the GP cooperative. Effort should be put in answering the question whether out-ofhours care should be an institute to quickly help patients with their problems but which is only tempotarily sufficient? Or should the GP cooperative provide complete care, and make sure that, as few people as possible, require follow-up care at their own GP? The latter indicating that patients with not so urgent cases are still treated at the GP cooperative and are not adwised to visit their own GP the next day. In this way the pressure or workload of the usual daytime practice can be alleviated. In addition, it would be interesting to know whether the overall contact rate with genetal practice (during and outside office hours) has increased.

In the general introduction of this thesis a remark has been made considering continuity of care. It has been argued that the introduction of GP cooperatives has been an impediment for continuity of care. Future research should also focus on this important aspect of general practice.

GP cooperatives provide a great opportunity for continuous standardised collection of data on morbidity during out-of-hours. Knowledge about morbidity may serve as a source for epidemiological research, support intervention research, but may also give direction to vocational training of GPs. Moreover, insight in these figures may enhance tuning of domains of care between the ED and the GP cooperative.

Many other aspects of out-of-hours primary care should receive attention by researchers in this field. For example, the accessibility of the GP cooperatives, cooperation between health care professionals, substitution of tasks, and diagnostic possibilities for GPs. 
With the introduction of GP cooperatives, general practice during outof-hours has become more professionalised. However, as argued by the Dutch Health Care Inspectorate ${ }^{74}$, many aspects of general practice out-ofhours care still have to be improved. We hope this thesis will contribute to a better understanding of different aspects of out-of-hours primary care and that it supports the development of high quality outwof-hours primary care.

\section{REFERENCES}

1. Giesen PHJ, Haandrikman LGR, Broens S, Schreuder JLM, Mokkink HGA. GP cooperatives: Does it benefit the GP? [Centrale huisartsenposten: wordt de huisarts er beter van?]. Huisarts $\mid W_{\text {et. }}$ 2000;43:508-10.

2. Giesen PHJ, Nurma A, Schreuder JLM, Busser G, Smits H. From working solo to working cooperatively. [Van solistisch werken naar samenwerken.] Med Contact. 1999;54:1445-7.

3. Giesen PHJ, Hiemstra N, Mokkink HGA, de Haan J, Grol R. Satisfied with out-ofhours care. GP cooperative meets expectations. [Tevreden over diensten. Centrale huisartsenpost voldoet aan verwachtingen.] Med Contact. 2002;57:1657-60.

4. de Bakker DH, Grielen SJ, Prins B. Workload reduction and patient satisfaction. [Werklastvermindering en tevredenheid patiënten.] Mvd Contact. 1999;54:1328-31.

5. Ebbens $E$, de Bruijne $M$. The nightwatch: A new organisation of out-of-hours care in Almere. [De nachtwacht: Een nieuwe organisatie wan de nachtdienst Almere.] Huisarts Wet. 2000;43:207-9.

6. Post J. General practice out-of-hours care. [Grootschalige bwisartsensorg buiten kantoonwren] [Thesis]. Groningen, RUG; 2004.

7. Van Loon AJ, Tijhuis M, Picavet HS, Surtees PG, Ormel J. Survey non-response in the Netherlands: effects on prevalence estimates and associations. Ann Epidentiol. 2003;13:105-10.

8. McKinley RK, Cragg DK, Hastings AM, et al. Comparison of out of hours care provided by patients' own general practitioners and commercial deputising services: a randomised controlled trial. II: The outcome of care. BMJ. 1997;314:190-3.

9. Meyboom-de Jong B. The GP as gatekeeper. [De huisarts als poortwachter.] Ned Tijdscbr Geneeskd. 1994;138:2668-73.

10. van den Bosch WJHM. The GP as gatekeeper. [Huisarts en poortwachter.] Ned Tijdstor Gentested. 1994;138:2646-9.

11. Bodenheimer T, Lo B, Casalino L. Primary care physicians should be coordinators, not gatekeepers. JAMA. 1999;281:2045-9.

12. Beasley JW. Gatekeeping: good or bad, but never indifferent. JAMA. 1998;279:908-9; discussion 909-10.

13. Claessens B. The gatekeeper function in front, not the GP. (De poottfunctie moet voorop staan, niet de huisarts.] HMF. 2001;26-7.

14. Feldman D. Gatekeeping: good or bad, but never indifferent. JAMA. 1998;279:908; discussion 909-10.

15. Feldman SR, Fleischer AB, Ir., Chen JG. The gatekeeper model is incfficient for the delivery of dermatologic services. I Am Acad Dermatol. 1999;40:426-32. 
16. Finestone AJ. Gatekeeping: good or bad, bur never indifferent JAMA. 1998;279:908; discussion $909-10$.

17. Forrest CB. Primary care in the United States: primary care gatekeping and referrals: effective filter or falled experiment BMJ. 2003;326:692-5.

18. Friele RD, Andela M. Consumers on GP as gatekeeper to specialist cate. CConsumenten over de huisarts als wachter voor de poorten tot de specialistische zorg. Mod Contact. 1997;52:1275:7.

19. Gross $\mathbb{R}$, Tabenkin $H$, Brammli Greenberg $S$. Who needs a gatekeeper? Patients' views of the fole of the primary care physician. Faw Prat. 2000;17:222-9.

20. Gross $\mathrm{R}$, Tabenkin $\mathrm{H}$, Brammli Greenberg $\mathrm{S}$. Gatekeeping: a challenge in the management of primary care physicians. J Monag Med 2001;15:283-98.

21. Grumbach K, Selby JV, Dambetg C, et al. Resolving the gatekeeper conundrum: what parients value in primary care and referrals to specialists. JAMA. 1999;282:261-6.

22. Halm FA, Causino N, Blumenthal D. Is gatekeeping better than traditional care? $\mathrm{A}$ surwey of physicians' attitudes. JAMA. 1997;278:1677-81.

23. Lawrence D. Gatekeeping reconsidered. N Engl/ Med. 2001;345:1342-3.

24. Lenzer JM. The benefits of gatekeeping. J Fan Prat. 1998;46:257-8.

25. McSherry J, Dickie GL. Swords to ploughshares. Gatekeepers turned advacates. Can Fan Pbysician. 1998;44:955-6.

26. St Peter RF. Gatekeeping arrangements are in widespread use. Data Bull /Cent Stud Heath Syst Cliange). 1997:1-2.

27. Strasser R, Harvey D. The GP as gatekeeper? Atut Fan Pbysician. 1999;28:1213-4.

28. Volpintesta $\mathbb{E}$ Gatekeeping: good or bad, but never indifferent. JAMA. 1998;279:909; discussion 909- 10.

29. Zarin DA, Pincus HA. Gatekeeping: good or bad, but never indifferent. JAMA. 1998;279:909; discussion 909-10.

30. Willems DI. Balancing rationalities: gatekeeping in health care. J Med Etbics. $2001 ; 27: 25-9$

31. Starfield B. Is primary care essential? Lamot. 1994;344:1129-33.

32. Boerma WG, wan der Zee J, Fleming DM. Service profiles of general practitioners in Europe. European GP Task Profile Study. BrJ Gen Pradt 1997:47:481-6.

33. Willems DL, Veldhuis M. Types of selection at the gate and their effects. A literature review. [Vormen van selectic aan de poort en hun effecten. Een literatuuronderzoek.)

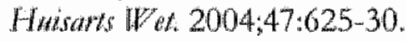

34. Ferris TG, Chang $\mathrm{Y}$, Blumenthal D, Pearson SD. Leaving gatekeeping behind--effects of opening access to specialists for adults in a health maintenance organization. N Engl J Med 2001;345:1312-7.

35. Schillinger $\mathrm{D}$, Bibbins-Domingo $\mathrm{K}$, Vranizan $\mathrm{K}$, Bacchetii $\mathrm{P}$, Luce JM, Bindman $\mathrm{AB}$. Effects of primary care coordination on public hospital patients. I Gen Intern Med. $2000 ; 15: 329-36$

36. Rask $\mathrm{KJ}$, Deaton $\mathrm{C}$, Culler SD, et al. The effect of primary care gatekeepers on the management of patients with chest pain. A m J Manag Care. 1999;5:1274-82.

37. Anderson GF, Hurst J, Hussey PS, Jee-Hughes M. Health spending and outcomes: trends in OECD countries, 1960-1998. Health Aff (Milhaod). 2000;19:150-7.

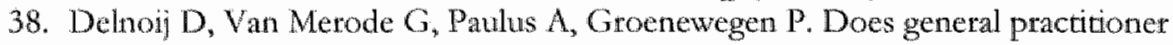
gatekeeping curb health care expenditurer J Health Sen Res Poligy. 2000;5:22-6.

39. Kulu-Glasgow I, Delnoij D, de Bakker D. Self-referral in a gatekeeping system: patients' reasons for skipping the general-practitioner. Health Polig. 1998;45:221-38.

40. Boerma WG. Profiles of General Practice in Exnope. An international sudy on mariation in the tack of geveral pratitioners [Thesis]. Maastricht, Maastricht University; 2003. 
41. Forrest CB, Weiner JP, Fowles J, et al. Self-referral in point-of-service health plans. JAMA. 2001;285:2223-31.

42. Lee A, Lau FL, Hazlett CB, et al. Factors associated with non-urgent utilization of Accident and Emergency services: a case-control study in Hong Kong. Sow Sa Med. 2000;51:1075-85.

43. Ward P, Huddy J, Hargreaves S, Touquet R, Hurley J, Fothergill J. Primary care in London: an evaluation of general practitioners working in an inner city accident and emergency department. J Accid Emerg Med 1996;13:11-5.

44. Murphy AW, Bury G, Plunketr PK, et al. Randomised controlled trial of general practitioner versus usual medical care in an urban accident and emergency department: process, outcome, and comparative cost. BMT. 1996;312:1135-42.

45. Dale J, Gteen J, Reid F, Ghoksman E. Primary care in the accident and emergency department: I. Prospective identification of patients. BMJ. 1995;311:423-6.

46. Colleman P, Irons R, Nicholl J. Will alternative immediate care services reduce demands for non-urgent treatment at accident and emergency? Emorg Med f. $2001 ; 18: 482-7$.

47. Singh $\mathrm{S}$. Self tefertal to accident and emergency department: parients' perceptions. BM]. 1988;297:1179-80.

48. Kini NM, Strait RT. Nonurgent use of the pediatric emergency department during the day. Pediat Emerg Care. 1998;14:19-21.

49. Jacobs HM, de Melker RA, van der Hell RJ. What do specialists know about the work of GPs? [Wat weten specialisten van het werk van de huisarts?] Huisants wht. $1990 ; 33: 152-6$.

50. Vlek JPM. Cardialogue. Joint consultation of geweral practitioners and cardiologists in a primary care setting [Thesis]. Maastricht, Maastricht University; 2000.

51. Nurse telephone-triage. Lanot. 2001;357:323.

52. Bunn $F$, Byrne $G$, Kendall S. Telephone consultation and triage: effects on health care use and patient satisfaction. Cocbrone Database Syst Rew 2004:CD004180.

53. Fortune T. Telephone triagen an Irish view. Accid Emyerg Nurs. 2001;9:152-6.

54. Lattimer V, George $S$, Thompson $\mathrm{F}$, et al. Safety and effectiveness of nurse telephone consultation in out of hours primary care: randomised controlled trial. The South Wiltshire Out of Hours Project (SWOOP) Group. BMJ. 1998;317:1054-9.

55. Niemann S, Meer $A$, Simonin $C$, Abel T. Medical telephone triage and paticnt behaviour: How do they compare? Swis Med Whol 2004;134:126-31.

56. Tumer $\mathrm{VF}$, Bendey $\mathrm{PJ}$, Hodgson $\mathrm{SA}$, et al. Telephone triage in Western Australia. Med J Awst 2002;176:100-3.

57. Salisbury C. Postal snrvey of patients' satisfaction with a general practice out of hours cooperative. BMJ. 1997;314:1594-8.

58. Shipman C, Payne F, Hooper R, Dale J. Patient satisfaction with out-of hours services; how do GP co-operatives compare with depurizing and practice-based arrangements? Public Health Wed. 2000,22:149-54.

59. Hansen BL, Munck A. Out-of-hours service in Denmark: the effect of a structural change. BrJ Gen Pract. 1998;48:1497-9.

60. Christensen MB, Olesen F. Out of hours service in Denmark: evaluation five years after reform. BMJ. 1998;316:1502-5.

61. Pickin DM, O'Cathain A, Fall M, Morgan AB, Howe A, Nicholl $\rrbracket$. The impact of a general practice co-operative on accident and emergency services, patient satisfaction and GP satisfaction. Fan Pratt. 2004;21:180-2.

62. Car J, Sheikh. A. Telephone consultations. BMJ. 2003;326:966-9. 
63. Car ], Freman GK, Partridge MR, Sheikh A. Improving quality and safery of telephone based dedivery of care: teaching telephone consultation skills. Qwal Saf Hoalth Cave. $2004 ; 13: 2-3$.

64. Crouch R, Dale J. Telephone triage--how good are the decisions? (Part 2). Nurs Siand. 1998;12:33-9.

65. Higgs $R$, Blache $G$, Peters $M$, Armstrong $E$, Jessopp $L$. Telephone consultation requires approprate training, BMJ. 2003,327:53.

66. Foster J, Jessopp L, Dale J. Concerns and confidence of general practitioners in prowiding telephone consultations. Br J Ger Prat 1999;49:111-3.

67. van Eijk JTM. General practice and weekend duty in Holland. Der Pratktische Arst. $1979 ; 4: 360-3$.

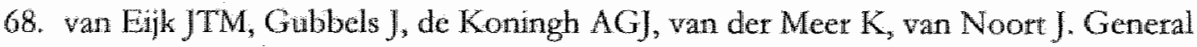
practice out-of-hours care in the Netherlands (T). [De weekenddienst wan huisartsen in Nederland (1).I Med Contact. 1978;33:17-22.

69. van Eijk JTM, Gubbels J, de Koningh AGJ, van der Meer K, van Noort J. General practice out-of-hours care in the Netherlands (T). [De weekenddienst van huisartsen in Nederland (ID). Med Contact. 1978;33:37-41.

70. van Eijk JTM, Gubbels J, van der Meer $K$. Experiencing the group climate in practice totas. [Beleving van het groepsklimat in weekenddienstgroepen.] Hwisds Whet. 1977;20:345-9.

71. van Eijk JTM, Gubbels J, van der Meer K. General practice out-of-hours care in the Netherlands (IID). De weekenddienst van huisartsen in Nederland (III). . Med Contact. $1978,33: 73-8$.

72. van Eijk JTM, Gubbels J, van der Meer $K$, de Koningh $A G$ J, van Noort J. Is testing between co-workers through practice rotas feasible? [Intercollegiale toetsing via waarnemingsgroepen een haalbare kaart?' Haisants W ot 1977;20:378-9.

73. Smit PT. Acute care in general practice. [Spoedgewallen in een buisartspraktijte] [Thesis]. Nijmegen, University of Nijmegen; 1974 .

74. General Practitioner Cooperatives in the Netberlands IHwisartsenposten in Nederland: Inspectie poor de Gezondheidrowgy. The Hague: Health Care Inspectorate; 2004. 


\section{SUMMARY}




\section{CHAPTER 1 - GENERAL INTRODUCTION}

Out-of-hours care was and still is an important part of general practice. In a renewed mission statement the Dutch College of General Practitioners (NHG) and the Dutch Association of General Practitioners (LHV) acknowledged the 24-hour responsibility of GPs for their patients as one of the comerstones of general practice. During the last decade, the organisation of out-of-hours primary care in the Netherlands has experienced a radical shift from GPs providing care to patients in small practice groups to a situation where out-of-hours care is organised in largescale GP cooperatives. In these cooperatives, generally between 40 and 120 GPs are joined, providing care for populations ranging from 80,000 to 300,000 inhabitants. The reorganisation in the Netherlands was preceded by similar reorganisations in out-of-hours primary care in the early $1990 \mathrm{~s}$ in the UK and Denmark. The change in the out-of-hours primary care organisation was mainly motivated by increased GP dissatisfaction with performing these services. The development of organisational structures of GP cooperatives has been predominantly guided by local preferences, which resulted in many differences between GP cooperatives. Generally, there is a distinction in accessibility and a distinction in cooperation with the hospital emergency department. An important part of this thesis addresses issues related to the effects resulting from differences in organisation between GP cooperatives working in close collaboration with a hospital emergency department and those GP cooperatives that are organised independently of hospital emergency services.

The purpose of the studies in this thesis was to gain insight into different aspects of out-of-hours primary care. These aspects are related to changes in care utilisation, costs, patient and GP satisfaction, and telephone triage. Results from these studies are intended to support health care professionals and health policy makers in optimising out-of-hours general practice.

\section{CHAPTER 2}

This chapter presents the effect of the Maastricht out-of-hours GP cooperative on the caseload at the emergency department of the University Hospital Maastricht. It also gives a description of characteristics of patients utilizing out-of-hours care. In January 2000 out-of-hours primary care in Maastricht was reorganised, and a GP cooperative was set up. This cooperative is located at the emergency department of the University Hospital Maastricht; the city's only hospital. In the first year after the set up, 59 GPs participated in the GP cooperative. All patients attending the 
Maastricht out-of-hours care facility are first seen by a GP, unless they have a referral for secondary care. During a three-week period a year before and a three-week period a year after the set up of the GP cooperative, all patient records with out-of-hours primary and hospital emergency care were analysed. The main outcome measures in this study were: the number of patients utilizing out-of-hours care, their age and gender, diagnoses, postED care, and serious adverse events. We found that after establishing the GP cooperative, the proportion of patients utilising emergency care decreased by $53 \%$, and the proportion of patients utilising primary care increased by $25 \%$. The shift was the largest for patients with musculoskeletal disorders or skin problems. There were fewer hospital admissions, and fewer subsequent referrals to the patient's own GP and medical specialists. No substantial change in new outpatient visits at the hospital or in mortality occurred. Based on these findings we concluded that the GP cooperative in Maastricht had complemented the hospital emergency department and reduced the use of hospital emergency care during out-of-hours.

\section{CHAPTER 3}

In this chapter we investigated numbers and characteristics of patients utilising primary or emergency care in two different organisations of out-ofhours care. We compared the Maastricht GP cooperative (a representative of an integrated out-of-hours care model) with the Heerlen GP cooperative (a representative of a separated out-of-hours care model). Important differences between these two organisations are the accessibility and the location of GP cooperative. The Heerlen GP cooperative is situated in the centre of the city and is more than $5 \mathrm{~km}$ away from the nearest emergency department. This GP cooperative can only be visited by appointment. The Maastricht GP cooperative has free access and is located within the emergency department of the University Hospital Maastricht. During a three-week period in 2001 all registration forms of patient contacts with out of hours care (GP cooperative and emergency department) were collected and with respect to the primary care patients a random sample of one thitd was analysed. The results of the study showed that the Heerlen GP cooperative had 238 patient contacts per 1000 inhabitants per year, and the Maastricht GP cooperative had 279 patient contacts per 1000 inhabitants per year. The contact rate at the emergency departments in the Heerlen region is 66 per 1000 inhabitants per year and of the emergency department in Maastricht 52 per 1000 inhabitants per year. About half of all patients attending the emergency departments in the Heerlen region during out-of- 
hours were self-referred. In contrast, at the emergency department in Maastricht only $16 \%$ was labelled as self-referred. We concluded that the organisation of out-of-hours care in Maastricht has optimised the GP's gatekeper function and thereby led to fewer self-referrals at the emergency department, compared with Heerlen. Moreover, it appears that the integrated model results in relatively more patients being seen at the primary care facility and fewer at the emergency department; compared with the separated model.

\section{CHAPTER 4}

In this chapter we discuss the costs of out-of-hours primary care, and focus on implications of differences in organisation of GP cooperatives on costs. General practice outside office hours changed very quickly and the set up of the new out-of-hours care organisation was predominantly guided by local preferences. In this study we investigated costs of the two GP cooperatives described in chapter 3 , i.e. an integrated and a separated GP cooperative. In addition, the costs of the emergency department of the University Hospital Maastricht before and after the set up of the GP cooperative were analysed. Previous studies have shown that integrating the GP cooperative with a hospital emergency department results in a substantial reduction in patients utilising hospital emergency care and an increase in patients utilising primary care. It was expected that this shift would have an effect on costs of out-of-hours care. This study was performed to provide insight in costs of these two different models of outof-hours care in order to support health care professionals and policy makers in developing out-of-hours primary care. GP cooperatives' annual accounts of 2003 were used to assess costs. With respect to the emergency department of the integtated model, we used the annual accounts of the year before and the year after the set up of the GP cooperative. The study results show that the costs of primary care appear to be more dependent on the size of the population the cooperative covers, than on the way the GP cooperative is organised, i.e. separated versus integrated. In addition, despite the substantial reduction of patients, locating the GP cooperative at the same site as the emergency department was found to have little effect on costs of the emergency department. We suggest that sharing more facilities and personnel between the emergency department and the GP cooperative may improve cost-efficiency. 


\section{CHAPTER 5}

In this chapter we describe a study on GP satisfaction with out-of-hours primary care in the Maastricht and Heerlen region. The purpose of this study was to gain insight into GPs' satisfaction with working at GP cooperatives for out-of-hours care in separated and integrated cooperatives. A random sample of 50 GPs per GP cooperative was selected. Telephone interviews were performed to assess GP satisfaction. Opinions on different aspects of GP cooperatives for out-of-hours care were measured, and regression analysis was performed to investigate if these could be related to GP satisfaction with out-of-hours care organisation. The results showed that GPs from the separated model were more satisfied with the organisation of out-of-hours care than GPs from the integrated model. Satisfaction about out-of-hours care organisation was related to opinions on workload, guarantee of gatekeeper function, and attitude towards out-ofhours care as being an essential part of general practice. Cooperation with medical specialists was much more appreciated at the integrated model versus the separated model. We concluded that GPs of both cooperatives appear to be generally satisfied with the organisation of GP cooperatives for out-of-hours care.

\section{CHAPTER 6}

It has been argued that the setting up of GP cooperatives would not only increase use of out-of-hours primary care but also increase the use of hospital emergency services. In chapter 6 we present a study that investigated use of out-of-hours primary and secondary care before and after the set up of three GP cooperatives in adjacent regions. During a foutweek period before (2001) and a four-week period after (2002) the reorganisation of out-of-hours primary care all patient contacts with general practitioners and hospital emergency departments were analysed. The study was conducted in the South of the Netherlands. The study results showed a $10 \%$ increase in patient contacts with out-of-hours primary care, and a $9 \%$ decrease in patient contacts with out-of-hours emergency care in the new situation. The number of self-referrals at the emergency departments was reduced by approximately $4 \%$. We concluded that the reorganisation of out of-hours primary care has led to a shift in patient contacts from hospital emergency care to primary care. 


\section{CHAPTER 7}

Chapter 7 presents a study on patient satisfaction in the province of Limburg. Patient satisfaction has been acknowledged as an important feature that can supply health care providers and policy makers with important information on the patient's perception of the quality of care. From March to June 2003, we distributed 2805 questionnaires to patients within three weeks after they had contacted the GP cooperative in their region. One-third of these questionnaires was sent to patients who had only recerved telephone advice, one-third to patients who attended the GP cooperative for consultation, and one-third to patients who received a home visit. Four weeks after the first reminder, a non-respondents telephone interview was performed among a random sample of 100 patients. Analyses were performed with respect to the type of consultation. About $42 \%$ of the patients returned the questionnaire. Sixty-seven percent of patients who received telephone advice only reported to be satisfied with out-of-hours care. About $80 \%$ of patients who went to the GP cooperative for consultation or those receiving a home visit, reported to be satisfied. Factors that were strongly associated with overall satisfaction included, the doctor's assistant's attitude on the phone, opinion on GP's treatment, and waiting time. Our conclusion is that patients seem generally satisfied with out-of-hours primary care as organised in GP cooperatives. Moreover, patients who received telephone advice only are less satisfied compared to those who attended the GP cooperative or those who received a home visit. Differences in patient expectation about the type of care that is appropriate for their problem and the actual received care may explain these differences in satisfaction.

\section{CHAPTER 8}

In chapter 8 we report on a study that investigated patient and GP opinions on out-of-hours primary care telephone triage. Telephone triage has become an important facet of out-of-hours general practice. Most GP cooperatives nowadays use telephone triage to assess the urgency of the patient's problem in order to prioritise treatment. We performed this study to gain insight in patient and GP opinions on telephone triage with and without computer based decision support software (the Telephone Advice System (TAS)) at GP cooperatives for out-of-hours primary care. Questionnaires were sent to patients and GPs of two GP cooperatives. In these questionnates respondents were asked about their opinions on aspects of telephone triage. At one GP cooperative the doctor's assistants 
performing telephone triage use TAS, and at the other GP cooperative the telephone triage process is supported by written protocols and guidelines. Approximately $36 \%$ of the patients and $80 \%$ of the GPS returned the questionnaire. The results show that patients who contacted the cooperative that uses TAS were generally more satisfied about the telephone advice, but less satisfied about the accessibility of the GP cooperative by phone. GPS of the cooperative that uses TAS were more satisfied about their role as telephone GP, but were equally satisfied about the information given by the doctor's assistant to supervise and authorise the handling of the call. GPS of both cooperatives were also equally satisfied about the selection of consultations. From these findings we concluded that the use of TAS seems to increase patient satisfaction with telephone advice. However, according to GPs' opinions, the appropriateness of the selection of consultations at the cooperative that uses TAS is equal to that of the GP cooperative that uses written protocols and guidelines to support the telephone triage process.

\section{CHAPTER 9}

Chapter 9 focuses on the process of care after patients have contacted the GP cooperative. Little is known about this process and therefore, this study was undertaken to determine the dimension of follow-up care after contact with a GP cooperative for out-of-hours care. We also investigated factors that might be related to this follow-up care. Data from the patient satisfaction questionnaire (chapter 7) were used. In the same questionnaire patients were asked whether they had attended their own GP within a week after their contact with the cooperative, and for what reason. To investigate whether other variables are related to follow-up care, a logistic regression analysis was applied. Variables that were entered in this analysis were patient characteristics (age, gender, etc.) and patient opinion on cortectness of diagnosis, urgency and severity of the medical complaint. 'The response rate was $42 \%$. In total, $48 \%$ of the respondents received follow-up care with their own GP. Only $20 \%$ was referred or advised to attend their own GP. Others attended because their medical condition worsened or because they were concerned about their complaint. Variables that predicted follow-up care vere the patient's opinion on the correctness of the diagnosis, patient's health insurance, and severity of the medical problem. Although the low response rate limits generalisability of the study results, the study indicates that a large proportion of patients who contact the GP cooperative for outof-hours care attend their own GP during office hours within a week for the same medical complaint. Most important factor that predicted follow-up 
care at the patient's own GP after an out-of-hours contact was the patient's degree of confidence with the diagnosis established at the GP cooperative. This study is a first step in providing insight into the dimension of followup care after a patient has contacted the GP cooperative for out-of-hours primary care.

\section{CHAPTER 10 - GENERAL DISCUSSION}

In chapter 10 we present a general discussion of the main findings and methodological aspects of the studies described in this thesis. Moreover, the relevance of these findings is discussed and recommendations for health care policy and future research are given. Also, a view on future development of out-of-hours general practice is presented. The thesis' study results showed that an integrated out-of-hours care model has the ability to divert primary care patients away from the hospital emergency department towards out-of-hours general practice. This indicates that this system is conditional for an optimal GP gatekeeper function. The benefit of this specific model is that out-of-hours primary and secondary care when concentrated at one single site, supply patients with clarity about which facility to attend in case of a medical problem during out-of-hours. Additionally, the close collaboration between the emergency department and the GP cooperative has the potential to enhance cooperation between individual health care providers, which may enable them to exchange expertise and to gain knowledge of each other's working methods. Other important aspects of general practice out-of-hours care, such as telephone triage, follow-up care, vocational training, et cetera, should receive intensive attention by health policy makers, health professionals, and the scientific community in the near future in order to optimise the system of current out-of-hours care. 
SAMENVATTING 


\section{HOOFDSTUK 1 - ALGEMENE INTRODUCTIE}

De avond-, nacht- en weekenddiensten (ANW diensten) van huisartsen maken nog steeds een belangrijk onderdeel uit van de Huisartsgeneeskunde. In 2002 publiceerden het Nederlands Huisartsen Genootschap (NHG) en de Landelijke Huisartsenvereniging (LHV) een herziene visie of de Huisartsgeneeskunde, waarin de 24-uurs verantwoordelitkheid van huisartsen voor hun patiënten als cen van de hoekstenen van de Huisartsgeneeskunde wordt exkend. Tijdens het afgelopen decennium is de organisatie van de ANW diensten rigoureus veranderd. Waar eerst huisartsen in klein groepsverband de diensten regelden, worden de diensten nu in grootschalige huisartsendienstenstructuren (huisartsenposten) georganiseerd. Gemiddeld genomen participeren tussen de 40 en 120 huisartsen binnen één zo'n dienstenstructuur, waarbij zij gezamenlijk zorg dragen voor zo'n 80 tot 300 duizend inwoners. Een soortgelijke reorganisatie van de ANW diensten voor huisartsen heeft zich begin 90 -er jaren in het Verenigd Koninkrijk en Denemarken voorgedaan. Een van de belangrijke redenen voor de Nederlandse reorganisatie was de toenemende ontevredenheid van huisartsen met deze diensten. De ontwikkeling van de organisatiestructuren van de huisartsenposten is op de meeste plaatsen in Nederland met name geleid door lokale voorkeuren, waardoor er toch wat verschillen tussen de huisartsendienstenstructuren bestaan. In het algemeen kan er onderscheid worden gemaakt op het gebied van de toegankelijkheid (vrije inloop óf van tevoren een telefonische afspraak maken) én op het gebied van de samenwerking of integratie met de spoedeisende hulp van het lokale ziekenhuis. Het doel van het onderzoek in dit proefschrift is om inzicht te krijgen in de verschillende aspecten van de ANW diensten van huisartsen. Daarbij wordt ook specifiek aandacht besteed aan verschillen tussen organisatiestructuren van huisartsenposten en hun invloed op diverse aspecten, zoals het gebruik van voorzieningen, kosten, patiënten- en huisartstevredenheid, en telefonische triage. De resultaten van deze studies zijn bedoeld om professionals en beleidsmakers in de gezondheidszorg te ondersteunen bij het oprimaliseren van de ANW dienstenstructuren.

\section{HOOFDSTUK 2}

Dit hoofdstuk beschrijft een onderzoek naar het effect van de reorganisatie van de Maastrichtse ANW diensten op het gebruik van eersteen tweedelijns voorzieningen buiten kantooruren. In januari 2000 is de huisartsenpost in Maastricht opgericht. Deze huisartsenpost fungeert als voorportaal van de spoedeisende hulp van het academisch ziekenhuis 
Maastricht (azM). Het azM is het enige zlekenhuis in deze regio. Gedurende het eerste jaar deden alleen de Maastrichtse huisartsen dienst vanoit deze huisartsenpost. Tijdens de openingsuren van de huisartsenpost worden pariënten zonder verwijzing door de huisarts gezien en indien nodig doorgestuurd naar de spoedeisende hulp. Gedurende een drieweekse periode een jaar vóór en een drieweekse petiode een jaar ná de reorganisatie hebben we alle patiëntencontacten met de huisartsenpost en de spoedeisende hulp geanalyseerd. De belangrijkste uitkomstmaten waren het aantal patiënten dat gebruik maakt van deze voorzieningen, hun leeftijd en geslacht, diagnoses, vervolgzorg, en sterftecijfers en polibezoeken over een heel jaar. De resultaten tonen aan dat het aantal patiënten dat buiten kantooruren op de spoedeisende hulp kwam ná oprichting van de huisartsenpost met zo'n $53 \%$ was gedaald. Daar staat tegenover dat het aantal patiënten dat bij de huisarts kwam met $25 \%$ was gestegen. Deze verschuiving was het grootst voor mensen met klachten aan het bewegingsapparaat of verwondingen aan de huid. Het aantal ziekenhuisopnames liet een lichte daling zien en er waren minder verwijzingen naar de eigen huisarts of medisch specialist. Er werden geen substantiële veranderingen in sterftecijfers of nieuwe ziekenhuisopnames tussen 1998 en 2001 waargenomen. Op basis van deze gegevens concludeerden we dat de huisartsenpost en spoedeisende hulp complementair aan elkaar zijn en dat de huisartsenpost een significante daling van het aantal patiënten op de spoedeisende hulp heeft bewerkstelligd.

\section{HOOFDSTUK 3}

In dit hoofdstuk beschrijven we een studie naar het aantal patiënten en hun kenmerken dat gebruikmaakt van huisartsenzorg en spoedeisende hulp bij twee verschillende organisatiestructuren voor zorg buiten kantooruten. We vergeleken de situatie in Maastricht, waarbij de huisartsenpost in het ziekenhuis op de spoedeisende hulp gevestigd is (zie hoofdstuk 2), met de situatie in Heerlen waarbij de huisartsenpost op enige afstand van het ziekenhuis is gevestigd. De huisartsenpost in Heerlen kan alleen volgens telefonische afspraak worden bezocht, terwijl men bij de huisartsenpost in Maastricht ook zonder afsprak kan binnenlopen (hoewel dit ontmoedigd wordt). Gedurende een drie weken durende periode in 2001 zijn alle patiëntcontacten met de huisartsenposten en de spoedeisende hulpen in deze regio's geanalyseerd. De resultaten laten zien dat, volgens extrapolatic, de huisartsenpost in Heerlen 238 patiënten per 1000 inwoners per jaar zag en de huisartsenpost in Maastricht zo'n 279 patiënten per 1000 inwoners 
per jaar. Het antal contacten met de spoedeisende hulp in de regio Heerlen bedroeg 66 per 1000 inwoners per jaar tegenover 52 patiëntcontacten per 1000 inwoners per jaar voor de spoedeisende hulp in Maastricht. Ongeveer de helft van het aantal patiënten op de spoedeisende hulp in de regio Heerlen kwam zonder verwijzing. In Maastricht werd $16 \%$ als "zelfverwijzer' geclassificeerd. De resultaten wijzen erop dat de organisatie van de diensten in Maastricht de poortwachterfunctie van de huisarts heeft geoptimaliseetd, waarbij er relatief meer patiënten bij de huisarts terechrkomen en relatief minder bij de spoedeisende hulp van het ziekenhuis.

\section{HOOFDSTUK 4}

In dit hoofdstuk zijn de kosten van de huisartsendienstenstructuren in Maastricht en in Heerlen bestudeerd. Tevens hebben we gekeken naat de kosten van de spoedeisende hulp in Maastricht vóór en ná de opening van de Maastrichtse huisartsenpost. Op basis van de resultaten van het onderzoek in hoofdstuk 2, waarbij een forse reductie van het aantal patiënten op de spoedeisende hulp werd gevonden, was de verwachting dat deze reductie mogelijk van invloed zou zijn op de kosten van de spoedeisende hulp. Bij de bepaling van de kosten van de huisartsendienstenstructuur in Maastricht en Heerlen is gebruik gemaakt van de jaarrekeningen uit 2003 . Ter bepaling van eventuele verandering in kosten van de spoedeisende hulp van het azM zijn de jaarrekeningen van 1999 en 2000 gebruikt (een jaar voor en een jaar na de opening van de huisartsenpost). Het doel van dit onderzoek was om inzicht te krijgen in de invloed van verschillen in organisatie van de ANW diensten op de kosten van die dienstenstructuur. De resultaten van de studie wijzen erop dat de kosten van de huisartsenpost, uitgedrukt per inwoner per jaar, meer bepaald worden door de grootte van het adherentiegebied dan door de organisatievorm (apart van de spoedeisende hulp gelokaliseerd (Heerlen) versus geïntegreerd (Maastricht)). Tevens valt op dat de kosten van de spoedeisende hulp wan het azM, ondanks de substantiële daling van het aantal patiënten (zie hoofdstuk 2), nauwelijks zijn veranderd. Het verder integreren van diverse faciliteiten en personeel kan mogelijk leiden tot hogere kostenefficiëntie. 


\section{HOOFDSTUK 5}

In dit hoofdstuk wordt een beschtijving gegeven van een onderzoek nat satisfactie en opinies van huisartsen over de huisartsendienstenstructuur in Maastricht en Heerlen. Het doel was om inzicht te krijgen in tevredenheid van huisartsen en te zien welke factoren daarbij een tol spelen. Tevens is bekeken of er verschillen waren tussen satisfactie en opinies van Heerlense en Maastrichtse huisartsen. Per huisartsenpost is een steekproef van 50 huisartsen getrokken die volgens afspraak telefonisch zijn geinterviewd. De resultaten laten zien dat huisartsen van de Heerlense dienstenstructuur gemiddeld genomen meer tevteden waren over hun huisartsenpost dan hun collega's van de Maastrichtse huisartsenpost. Tevredenheid over de dienstenstructuur bleek met name samen te hangen met opinies over werkdiuk, visie op de poortwachterfunctie van de huisarts en de mening over de diensten als essentieel onderdeel van het huisartsenvak. Nadere analyses lieten zien dat in Maastricht met name de factor werkdruk een grote rol speelt bij tevredenheid. In Heerlen spelen met name de twee andere factoren (de poortwachterfunctie en de diensten als essenticel onderdeel) een rol bij tevredenheid over de huisartsenpost. Samenwerking met medisch specialisten werd hoger gewaardeerd in Maastricht dan in Heerlen. De conclusie van het onderzoek luidt dat huisartsen in de regio's Heerlen en Maastricht over het algemeen tevteden zijn over hun nieuwe dienstenstructuur.

\section{HOOFDSTUK 6}

Vóór oprichting van de huisartsenposten werd vaak geopperd dat de nieuwe dienstenstructuur een toename van het aantal patiënten op de spoedeisende hulp van het ziekenhuis zou veroorzaken. In dit hoofdstuk presenteren we een studie waarbij we het gebruik van cerste- en tweedelijns zorg buiten kantooruren in drie Limburgse regio's (Roermond, Weert en Sittard/Geleen) hebben bestudeerd. Gedurende een vierweckse periode in 2001 (vóór oprichting van de drie huisartsenposten in deze regjo's) en tijdens een vierweekse periode in 2002 (ná oprichting van do huisartsenposten) zijn alle patiëntcontacten geanalyseerd. De resultaten van de studie laten zien dat het aantal patienten dat buiten kantooruten contact heeft met de huisarts na oprichting van de huisartsenpost met ongeveer $10 \%$ is gestegen, terwiil het aantal patiënten dat contact heeft met de spoedeisende hulp buiten kantooruren met zo'n $9 \%$ is gedaald. Her percentage zelfverwijzers op de afdelingen spoedeisende hulp, na oprichting van de huisartsenposten, was gedaald met $4 \%$. De resultaten van dit 
onderzoek wijzen er dus op dat de reorganisatie van de huisartsendienstenstructuren heeft geleid tot een verschuiving in het aantal patiënten dat buiten kantooruren gebruik maakt van medische vootzieningen van de tweede lijn naar de eerste lijn.

\section{HOOFDSTUK 7}

In dit hoofdstuk presenteren we een onderzoek naar tevredenheid van patiënten met de huidige huisartsendienstenstructuren. In de periode van maart tot juni in 2003 hebben we zo'n 2800 patiënten van de vijf Limburgse huisartsendienstenstructuren een vragenlijst toegestuurd. De vragenlijst werd binnen drie weken na contact met de huisartsenpost naar de patiënten verzonden. Eendete van de vragenlijsten werd gestuurd naar patiënten die alleen een telefonisch contact hebben gehad, eenderde naar patiënten die voor een consult op de huisartsenpost zijn geweest en eenderde naar patiënten waarbij de huisarts een visite had afgelegd. Vier weken nadat een 'reminder' was verstuurd, werd telefonisch een korte vragenlijst afgenomen onder een steekproef van 100 niet-responderende patiënten. De analyses zijn per type verrichting uitgevoerd. De respons bedroeg zo'n $42 \%$. Zevenenzestig procent van de patiënten die alleen telefonisch contact hadden gaf aan tevreden te zijn over het contact met de huisartsenpost. Ongeveer $80 \%$ van de patiënten die op de post waren geweest of waarbij de huisarts een visite had afgelegd gaf aan tevteden te zijn over het contact met de huisartsenpost. Factoren die sterk samenhangen met tevredenheid hebben betrekking op opinies van patiënten over de attitude van de doktersassistente aan de telefoon, de behandeling van de huisarts en de wachttijd. Concluderend, patiënten blijken gemiddeld wel tevreden over het contact met de huisartsenpost, mar in geval van alleen een telefonische afhandeling is de tevredenheid een stuk lager. De verwachting van de patiënt over het type verrichting (bijvoorbeeld een visite door de huisarts in plats van een telefonische afhandeling) speelt mogelijk een grote rol bij dit verschil in tevredenheid.

\section{HOOFDSTUK 8}

In dit hoofdstuk beschrijven we een onderzoek naar opinies van patiënten en huisartsen over de telefonische triage tijdens de diensten. Telefonische triage is tegenwoordig een belangrijke element binnen de ANW diensten, en wordt gebruikt om de urgentie van de klacht in te schatten en daarop het te volgen beleid af te stemmen. In dit onderzoek 
hebben we opinies van patiënten en huisartsen wan twee verschillende huisartsendienstenstructuren onderzocht. Bij de ene huisartsenpost werken de triagisten met computerondersteunende beslissingssoftware (TAS) en bij de andere huisartsenpost wordt het triage proces ondersteund met schriftelijke protocollen en de telefoonwijzer van het Nederlands Huisartsen Genootschap (NHG). Ten behoeve van het onderzoek zijn vragenlijsten ontwikkeld en naar een steekproef wan patiënten en naar alle participerende huisartsen uit deze regio's gestuurd. In de vragenlijsten wordt specifiek gevraagd naar opinies over diverse aspecten tan telefonische triage. Ongeveer $36 \%$ van de patiènten en $80 \%$ van de huisartsen heeft de vtagenlijst teruggestuurd. De resultaten laten zien dat patiënten uit de regio van de huisartsenpost die werkt met TAS gemiddeld meer tevreden zijn over het telefonisch advies, maar minder tevreden over de telefonische bereikbaarheid dan patiënten uit de andere regio. De huisartsen van de huisartsenpost waar TAS wordt gebruikt waten meer tevreden over hun rol als telefoonarts dan hun collega's van de andere huisartsenpost, maar waren even tevreden over de informatie die door de triagist wordt verstrekt om de telefonische afhandeling te kunnen superviseren en accorderen. Huisartsen van beide posten zijn even tevreden over de selectie van consulten en visites. Het lijkt er op dat patiënten meet tevreden zijn over het telefonisch advies wanneer dit gestandaardiseerd is, zoals dat gebeurt bij het TAS systeem.

\section{HOOFDSTUK 9}

In hoofdstuk 9 richtten we ons op het zorgproces nadat de patiënt contact heeft gehad met de huisartsenpost. Tot op heden is er zecr weinig bekend over de redenen en omvang van deze vervolgzorg. Door middel van een vragenlijstenonderzoek zijn we nagegaan hoe vaak en met welke reden mensen alsnog binnen een week nadat men de huisartsenpost heeft gecontacteerd de eigen huisarts voor dezelfde klacht bezoeken. Om na te gaan of andere variabelen (o.a. leeftijd, geslacht, ziektekostenverzekering, de mening van de patiënt over de juistheid van de diagnose, en urgentie en ernst van de klacht volgens de patiënt) ook een rol spelen bij het vervolgbezoek aan de eigen huisarts hebben we een logistische regressie uitgevoerd. De gegevens van dit onderzoek zijn verzameld met behulp van de vragenlijst die is verstrekt aan patiënten beschreven in hoofdstuk 7 . Ongeveer $42 \%$ van de vragenlijsten is teruggestuurd. In totaal gaf $48 \%$ van de respondenten aan binnen een week na contact met de huisartsenpost naar de eigen huisarts te zijn gegaan. Slechts $20 \%$ gaf aan dat dit was op verwijzing of advies van de huisarts of doktersassistent van de 
huisartsenpost. Overige redenen voor het bezoek aan de eigen huisarts waren: verergering wan de klachten en bezorgdheid over de klacht. Andere variabelen die samenhangen met het bezoek aan de eigen huisarts zijn: de mening van de patiënt over de juistheid van de diagnose, type zorgverzekering en de ernst van de klacht volgens de mening van de patiënt. Hoewel de matige respons de generaliseerbaarheid van deze resultaten beperkt, wijst deze studie erop dat een substantieel deel van de patiënten naar de eigen huisarts teruggaat voor dezelfde klacht als waarmee ze de huisattsenpost hebben gecontacteerd. Deze studie is een eerste stap om inzicht te krijgen in de omvang en redenen van vervolgzorg.

\section{HOOFDSTUK 10}

In dit hoofdstuk presenteren we een algemene discussie van de resultaten en methodologische aspecten van de studies zoals die zijn beschreven in dit proefschrift. De relevantie van de resultaten wordt bediscussieerd en aanbevelingen voor de organisatie van de huisartsenzorg buiten kantooruren en toekomstig onderzoek worden gegeven. Tevens wordt stilgestaan bij toekomstige ontwikkelingen op het gebied van de ANW diensten. De resultaten in dit proefschrift laten zien dat het geintegreerde model mogelijkheden biedt om op effectieve wijze een substantieel van de patiënten die, volgens onderzoek, onterecht op de spoedeisende hulp terecht zijn gekomen, in de eerste lijn te behandelen. Dit impliceert dat deze organisatievorm voorwaardelijk is voor een optimale poortwachterfunctie van de huisarts. Het voordeel van dit specifieke model is dat de eerstelijns en tweedelijns zorg op een locatie geconcentreerd zijn wat helderheid voor patienten geett over watr ze moeten zijn woor medische klachten buiten kantooruren. Tevens biedr de nauwe samenwerking tussen de spoedeisende hulp en de huisartsenpost een kans om op individueel niveau van zorgverleners ook een sterkere samenwerking te bewerkstelligen. Bijvoorbeeld op het gebied van expertise uitwisseling, afstemming van zorgtaken en begripsvorming over elkanders werkwijzen. Andere belangrijke aspecten wan huisartsenzorg buiten kantooruren, zoals telefonische triage, efficiëntie van vervolgzorg, opleidingen voor huisartsen en triagisten, et cetera, verdienen intensieve aandacht van beleidsmakers, professionals en onderzoekers in deze sector van de zorg om het systeem van diensten te optimaliseren. 
DANKWOORD 


\section{DANKWOORD}

Wetenschap doe je niet in je eentje. Dit proefschrift is dus niet alleen de pennenvrucht van mijn persoontje, maar ook die van vele anderen die mij hebben gestimuleerd en ondersteund in het gehele proces van promoveren en daarvoor wil ik hen dus hartelijk danken.

Allereerst mijn begeleidingsteam: Harry Crebolder, Onno van Schayck, Ron Winkens en Geertian Wesseling. Harry, bedankt voor je grote betrokkenheid bij het onderwerp en je motiverende en intensieve begeleiding. Wat dat laatste betreft heb ik geluk gehad dat je enige tijd geleden met emeritaat bent gegaan. Ik heb het zeer op prijs gesteld dat je altijd woor me klaar hebt gestaan als ik advies nodig had, of even snel iets nagekeken wilde hebben. Onno, bedankt dat je me bij Huisartsgeneeskunde hebt binnengehaald. Hoewel ik uiteindelijk op een ander project ben terecht gekomen dan waarvoor $\mathrm{ik}$ was aangenomen heb je me altijd op een zeer positieve en inspirerende wijze ondersteund. En zie, het is allemaal toch nog goed gekomen (en ik heb er nog plezier aan beleefd ook). Ron en Geertjan, als copromotoren hebben jullie bijgedragen aan de totstandkoming van de diverse projecten en artikelen. Ik kan zeer tevreden zijn op de snelle en adequate wijze waarop jullie mijn stukken beoordeelden. Dit heeft cen belangrijke bijdrage geleverd aan de 'snelle' afronding van dit proefschrift.

De leden van de leescommissie, prof.dr. J.A.M. Maarse, prof.dr. P.R.G. Brink, prof.dr.mr. R.P.T.M. Grol, prof.dr. J. de Haan en mw. dr. Y.D. van Leeuwen wil ik bedanken voor het lezen en beoordelen van mijn proefschrift.

Hans Fiolet, mijn baas van de afdeling Transmurale Zorg van het academisch ziekenhuis Maastricht, jou ben ik zeer veel dank verschuldigd voor de ruimte die je hebt gecreëerd om dit onderzoek uit te kunnen voeren. Bedankt voor het vertrouwen dat je in me gesteld hebt. Ook Job Metsemakers, voorzitter van bovengenoemde afdeling én van de capgroep Huisattsgeneeskunde, jou wil ik danken voor de ruimte die je me biedt om me verder te ontwikkelen en voott te botduren op het onderzoek van de afgelopen jaren.

Dank gaat ook uit naar de stuurgroep die met name in het begin van mijn onderzoek intensief betrokken was. Deze stuurgroep bezat klaarblijkelijk de eigenschap om bij verhitting uit te zetten; naarmate de zomer naderde (en de gemiddelde temperatuur dus steeg) was de groep inmiddels uitgegroeid tot meer dan 15 hoog-en zeergeleerden. Het gevolg 
was dat van alle relevante disciplines een afvaardiging aanwezig was. Dit heeft geleid tot vruchtbare discussies en een brede basis wan het onderzoek.

In het begin van mijn promotietraject ben ik eens door Paul Zwietering en Sjoetd Hobma gebeld met de vraag of ik samen met hen een onderzoek wilde doen naar de telefonische triage op de huisartsenpost in Sittard. Ik ben blij dat jullie toen dat initiatief hebben genomen. Later zijn daar ook Andre Ament, Mariëtte Hübben, Marloes Elferink, Ilse Vossen en Elles van Cromvoirt bijgekomen. Ik heb de samemwerking binnen dit project altijd zeer prettig en leuk gevonden. Bedankt voor de leuke tijd. In elk geval hebben we er al één publicatie uit mogen slepen.

Sommigen van u weten het, ik leid een gespleten bestaan. Een baan in Nijmegen en een in Maastricht. Om gek van te worden zou je denken, maar dat is slechts ten dele waar.... Nijmeegse en Maastrichtse collega's, hartelijk dank voor de fijne werksfeer en jullie collegialiteit. In het bijzonder wil ik het Nijmeegse onderzoeksclubje nog even noemen. Carien, Marian, Jan, en Jaap, ik ga altijd met plezier naar mijn werk en dat is mede dankzij jullie. Jullie enthousiasme en collegialiteit zorgen ervoor dat er altijd een goede sfeer hangt. Met veel genoegen werk ik met jullie samen aan de wetenschappelijke onderbouwing van de Fysiotherapie. Jorke, Hans en Steven, mijn bazen aldaar, zeer bedankt voor het vertrouwen en de ruimte die jullie mij gegeven hebben.

Matti en Elly, jullie bedankt voor de hulp tijdens het onderzoek en voor het invoeren van die grote hoeveelheid data. Guy, mijn Maastrichtse kamergenoot, naast al dat keiharde werken dat we dagelijks doen hebben we toch ook veel lol samen. Onze regelmatige bezoekjes aan 'The Family', waar we inmiddels een vaste tafel hebben, zijn een welkome lunchonderbteking van de dag. Ook mijn collega's van KEMTA wat ik de eerste maanden van mijn Maastrichtse periode heb doorgebracht wil ik bedanken voor hun gastvrijheid en prettige werksfeer. In het bijzonder dank aan Fred Nieman en Gemma Voss voor hun bijdragen aan het onderzoek in dit proefschrift.

Limburgse huisartsenposten en de huisartsenpost in "Tilburg, jullie bedankt voor medewerking aan ons onderzoek. De pretrige sfeer tijdens de bijeenkomsten van de voorzitters en directeuren van de Limburgse huisartsenposten heeft ervoor gezorgd dat ik graag met jullie hel samengewerkt. In het bijzonder ook nog dank aan Math Hundscheid, die de data-extractie en patiëntenselectie een stuk eenvoudiger heeft gemaakt. Dit heeft ons veel tijd en ongemakken bespaard. Toine, als deskundige van huisartsendiensten, je bent immers voorzitter van de Maastrichtse post, heb je me op zijn tijd bijgepraat over nieuwe ontwikkelingen op het gebied van 
huisattsenzorg. Met veel plezier heb ik regelmatig je betrokken pleidooi om de regie bij de huisarts te houden aangehoord.

To my American friends. Marcus and Roger, thank you very much for the nice cooperation in the past six years. I have always looked forward to your visits to the Netherlands, but even more to my own trips to the US. And of course, thanks for regularly checking my English.

Vrienden en familie, bedankt dat jullie er waren en zijn. Jullie maken het leven een stuk draaglijker (niet te zwaar opvatten...). Zonder de anderen tekort te doen wil ik er sommigen toch even uitlichten. Mark S, je probeert me regelmatig uit te lokken tot een hardloopwedstrijdje, maar ik trap er mooi niet in (soms wel, maar daar heb ik dan ook weer snel spijt van). Ik ben meer in voor een Erdinger en wat slap geouwehoer over werk en andere wereldse zaken. Mark R, een tijdje was je ook nog mijn trouwste stagiair, maar gelukkig ben je nog veel langer een zeer goede vriend. Het feit dat je nu bijna een Duitser bent heeft in elk geval als groot voordeel dat je altijd zeer goed bier in voorraad hebt. Jason, tia, het is toch jammer dat wij na zoveel jaren zulke 'prachtige' muziek te hebben gemaakt in de vochtige kelder van ons studentenhuis, nooit zijn doorgebroken. Dan had het leven er een stuk anders uitgezien.....

Pap en mam, bedankt voor de mogelijkheden en ruimte die jullie mij geboden hebben. Jullie steun door de jaren heen heeft een belangrijke bijdrage geleverd aan de totstandkoming van dit boekje. Mam, bedankt voor de warmte en geborgenheid die je me altijd gegeven hebt en nog steeds geeft tijdens mijn regelmatige bezoekjes, wanneer ik weer in Nijmegen ben. $\mathrm{Pa}$, helaas ben je er nu niet meer en heb je deze belangrijke gebeurtenis in mijn leven nier mee kunnen maken. Ik weet hoe trots je op me bent, maar het doet me pijn dat je me dit niet meer kunt zeggen. Nancy, lief zusje, ik ben blij dat ik jou 'grote' broer ben.

Lieve Brigitte, je weet het al, dus hoeft het eigenlijk niet geschreven te worden, maar beter toch van wel: ik houd van je. Bedankt dat je mijn leven bent. 


\section{CURRICULUM VITAE}




\section{CURRICULUM VITAE}

Caro wan Uden werd geboten op 13 september 1971 te Nijmegen. Hij groeide op in Grave waar hij in 1988 de HAVO voltooide. In datzelfde jaar, niet wetende wat anders te doen, begon hij aan de MTS in Nijmegen. Ondanks dat dit geen goede keuze bleek, heeft hij deze opleiding wel afgemaakt. In 1991 startte hij met de opleiding Fysiotherapie te Nijmegen, waarvoot hij in 1995 zijn diploma ontving. Inmiddels geinteresseerd geraakt in wetenschap vertrok hij in 1995 nat Maastricht om daar Bewegingswetenschappen te gaan studeren. Zijn bul kreeg hij eind 1997. Tussen 1998 en 2001 werkte hij als fysiotherapeut bij Fysiotherapiepraktijk Bronzwaer te Maastricht. Vanaf 1998 is Caro ook parttime werkzaam als onderzoeker op de afdeling Fysiotherapie van het UMC St Radboud Nijmegen. In februari 2001 is hij gestopt als fysiotherapeut en gestart met een promoticonderzoek aan de Universiteit Maastricht en het academisch ziekenhuis Maastricht; wat heeft geresulteerd in dit proefschrift. Op dit moment is Caro werkzaam in Nijmegen en Maastricht, waar hij betrokken is bij diverse projecten op het gebied van huisartsgeneeskunde buiten kantooruren, osteoporose, chronische veneuze insufficiëntie en werkgerelateerde klachten. 


\section{PUBLICATIES}

van Uden CJT, Bloo JKC, Kooloos JGM, Van Kampen A, de Witte J, Wagenaar RC. Dynamische analyse van het hinkelen bij patienten met een voorste kruisbandreconstructie. Ned T Fysiother: 2000;110:108 113.

Spigt MG, van Uden CJT. Leesopdracht: beoordelen van dragnostische onderzoeken. In:

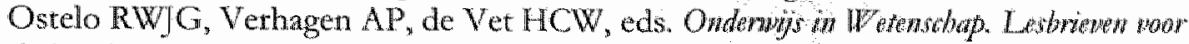
de fisiotbrapent. Houten/Diegem: Bohn Stafleu Van Loghum; 2002.

van Uden CJT, Spigt MG. Leesopdracht: beoordelen van effectondetzocken. In: Ostelo

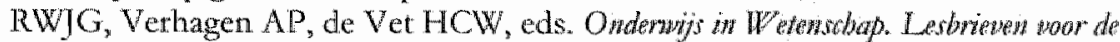
fysotherapen: Houten/Diegem: Bohn Stafleu Van Loghum, 2002,

van Uden CJT, Bloo JKC, Kooloos JGM, van Kampen A, de Witre J, Wagemaar RC. Coordination and stability of one-legged hopping patterns in pacients with anterior cruciate ligament reconstruction: preliminary results. Clin Biomech. 2003;18:84-87.

wan Uden CJT, Winkens RAG, Wesseling GJ, Crebolder HHM, van Schayck CP. Use of out of hours services: a comparison between two organisations. Emmerg Med I. $2003 ; 20: 184-187$.

van Uden CJT, Winkens RAG, Wesseling GJ, van Schayck CP, Crebolder HMJM. Contacten buten de kantooruren: klachten gepresenteerd aan de huisarts en aan de spoedeisende hulp. Ned Tijdrob Geneeskd. 2003;147:223.

van Uden CJT, Besser MP. Test-retest reliability of temporal and spatial gait characteristics measured with an instrumented walkway system (GAITRire). BMC Mwrowloseden Dirord. 2004,5:13.

van Uden CJT, van der Vleuten CJM, Kooloos JGM, Haenen JH, Wollersheim H. Gait and calf muscle endurance in patients with chronic venous insufficiency. Clin Rebab. 2005; in press.

van Uden CIT, Crebolder HFJM. Does setting up out of hours primary care cooperatives outside a hospital reduce demand for emetgency care? Emerg Med J. 2004;21:722-723.

van Uden CJT, Ament AJHA, Fobma SO, Zwietering PJ, Crebolder HFJM, Patient satisfaction with out-of-hours primary care in the Netherlands. BMC Health Serv Res. $2005 ; 5: 6$.

van Uiden CJT, Winkens RAG, Wesseling GJ, Fiolet JFBM, van Schayck CP, Crebolder $H$ HIM. The impact of a primary care physician cooperative on the caseload of an emergency department. The Mastricht integrated out of-houss service. I Gen lan Med. 2005: in press.

Brunnekteef J], wan Uden CJT, wan Moorsel S, Kooloos JGM. Reliability of videotaped observational gait analysis in patients with otthopedic impaiments. BMC Massulosketet Disont. 2005; accepted. 